ESCOLA POLITÉCNICA DA UNIVERSIDADE DE SÃO PAULO

DEPARTAMENTO DE ENGENHARIA DE TRANSPORTES

FABIO LUIZ ALBARICI

POSICIONAMENTO RELATIVO: ANÁLISE DOS RESULTADOS COMBINANDO AS OBSERVÁVEIS L1 DOS SATÉLITES GPS E SBAS. 
FABIO LUIZ ALBARICI

\section{POSICIONAMENTO RELATIVO: ANÁLISE DOS RESULTADOS COMBINANDO AS OBSERVÁVEIS L1 DOS SATÉLITES GPS E SBAS}

Dissertação apresentada à Escola

Politécnica da Universidade de São Paulo para obtenção do título de Mestre em Engenharia.

Área de Concentração:

Engenharia de Transporte

Orientador:

Prof. Dr. Edvaldo Simões da Fonseca Junior 
Aos meus queridos pais Celso e Fátima e aos meus irmãos Tatiane, Viviane e Felipe pelo constante incentivo e a minha esposa Deborah pelo companheirismo e dedicação. 


\section{AGRADECIMENTOS}

Ao meu orientador Prof. Dr. Edvaldo Simões da Fonseca Junior, pela orientação, constante incentivo e confiança transmitido durante todo o trabalho.

A CAPES pela bolsa concedida.

À empresa Alezi Teodolini, pela liberação no período de trabalho.

Ao Instituto Federal do Espírito Santo - Campus Nova Venécia e a Prof ${ }^{a}$. M.Sc. Deborah Valandro de Souza pela disponibilidade dos receptores GPS e coleta de dados.

Ao Instituto Federal do Tocantins - Campus Palmas pela liberação no período das aulas, para resolução dos problemas relacionados a esta dissertação.

Aos amigos Wagner Carrupt Machado e Gabriel Guimarães pela ajuda, discussões e incentivo durante o trabalho.

Ao amigo Eduardo de Magalhães Barbosa pela ajuda e discussão sobre o trabalho e também por proporcionar minha estadia em Palmas - TO mais agradável.

A todos que direta ou indiretamente contribuíram para o sucesso deste trabalho. 


\section{RESUMO}

Os sistemas de aumento, conhecidos como SBAS (Satellite-Based Augmentation System) fornecem informações de integridade e acurácia em tempo real para seus usuários, utilizando-se das correções diferenciais que são transmitidas pelos satélites geoestacionários e estão disponíveis em algumas regiões do globo terrestre. Fora da sua região de abrangência o sistema ainda não disponibiliza os dados de correção em tempo real. Entretanto, o sinal é transmitido na mesma frequência L1 do GPS, o qual fica disponível aqui no Brasil, e alguns receptores GNSS possuem canais de frequência específica que captam este sinal, com a perspectiva de que os dados destes satélites melhoram as condições do rastreio, além da melhoria na acurácia das coordenadas. Partindo deste princípio, foi utilizada a observável fase da onda portadora (L1) para inferir sobre a sua contribuição para o posicionamento. Os rastreios foram realizados em diferentes localidades devido à elevação dos satélites SBAS variar em função da latitude e longitude. Contudo, este estudo foi direcionado para os dados dos satélites PRN 138 (WAAS), PRN 120 e 124 (EGNOS), pois foram os únicos visíveis durante todo o rastreio, tendo simultaneidade dos dados entre os receptores base e móvel. Durante a etapa de processamento, o qual foi utilizado o software GNSS Solution, alguns experimentos foram realizados, tais como: 1) Processamento com todas as observáveis $L 1$ dos satélites disponíveis (GPS e SBAS), análise dos desvios-padrão e comparação das coordenadas obtidas com as consideradas verdadeiras; 2) Processamento sem as observáveis L1 dos satélites SBAS, análises e comparações; 3) Retirada gradativa dos satélites GPS e reprocessamento em conjunto (GPS+SBAS) e separadamente (apenas GPS). A finalidade principal desses experimentos foi verificar a potencialidade da observável L1 dos satélites SBAS processadas em conjunto com a observável L1 do GPS, no posicionamento relativo. Análises estatísticas, como tendência e erro médio quadrático (RMS), foram aplicadas para verificar a existência de erros sistemáticos e a acurácia das coordenadas. Os resultados mostram que, especificamente nos locais de rastreio, as observáveis L1 dos satélites SBAS ao serem adicionados ao processamento, combinado com as observáveis L1 dos satélites GPS, não são determinantes para melhoria da acurácia das coordenadas.

Palavras-chave: Observável L1, SBAS, GNSS. 


\begin{abstract}
The augmentation systems, known as SBAS (Satellite-Based Augmentation System) provide information for completeness and accuracy in real time to its users, using the differential corrections that are transmitted by geostationary satellites. They are available in specific regions of the globe such as USA, Canada and Europe. Outside their region of coverage the system still does not provide the correction data in real time. However, the signal is transmitted at the same frequency L1 GPS, which is available here in Brazil, and some GNSS receivers have specific frequency channels that capture this signal, with the prospect that the data from these satellites improve the conditions of screening, besides improving the accuracy of the coordinates. With this assumption, we used the observed phase of the carrier wave (L1) to infer its contribution to the placement. The surveys were conducted in various locations due to rising SBAS satellites vary with latitude and longitude. However, this study was directed to the data from the WAAS satellites (PRN 138) and EGNOS (PRN 120 and 124) because they were the only visible throughout the screening taking simultaneity between the base and mobile receivers. During the processing stage, which was used the software GNSS Solution, some experiments were performed, such as: 1) Processing with all the L1 observable from available satellites (GPS and SBAS), analysis of standard deviations and comparison of the coordinates obtained with the true, 2) processing without observable L1 SBAS satellites, analysis and comparisons, 3) gradual withdrawal of the GPS satellites and reprocessing together (GPS + SBAS) and separately (GPS only). The main purpose of these experiments was to investigate the potential of the L1 observable processed SBAS satellites together with GPS L1 observable in the relative positioning. Statistical analysis such as trending and root mean square (RMS) were applied to verify the existence of systematic errors and accuracy of these coordinates. The results show that, specifically at sites of screening, the observables L1 SBAS satellites to be added to the processing, combined with the L1 observable GPS satellites, are not decisive for improving the accuracy of the coordinates.
\end{abstract}

Keywords: L1 observable, SBAS, GNSS. 


\section{LISTA DE FIGURAS}

Figura 1: Sinais GPS (The European Galileo Program, 2006) .............................20

Figura 2: Estações de referência WAAS (WALTER et.al, 2006) ….........................26

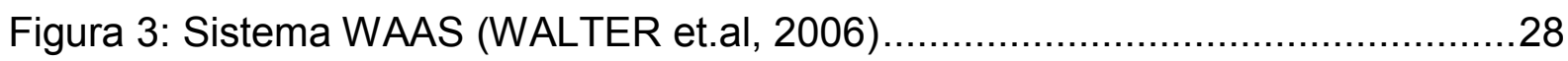

Figura 4: Posição dos satélites do Sistema EGNOS (FLAMENT et al., 2006)..........31

Figura 5: Distribuição dos satélites (SOUZA, 2006) ..................................................

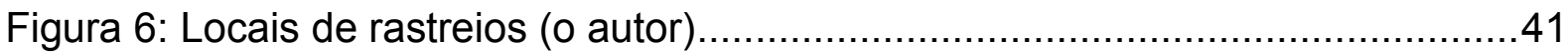

Figura 7: DOP (Diluição da Precisão) - Trimble Geo Office …………………….....43

Figura 8: RDOP (Hora Local) - Occupation Planning ….........................................4 44

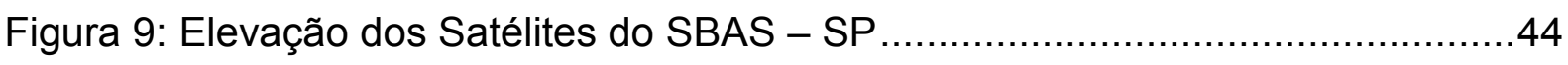

Figura 10: Disposição dos satélites GPS e SBAS - SP .......................................45

Figura 11: Local do rastreio em São Paulo - Raia da USP (Google Earth, 2010) ....46

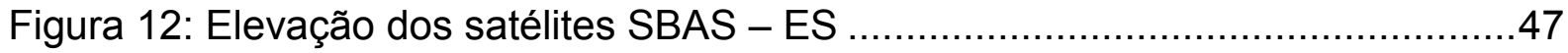

Figura 13: Disposição dos satélites GPS e SBAS - ES …………….................47

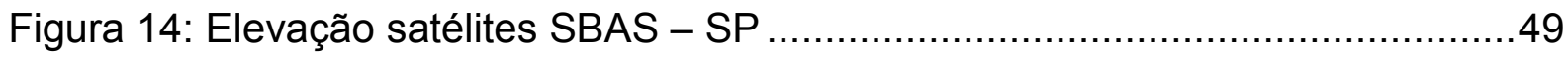

Figura 15: Disposição dos satélites GPS e SBAS - SP …………….................49

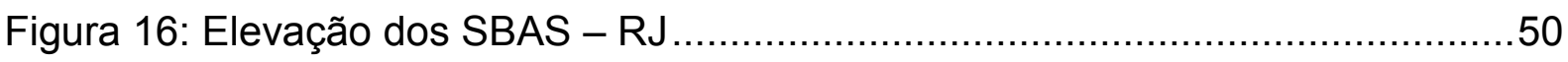

Figura 17: Disposição dos satélites GPS e SBAS - RJ .........................................51

Figura 18: Vista da torre de controle e dos receptores instalados...........................51

Figura 19: Altitude dos satélites SBAS em Mossoró RN ........................................52

Figura 20: Disposição dos satélites GPS e SBAS - Mossoró - RN .........................53

Figura 21: Elevação dos satélites SBAS - Manaus - AM .....................................54

Figura 22: Disposição dos satélites GPS e SBAS - Manaus - AM ...........................54

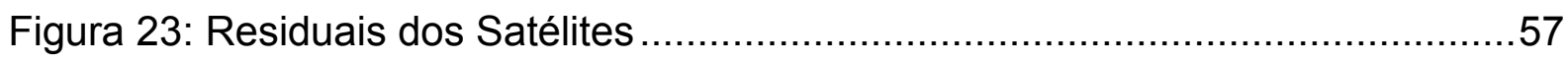

Figura 24: Elevação de todos os Satélites Rastreados.........................................57

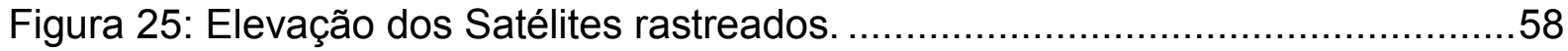

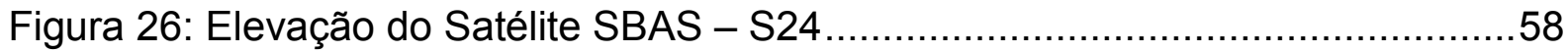

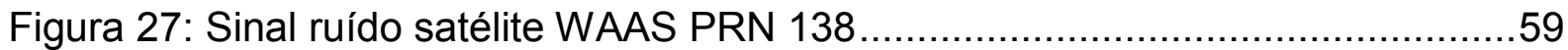

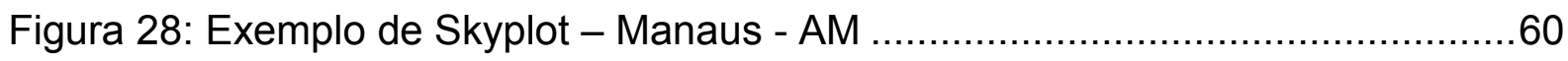

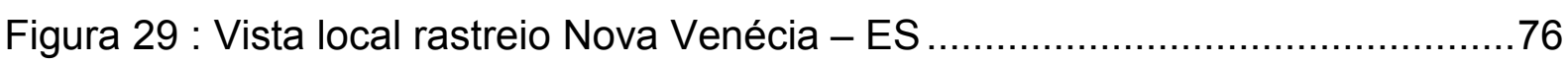

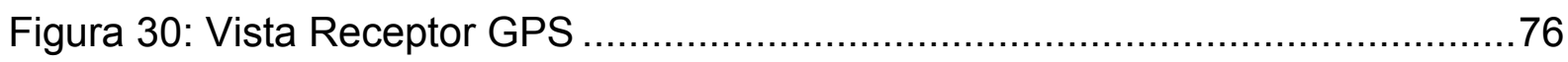




\section{LISTA DE TABELAS}

Tabela 1: Satélites e posição WAAS (The Wide-Area Augmentation System) ….....27

Tabela 2: Satélites e posição EGNOS (www.essp.be/about_egnos.html) .................31

Tabela 3: Erros envolvidos nas observações GPS (MONICO, 2008) ………............33

Tabela 4: Variação do DOP (adaptado de SEEBER, 2003) ...................................... 34

Tabela 5: Resumo do Rastreio de Campo (o autor) .............................................42

Tabela 6: Informações dos satélites SBAS (o autor)............................................55

Tabela 7: Sinal - Ruído do receptor da fabricante Magellan (adaptado <FTP

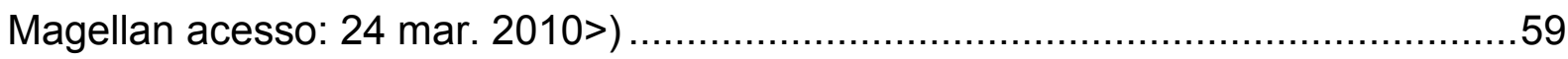

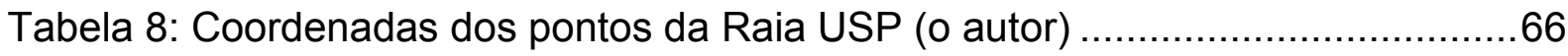

Tabela 9: Coordenadas Processadas - Situação ideal - Com SBAS/P (o autor).....67

Tabela 10: Coordenadas Processadas - Situação Ideal - Sem SBAS/ SP (o autor)67

Tabela 11: Coordenadas Processadas - Situação Crítica - Com SBAS /SP(o autor)

Tabela 12: Coordenadas Processadas - Situação Crítica - Sem SBAS/SP(o autor)

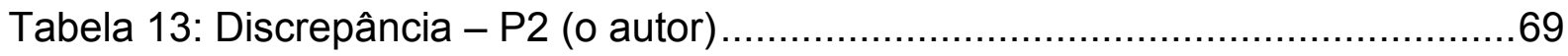

Tabela 14: Discrepância - P3C (o autor) ………….....................................

Tabela 15: Discrepância - P4 (o autor) ..........................................................

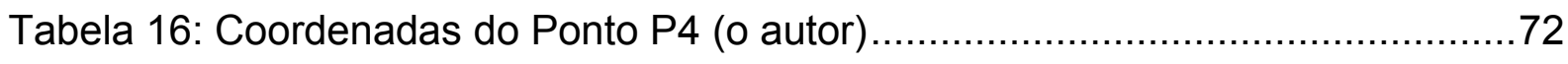

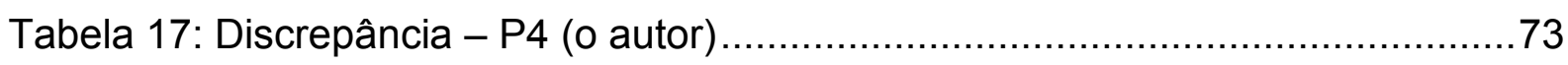

Tabela 18: Coordenadas Processadas - GPS - SP (o autor)............................... 74

Tabela 19: Coordenadas Processadas - GPS + SBAS - SP (o autor) .....................74

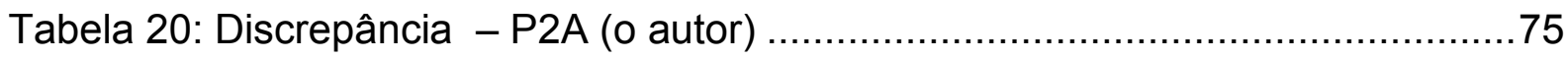

Tabela 21: Coordenadas Verdadeiras - Nova Venécia (o autor)...........................77

Tabela 22: Coordenadas Processadas - Situação ideal - Com SBAS / NV (o autor)

Tabela 23: Coordenadas Processadas - Situação Ideal - Sem SBAS / NV (o autor)

Tabela 24: Coordenadas Processadas - Situação Crítica - Com SBAS /NV (o autor) 
Tabela 25: Coordenadas Processadas - Situação Crítica - Sem SBAS / NV (o autor)

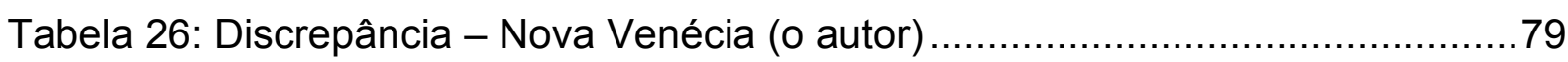

Tabela 27: Discrepância - P990B (o autor)

Tabela 28: Coordenadas Processadas situação ideal - Com SBAS - P001 e Deb1

(o autor).

Tabela 29: Coordenadas Processadas situação ideal - Sem SBAS - P001 e Deb1

(o autor)

Tabela 30: Coordenadas Processadas situação crítica - Com SBAS - P001 e

Deb1(o autor)

Tabela 31: Coordenadas Processadas situação crítica - Sem SBAS - P001 e

Deb1(o autor)

Tabela 32: Discrepância - PDeb1 (o autor) .

Tabela 33: Discrepância - Ponto P001 (o autor)

Tabela 34: Coordenadas Verdadeiras - Rio de Janeiro (o autor)

Tabela 35: Coordenadas Processadas situação ideal - Com SBAS /RJ (o autor)....83

Tabela 36: Coordenadas Processadas situação crítica - Sem SBAS/RJ (o autor)...83

Tabela 37: Coordenadas Processadas situação crítica - Com SBAS/RJ (o autor)...84

Tabela 38: Coordenadas Processadas situação crítica - Sem SBAS/RJ (o autor)...84

Tabela 39: Discrepância - P8002 (o autor).

Tabela 40: Coordenadas Verdadeiras - Mossoró (o autor)

Tabela 41: Coordenadas Processadas situação ideal - Com SBAS/Mossoró (o autor)

Tabela 42: Coordenadas Processadas situação ideal - Sem SBAS/Mossoró (o autor)

Tabela 43: Coordenadas Processadas situação crítica - Com SBAS/Mossoró

(o autor).

Tabela 44: Coordenadas Processadas situação crítica - Sem SBAS /Mossoró

(o autor). 86

Tabela 45: Discrepância - P409 (o autor) ............................................... 88

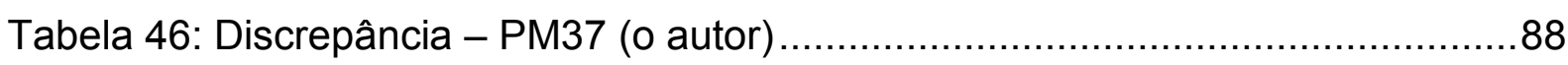

Tabela 47: Coordenadas verdadeiras - Manaus (o autor)

Tabela 48: Coordenadas Processadas situação ideal - Com SBAS/ Manaus (o autor) 
Tabela 49: Coordenadas Processadas situação crítica Com SBAS Manaus (o autor) 89

Tabela 50: Coordenadas Processadas situação crítica Sem SBAS/Manaus (o autor) .89

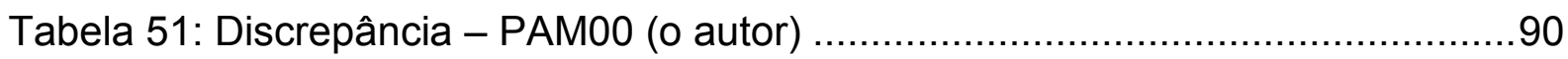

Tabela 52: Análise Estatística dos resultados do processamento GPS - ES ............91 Tabela 53: Análise Estatística dos resultados do processamento GPS+SBAS - ES.91 Tabela 54: Análise Estatística dos resultados do processamento GPS - SP ............91 Tabela 55: Análise Estatística dos resultados do processamento GPS+SBAS - SP 91

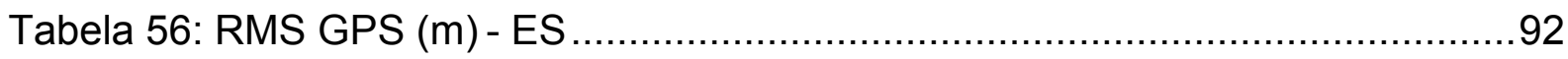

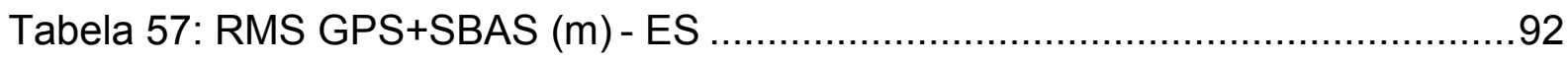

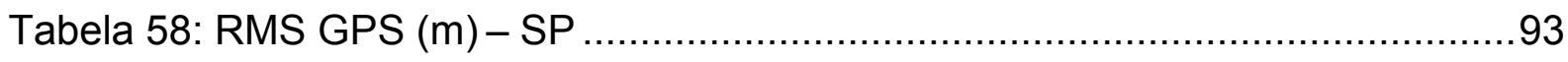

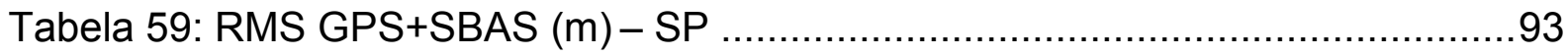




\section{LISTA DE GRÁFICOS}

Gráfico 1: Discrepância e Desvio padrão - P2 (N, E,h) (o autor) ..............................69

Gráfico 2: Diferenças e Desvio padrão - P3C (N, E, h) (o autor).............................70

Gráfico 3: Discrepância e Desvio padrão - P4 (N, E, h) (o autor).............................71

Gráfico 4: Discrepância e Desvio padrão - P4 (N, E, h) (o autor).............................73

Gráfico 5: Discrepância e Desvio padrão - P2A (N, E, h) (o autor) ..........................75

Gráfico 6: Discrepâncias e desvio padrão- P990A (N, E, h) (o autor) ………….....79

Gráfico 7: Discrepâncias e desvio padrão- P990B (N, E, h) (o autor) ......................80

Gráfico 8: Discrepância e desvio padrão - PDeb1 (N, E, h) (o autor) .......................82

Gráfico 9: Discrepância e desvio padrão- P001 (N, E, h) (o autor)..........................82

Gráfico 10: Discrepância e desvio-padrão - P8002 (N, E, h) (o autor) ....................84

Gráfico 11: Discrepância e desvio-padrão - P409 (N, E, h) (o autor) .......................87

Gráfico 12: Discrepância e desvio-padrão - M37 (N, E, h) (o autor) .........................87

Gráfico 13: Discrepância e desvio-padrão - PAM00 (N, E, h) (o autor) ....................89

Gráfico 14: RMS - Nova Venécia - ES ..........................................................

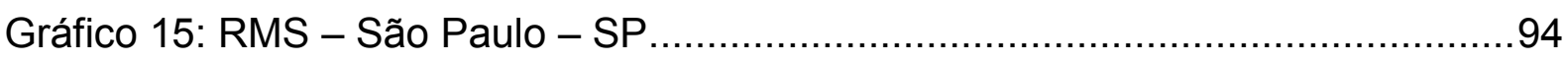

Gráfico 16: Coordenadas satélite PRN 138 - SP (o autor) .....................................95

Gráfico 17: Coordenadas satélite PRN 120 - SP (o autor) ....................................95 


\section{LISTA DE SIGLAS}

ASQF - Application Specific Qualification Facility

BPS - bits por segundo ou bps

C/A - Coarse/Acquisition (Código C/A)

CDMA - Code Division Multiple Access

DGPS - Differential GPS

DoD - Department of Defense

DOP - Dilution of Precision

DVP - Development Verification Platform

EGNOS - European Geostationary Navigation Overlay Service

E5a - Sinal de acesso aberto transmitido na portadora E5

E5b - Sinal de acesso aberto transmitido na portadora E5

E6C - Sinal de acesso comercial transmitido pela portadora E6

E6P - Sinal de acesso restrito transmitido na portadora E6

ESA - European Space Agency

FAA - Federal Aviation Administration

FDMA - Frequency Division Multiple Access

GAGAN - GPS Aided Geo Augmented Navigation

GBAS - Ground Based Augmentation Systems

GDOP - Geometrical DOP

GLONASS - Globalnaya Navigationnaya Sputnikovaya Sistema

GNSS - Global Navigation Satellite System

GPS - Global Positioning System

HDOP- Horizontal DOP

IBGE - Instituto Brasileiro de Geografia e Estatística

ICAO - International Civil Aviation Organization

IFES - Instituto Federal do Espírito Santo

L2C- Novo código civil

L1F - Sinal de acesso aberto transmitido na portadora L1

L1P - Sinal de acesso restrito transmitido na portadora $L 1$

LAAS - Local Area Augmentation System

M - M-Code

MVC - Matriz Variância Covariância 
MSAS - Multi-functional Satellite Augmentation System

OTF - On The Fly

P - Precise/Protected

PACF - Performance Assessment and System Checkout Facility

PDOP - Position DOP

PPM - Parte por milhão

PRN - pseudorandom noise

RBMC - Rede Brasileira de Monitoramento Contínuo

Ribac - Rede Incra de Bases Comunitárias do GPS

RDOP - Relative DOP

RMS - Erro Médio Quadrático

RTCM - Radio Techinical Commission for Maritime Services Special Committe 104

RTK - Real Time Kinematic

SAD 69 - South American Datum 1969

SBAS - Satellite-Based Augmentation System

S/N - razão Sinal-ruído

TDOP - Time DOP

TEC - Total Electron Content

TOA - Time Of Almanac

USP - Universidade de São Paulo

UTM - Universal Transversa de Mercator

VDOP - Vertical DOP

WAAS - Wide Area Augmentation System

WMS - WAAS Master Reference

WRS - WAAS Reference Stations 


\section{SUMÁRIO}

1 INTRODUÇÃO ..............................................................................................................15

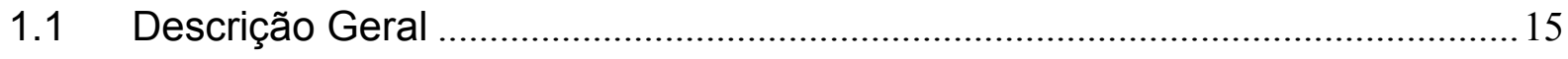

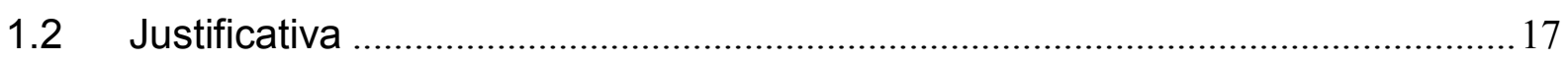

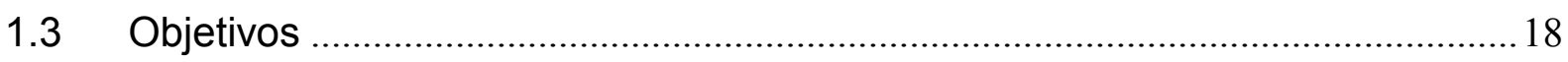

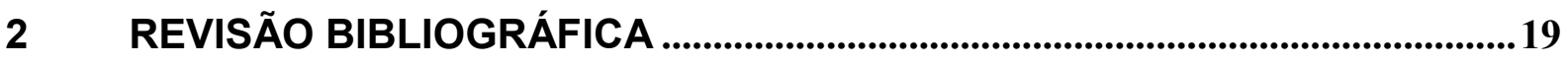

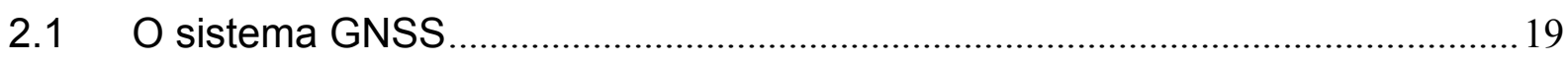

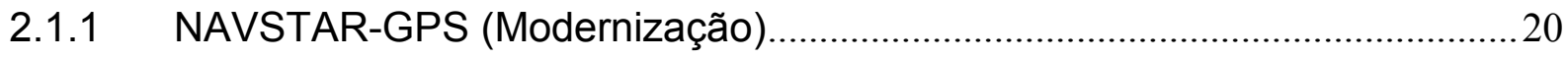

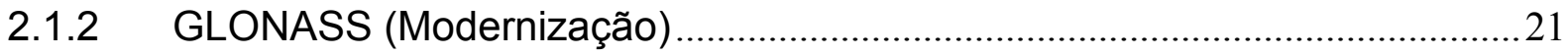

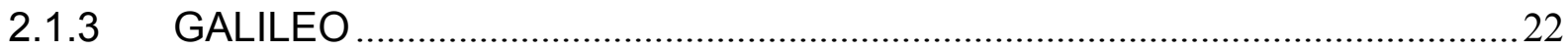

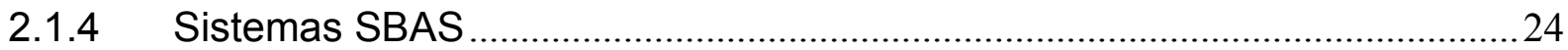

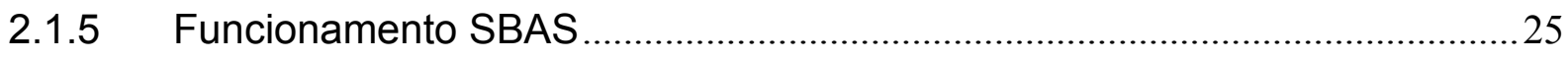

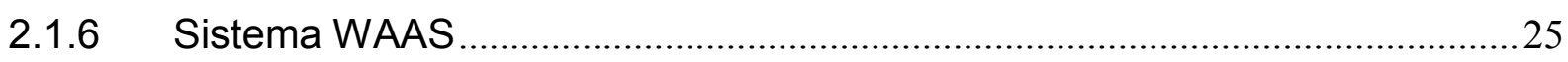

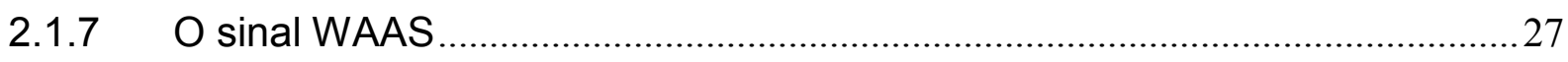

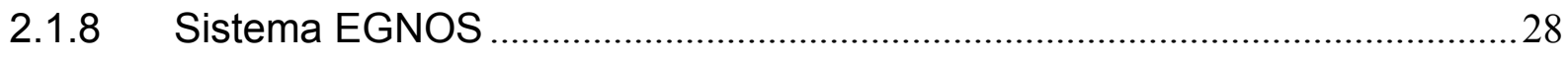

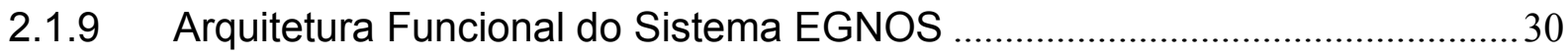

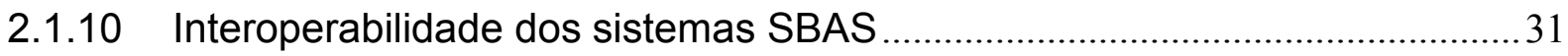

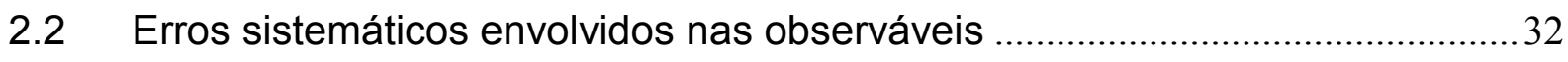

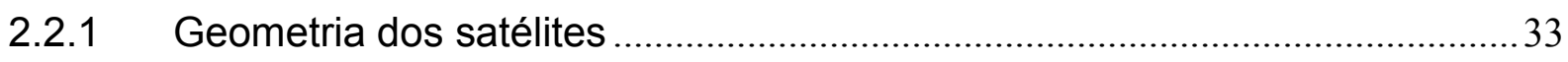

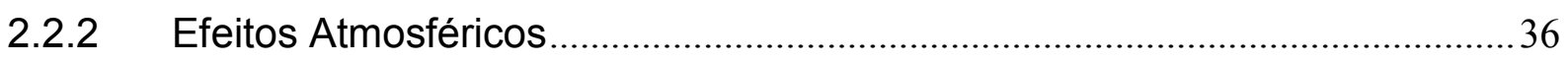

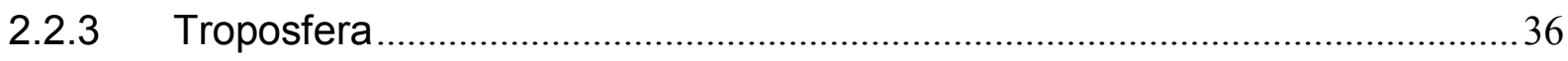

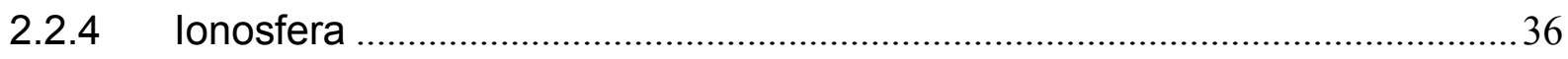

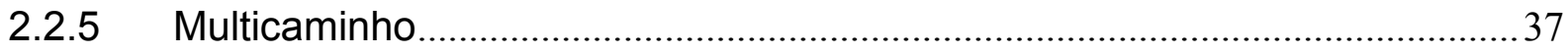

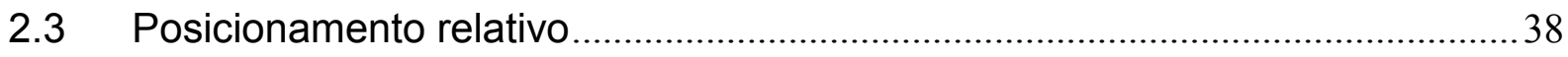

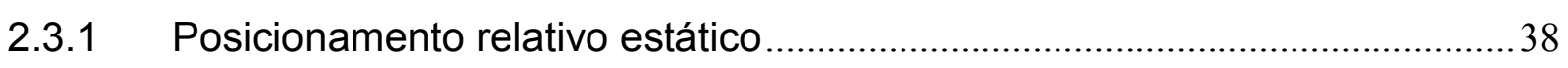

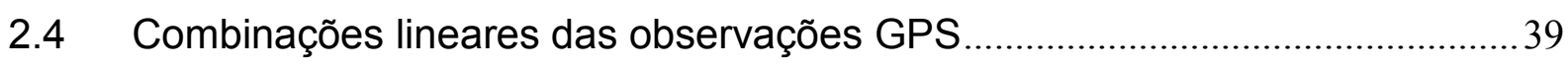

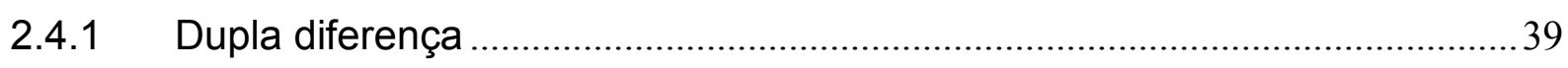

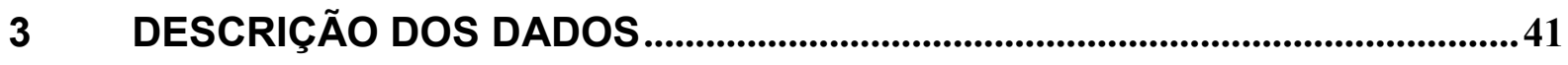

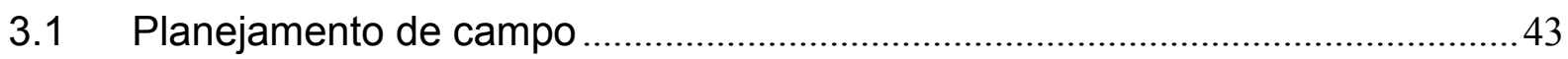

3.1.1 Trabalho de campo - primeiro rastreio com GPS L1/L2 ................................ 44 
3.1.2 Trabalho de Campo - Segundo rastreio GPS L1 ..........................................46

3.1.3 Trabalho de campo - Terceiro Rastreio GPS L1/L2 e L1 ..............................48

3.1.4 Trabalho de Campo - Quarto Rastreio GPS L1/L2 ........................................50

3.1.5 Trabalho de Campo - Quinto Rastreio GPS L1 ...............................................52

3.1.6 Trabalho de Campo - Sexto Rastreio GPS L1/L2 .........................................53

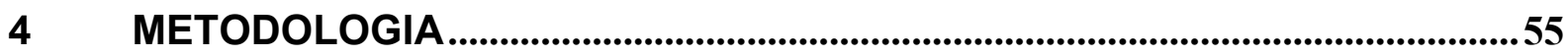

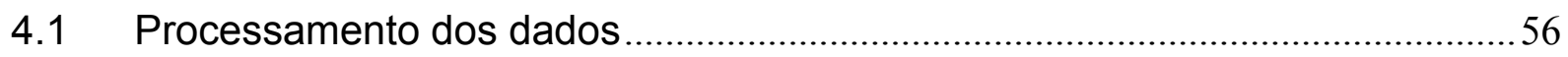

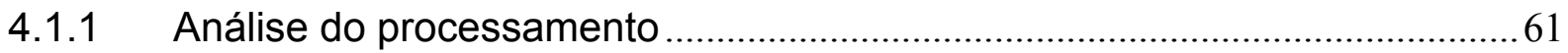

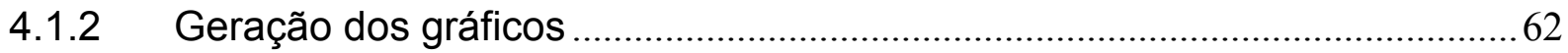

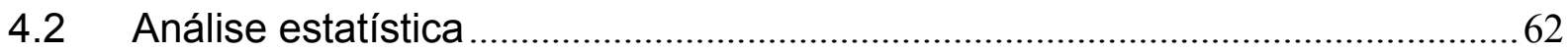

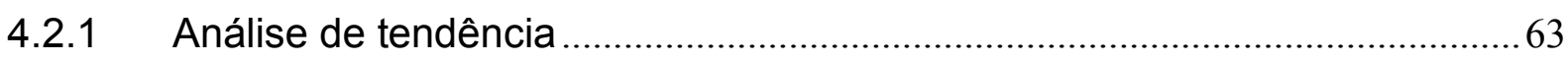

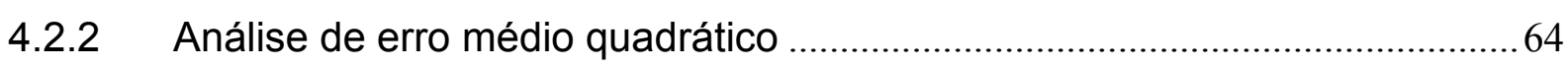

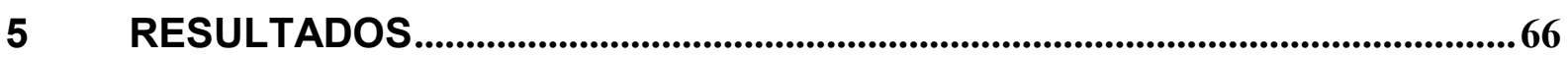

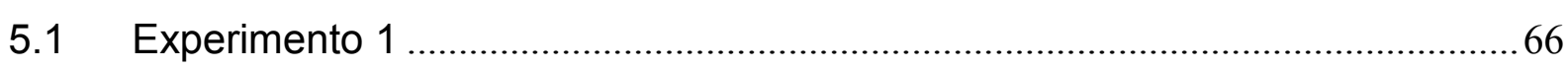

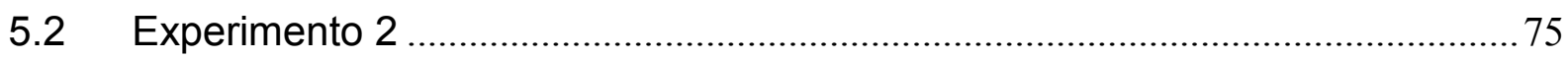

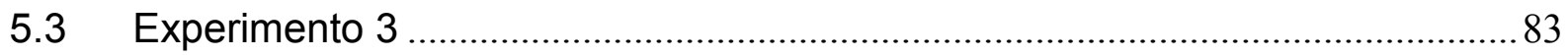

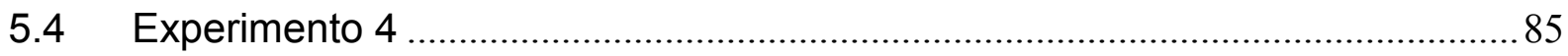

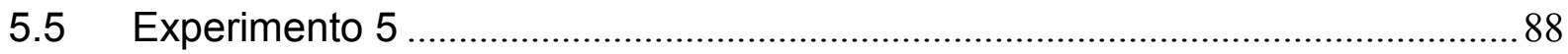

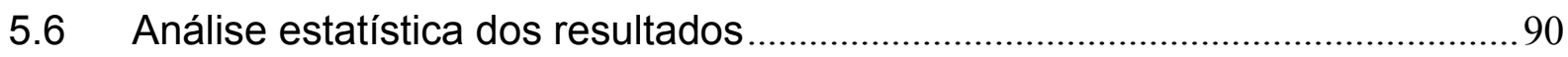

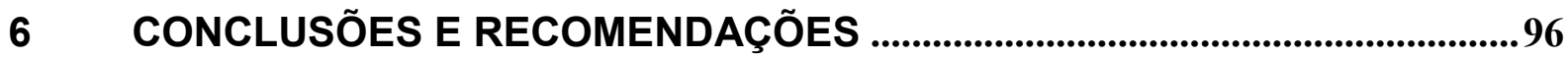

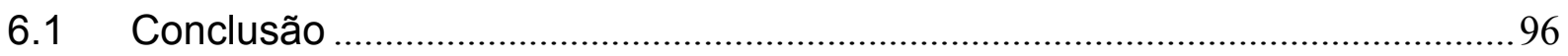

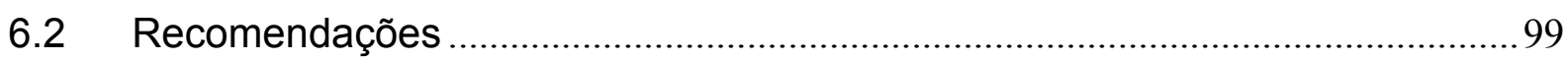

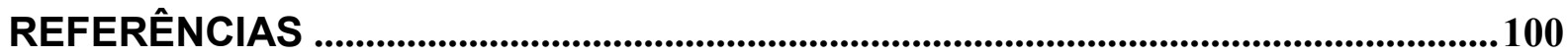

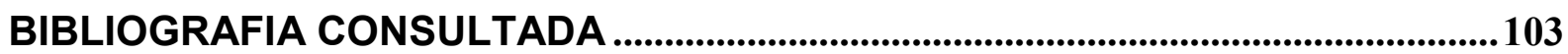

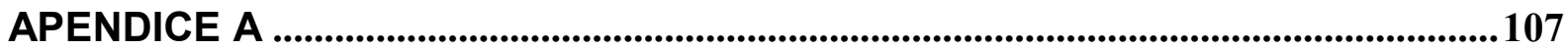

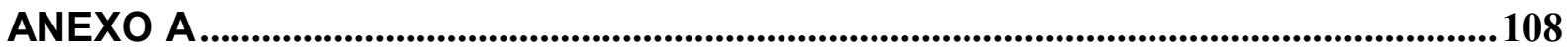




\section{INTRODUÇÃO}

\subsection{Descrição Geral}

A navegação por satélite é utilizada em um grande número de aplicações, decorrentes das mais variadas áreas do conhecimento, dentre elas se destaca a Geodésia.

$\mathrm{Na}$ atualidade, a disponibilidade de satélites acima do horizonte é abundante, constituindo-se por diversas constelações (GPS - Global Positioning System, GLONASS - Globalnaya Navigationnaya Sputnikovaya Sistema, GALILEO e SBAS Satellite-Based Augmentation System). Atualmente, a maioria dos receptores vendidos no mercado estão habilitados para receber sinais destas diversas constelações com apenas uma atualização do programa interno do receptor. Apesar destes sinais estarem disponíveis, o problema é a integridade dos dados transmitidos por estes satélites, como, por exemplo, os dados dos sistemas SBAS, em especial para o Brasil.

Caso um profissional não realize um planejamento de campo antes do rastreio, dificilmente não obterá sucesso em seu rastreio, pois há, em qualquer horário do dia, uma disponibilidade mínima de oito satélites acima do horizonte. $O$ planejamento de campo tem como fundamento principal a otimização do tempo e, conseqüentemente, a diminuição dos custos com as equipes de campo, sendo uma etapa importante que antecede o rastreio.

Nos últimos anos, as grandes obras de engenharia, como implantação de gasoduto, prospecção de petróleo, construções de estradas, mineração, dentre outras, necessitam obter coordenadas rápidas e precisas, praticamente em tempo real, para apoio aos levantamentos de campo. Com o uso da tecnologia GNSS (Global Navigation Satellite System), essa agilidade e precisão são alcançadas facilmente, utilizando-se de técnicas de levantamento que proporcionam soluções em tempo real (RTK - Real Time Kinematic), sem a necessidade de pósprocessamento.

Muitas técnicas foram desenvolvidas para explorar e utilizar a capacidade do sistema GNSS, e determinar as coordenadas com precisão de um ponto com o 
menor tempo de ocupação possível.

Alguns receptores GNSS utilizam apenas algoritmos para solucionar a ambigüidade, mas existe outra tecnologia que, além do padrão tradicional, utiliza-se das observáveis L1, fornecidos pelos satélites geoestacionários, para melhorar a geometria, assim, reduzindo o tempo de rastreio e mantendo a acurácia das coordenadas (Magellan, 2010).

O sistema GPS, em sua configuração atual, não é preciso e nem confiável o suficiente para ser aceito como o único meio de navegação aérea, devido a não emitir nenhuma mensagem aos usuários, imediatamente, caso haja alguma falha no sistema. Partindo dessa limitação, os sistemas SBAS foram concebidos para auxiliar na solução do problema, onde a utilização do GNSS é mais crítica (como, por exemplo, na aproximação em pousos e decolagens de aeronaves). Estes sistemas são independentes do sistema GPS, monitoram seu desempenho continuamente e, o mais importante, detectam possíveis falhas em tempo real, e informam aos usuários quase que imediatamente (WALTER et. al. 2006). Tais sistemas, mesmo sendo desenvolvido visando puramente o auxílio à aviação, outros setores também perceberam um potencial de aplicabilidade, como, por exemplo, no posicionamento preciso.

Os sistemas SBAS (WAAS - Wide Area Augmentation System) e EGNOS (European Geostationary Navigation Overlay Service) fornecem sinais transmitidos pelo satélite geoestacionários (GEO), com correções diferenciais na sua área de abrangência e parâmetros destinados a garantir a integridade do posicionamento do usuário GNSS (SÁNCHES et al, 2006). Essas correções não se aplicam para o Brasil e as informações SBAS são transmitidas para os usuários na mesma frequência L1 (1575,42 MHz) do sistema GPS (WALTER et al, 2006). Além disso, informações sobre a sua posição e deriva do relógio também são enviadas. Tais informações permitem incluir as observáveis L1 do sistema SBAS, combinadas com as observáveis L1 do sistema GPS (WANNINGER, 2007). Assim, a combinação das observáveis do sistema SBAS e GPS, poderá permitir a melhora do posicionamento.

Estudos utilizando-se da combinação da fase da onda portadora $L 1$ dos sistemas GPS, GLONASS e SBAS (WAAS e EGNOS) para aplicações que exijam acuraria foram realizados, afim de obter melhor disponibilidade e resolução mais rápida das ambigüidades (WANNINGER, 2007).

Segundo Wanninger (2007, p.9) os parâmetros de órbita e do relógio dos 
satélites EGNOS estão com baixa qualidade em posicionamento diferencial, sendo apenas utilizado para bases curtas. [..] "Presently, the EGNOS satellite orbit and clock parameter are of such a poor quality that precise differential positioning is limited to short baselines." [..].

Novas pesquisas estão sendo realizadas para a adição de novas bases em locais estratégicos, inclusive na América do Sul, assim iniciar a transmissão de sinais SBAS na região das Américas do Sul, Central e Caribe, onde testes já foram realizados, na Argentina no mês de outubro de 2010 (GPS WORD MAGAZINE, 2010).

No Brasil não existe, até a presente data, trabalhos sobre a combinação das observáveis L1 destes sistemas para melhoria da acurácia em posicionamento relativo.

Nesta pesquisa serão utilizadas, no processamento, as observáveis L1 do sistema GPS, combinados com as observáveis L1 do sistema SBAS. Assim realizarse-ão vários experimentos, utilizando-se do software comercial GNSS Solution, com o objetivo verificar se as observáveis L1 dos satélites SBAS, ao serem introduzidos no processamento, são determinantes ou não para a melhoria da acurácia das coordenadas e na melhoria das condições do rastreio (PDOP e RDOP).

\subsection{Justificativa}

Atualmente, ocorre uma grande disseminação de receptores GPS no mercado nacional, de diferentes fabricantes, nacionalidades e modelos, preparados para rastrear as diversas constelações disponíveis.

Os fabricantes, em seus catálogos técnicos, destacam a capacidade de seus receptores rastrearem as constelações NAVSTAR-GPS, GLONASS, GALILEO e SBAS, apenas com uma atualização do programa interno do receptor (firmware), contudo algumas dúvidas sobre a constelação SBAS permanecem sem resposta.

A primeira dúvida é sobre o funcionamento da observável L1, transmitida pelos satélites da constelação SBAS, no Brasil, e qual seria o nível de acurácia e integridade das observáveis fornecidas por este sistema. Uma outra dúvida é sobre a disponibilidade deste satélite no território brasileiro e se seus dados melhoram o 
posicionamento quando combinados com os dados da constelação GPS.

Dentre estas dúvidas, a que está mais ligada a esta pesquisa é sobre a utilização das observáveis $L 1$, transmitidas pela constelação SBAS, combinada com as observáveis L1 da constelação GPS, são determinantes ou não na melhoria da acurácia e do posicionamento relativo.

\subsection{Objetivos}

Com a grande demanda na utilização dos sistemas GNSS no posicionamento geodésico, este trabalho tem como finalidade:

$\checkmark$ Pesquisar se a observável L1, transmitida pelos satélites SBAS, quando combinadas com as observáveis L1 dos satélites GPS, são determinantes ou não para a melhoria da acurácia do posicionamento relativo;

$\checkmark$ Avaliar a qualidade dos resultados (coordenadas) provindos de software comercial, através dos relatórios de processamento, utilizando-se de várias estratégias de processamento;

$\checkmark$ Realizar análise de tendência e erro médio quadrático (RMS) das coordenadas. 


\section{REVISÃO BIBLIOGRÁFICA}

Para a compreensão da metodologia utilizada neste trabalho e análise dos resultados obtidos, deve-se conhecer os fundamentos teóricos envolvidos. Neste capítulo 2 serão apresentados de forma sucinta tais conceitos, pois estes conceitos já estão bem fundamentados nas várias bibliografias existentes.

\subsection{O sistema GNSS}

A expressão Global Navigation Satellite System (GNSS) foi criada na 10th Air Navigation Conference 1991, quando a ICAO (International Civil Aviation Organization) reconheceu que o futuro da navegação autônoma por satélites seria fornecida pelo GNSS (HEIN, 2000).

Os componentes desse sistema são: o GPS, desenvolvido pelo Departamento de Defesa dos Estados Unidos $(D \circ D)$, que se encontra em plena operação; o GLONASS, semelhante ao GPS, desenvolvido pela extinta União Soviética, e, atualmente, sendo de responsabilidade da República da Rússia; e o mais novo sistema Europeu GALILEO, que é de responsabilidade da União Européia, que de acordo com o planejamento atual, a fase de desenvolvimento e validação abrangeu o período 2005-2009, a fase de execução 2009-2012, e a fase operacional poderia começar em 2013, além dos sistemas SBAS regionais, que auxiliam na navegação aérea.

Para se estabelecer o conceito de GNSS, várias etapas foram definidas: GNSS 1 - utiliza o sistema GPS e GLONASS como espinha dorsal (base) e é aumentado com as componentes civis locais, como os sistemas SBAS; GNSS 2 - é uma segunda geração do sistema de navegação por satélites, que preenche os requisitos necessários para ser um GNSS, tal como será o GALILEO (SEEBER, 2003). 


\subsubsection{NAVSTAR-GPS (Modernização)}

O princípio básico da navegação pelo GPS consiste na medida da distância entre o usuário e pelo menos quatro satélites. Conhecendo as coordenadas dos satélites em um sistema de referência, é possível calcular a posição do receptor no mesmo sistema de referência dos satélites. Geometricamente, é necessário determinar as distâncias do receptor a apenas três satélites, mas, na verdade, são necessários, no mínimo quatro satélites para determinar a posição corretamente. Isto se deve ao não sincronismo dos relógios do satélite e receptor, gerando um erro denominado erro do relógio do receptor. Então, para sincronizar os relógios do satélite e receptor, uma nova incógnita é adicionada ao modelo matemático (MONICO, 2008).

Cada satélite transmite em duas ondas portadoras e terá com sua modernização mais uma portadora, denominada de L5, cuja frequência é de 1176,45 MHz e $\lambda=25,5 \mathrm{~cm}$, que tem como benefícios a atualização da constelação, a melhor precisão na navegação mundial, minimizando as interferências que ocorrem no GPS, como, por exemplo, interferências atmosféricas (MONICO, 2008).

Com esta modernização do sinal GPS, na portadora L1, estão disponíveis três códigos modulados, o C/A (Coarse/Acquisition), o código P (Precise/Protected) e o novo código militar $\mathrm{M}(\mathrm{M}-\mathrm{Code})$, já na portadora $\mathrm{L} 2$, tem-se o código $\mathrm{P}$ e $\circ \mathrm{M}$, além da nova L2C, conforme ilustra a Figura 1 (TORAN et al., 2006).

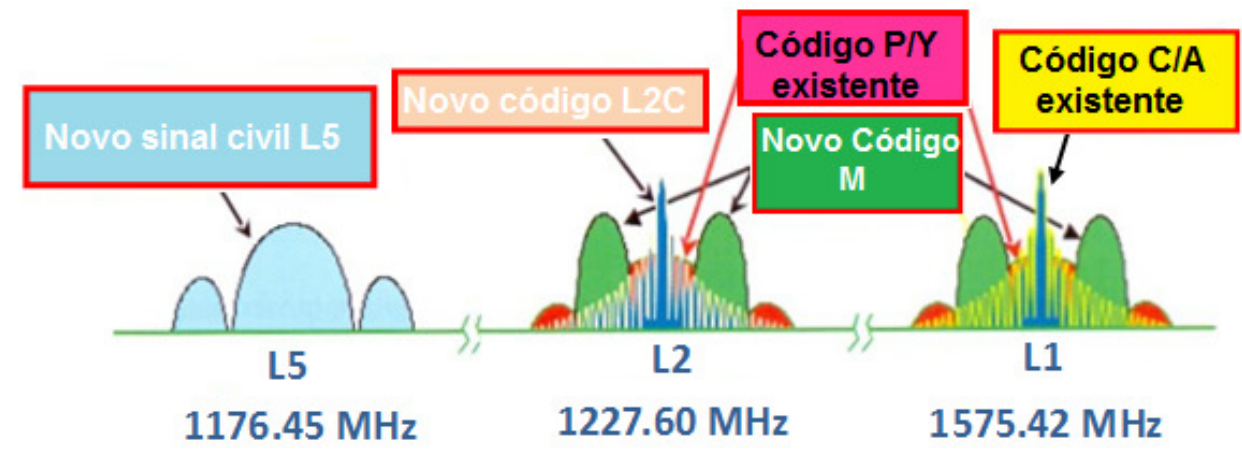

Figura 1: Sinais GPS (The European Galileo Program, 2006)

O novo sinal $\mathrm{L} 2 \mathrm{C}$, com frequência igual a $511,5 \mathrm{KHz}$, promete aumentar a robustez do sinal e a resistência a interferências, reduzindo assim, o ruído e aumentando a precisão, proporcionando também um melhor sinal no interior de 
edifícios e áreas arborizadas (LEICK, 2004).

Esta modernização do sistema espacial visa melhorar a quantidade e qualidade das observáveis e, conseqüentemente, melhorar o posicionamento, trazendo maior precisão, melhor resistência às interferências, melhorando o desempenho para os usuários em todo o mundo.

\subsubsection{GLONASS (Modernização)}

A Agência espacial Russa tem planos de aumentar o número de satélites para 30 até o fim de 2011. Em 12/08/2010 a constelação possuía 23 satélites em órbita, destes 20 estão ativos, 01 em manutenção e 02 em fase de testes (http://www.glonass-ianc.rsa.ru - acesso em 15 ago. 2010).

Os códigos utilizados no sistema GLONASS são similares aos do GPS. Possuem os códigos C/A e P, o primeiro disponível ao uso civil e o outro para usuários autorizados, os dois são modulados na portadora L1. No caso da portadora L2, é modulado apenas no código $P$ (MONICO, 2008). O sistema de navegação GLONASS está disponível para usuários civis, com o sinal de precisão L1 padrão sem qualquer restrição seletiva (KLIMOV; REVNIVYH, 2006).

Diferentemente dos satélites GPS, cada satélite GLONASS opera em uma frequência exclusiva na banda $L 1$ e na banda $L 2$, utilizando a técnica de Múltiplo Acesso por Divisão de Frequência (FDMA - Frequency Division Multiple Access) em L1 e L2 (HOFMANN - LICHTENEGGER, 2008). Desta forma, o sinal GLONASS é mais resistente contra interferências de banda estreita, e, além disso, a correlação entre o sinal de diferentes satélites GLONASS é baixa (HOFMANN LICHTENEGGER, 2008).

No caso da nova banda L3, que possui frequência entre as bandas L5 e L2 do GPS (GROVES, 2008), utilizará a técnica CDMA (Code Division Multiple Access) idêntico ao sistema GPS.

O referencial utilizado é o PZ 90, que recentemente foi refinado, sendo compatível com o ITRF2000 (MONICO, 2008). Além do sistema espacial, há planos de modernização do GLONASS, envolvendo também o segmento de controle com a adição de novas estações de referência. 


\subsubsection{GALILEO}

O sistema GALILEO está sendo projetado para atender uma variedade de necessidades dos usuários, dos quais um número representativo de serviços foi identificado a partir do projeto base, o que permitiu a definição das principais características do sistema (FALCONE et al., 2006).

\section{a) Segmento espacial}

A estrutura dos sinais GALILEO será transmitida em três bandas de frequência (E5, E6 e L1), usando quatro portadoras (MONICO, 2008; GROVES, 2008): E5A (1176,45 MHz), E5B (1207,14 MHz), E6 (1278,75 MHz), E1 (1575,42 $\mathrm{MHz})$.

Serão transmitidos seis sinais de navegação, definidos como L1F, L1P, E6C, E6P, E5a e E5b (FALCONE et al, 2006):

$\checkmark$ L1F - sinal de acesso aberto transmitido na portadora $L 1$, tendo um canal piloto e um canal de dados, respectivamente L1F-p e L1F-d. Este sinal apoiará os serviços de acesso aberto, acesso comercial e segurança a vida;

$\checkmark$ L1P - é um sinal de acesso restrito transmitido na portadora L1 e apoiará o serviço Público Regulamentado;

$\checkmark$ E6C - é um sinal de acesso comercial transmitido pela portadora E6, tendo um canal piloto e um canal de dados, respectivamente E6C-p e E6C-d. Apoiará o serviço de acesso comercial;

$\checkmark$ E6P - é um sinal de acesso restrito transmitido na portadora E6 e apoiará o serviço Público Regulamentado;

$\checkmark$ E5a - sinal de acesso aberto transmitido na portadora E5 tendo um canal piloto e um canal de dados, respectivamente E5a-p e E5a-d. Apoiará o serviços de acesso aberto;

$\checkmark$ E5b - sinal de acesso aberto transmitido na portadora E5 tendo um canal piloto e um canal de dados, respectivamente E5b-p e E5b-d. Apoiará os serviços de acesso aberto, acesso comercial e segurança a 
vida.

\section{b) Segmento de controle}

A estrutura que está disponível para o sistema EGNOS está sendo aproveitada para o sistema GALILEO, com acréscimo de algumas estações, em razão da abrangência global. No total serão trinta estações, que terão a função de determinação de órbitas e sincronização de tempo. Essas informações serão enviadas para dois centros de controle, que por sua vez são responsáveis pela geração de mensagens de navegação, sistema de tempo e integridade do sistema (MONICO, 2008).

\section{c) Segmento de usuário}

O diferencial do sistema está nos serviços que serão disponibilizados para os usuários (MONICO, 2008).

O sistema GALILEO (HOFMANN - LICHTENEGGER, 2008) oferecerá ao usuário cinco serviços distintos, sendo eles:

$\checkmark$ Serviço de Acesso Aberto - serviço básico de posicionamento;

$\checkmark$ Serviço de Acesso Comercial - para usuários que exigem serviço garantido e contrato de responsabilidade;

$\checkmark$ Serviço de Segurança a Vida - aplicadas à segurança aérea, marítima, entre outras que necessitem de integridade e disponibilidade;

$\checkmark$ Serviço Público Regulamentado - aplicações para policia, bombeiros, alfândega entre outros;

$\checkmark$ Serviço de Busca e Resgate (SAR) - a disponibilidade deste serviço é especificado para ter confiabilidade acima de $99,7 \%$ do tempo. À nova geração de rádio farol (beacon) serão incorporados um receptor GNSS, onde será modulada a informação de emergência. O centro de controle envia as informações para a central de salvamento que aciona a equipe de resgate local. 


\subsubsection{Sistemas SBAS}

O SBAS foi criado com o objetivo de padronizar os sistemas de aumento que utilizam um ou mais satélites, em geral geoestacionários, apesar de todos os sistemas SBAS serem independentes, suas arquiteturas são compatíveis para garantir integração entre os diversos sistemas mundiais de navegação.

Há Sistemas de Aumento Baseado em Solo (Ground Based Augmentation Systems - GBAS), Sistema de Áreas Locais de Aumento (Local Area Augmentation System - LAAS) ou GPS Diferencial (Differential GPS - DGPS) e também Sistemas de Aumento Baseados em Satélites (SBAS).

Os sistemas SBAS disponíveis transmitem os dados para os usuários por meio de uma frequência igual a L1 do GPS (L1 = 1575,42 MHz), mas em um formato diferente (WALTER et.al, 2006).

Segundo GLICA, 2008 várias aplicações, como por exemplo, pousos e decolagens de aeronaves e rotas de vôo comerciais, requerem informações mais precisas e com integridade do que as fornecidas apenas pelos sistemas GPS atuais. Essa maior precisão ocorre pela implementação destes sistemas de 'aumento' que não apenas incrementam a acurácia, mas também a integridade e disponibilidade dos dados.

Todos os sistemas SBAS disponíveis transmitem através de seus satélites em órbita mensagens de correções e parâmetros adicionais de garantia do sistema para a maior confiabilidade dos usuários GNSS (SÁNCHES et al., 2006), além de fornecer informações sobre as correções da órbita e relógio dos satélites GPS, GLONASS, GALILEO e GEO, correções ionosféricas e as estimativas dos erros associados a ionosfera (GROVES, 2008).

Estas mensagens de correção e parâmetros adicionais são geradas, pois existem as estações base cujas posições são conhecidas com precisão, de tal forma que os erros dos satélites podem ser calculados e corrigidos.

O sistema compreende: uma rede de estações de referência terrestre, que monitoram os sinais dos satélites, estação mestra, que coleta e processa dados das estações de referência e geram mensagens SBAS, estações de enlace de subida (uplink), que enviam as mensagens para satélites geoestacionários e transponders nos satélites GEO, que transmitem as mensagens SBAS para os usuários. 
Dentre os sistemas SBAS, existem: o WAAS nos Estados Unidos, o MSAS (Multi-functional Satellite Augmentation System) no Japão, o EGNOS na Europa, além do GAGAN (GPS Aided Geo Augmented Navigation) da Índia.

\subsubsection{Funcionamento SBAS}

Os sinais de navegação transmitidos pelos satélites GNSS são recebidos pela rede de monitoramento de integridade (Estações de Referência) distribuída sobre uma área geográfica. Estas estações retransmitem os dados a um equipamento de processamento central (Estação Mestra), que avalia o sinal e calcula as correções necessárias (erro do relógio do satélite, erros ionosféricos e as estimativas dos erros associados a ionosfera). Para cada satélite GNSS monitorado, a estação mestra estima os erros na transmissão dos parâmetros de efemérides e relógio do satélite, transmite estas correções para as Estações de Enlace de Subida (Uplink) que as envia aos satélites geoestacionários SBAS. Por fim, a mensagem de correção é transmitida ao usuário (SÁNCHES et al., 2006).

\subsubsection{Sistema WAAS}

O WAAS é um sistema de satélites e estações terrestres que fornecem correções diferenciais obtidas por meio da mensagem do sinal dos satélites desse sistema. Estas mensagens têm a função de corrigir erros contidos no posicionamento fornecido apenas pelo sistema GPS, melhorando, assim, a acurácia no posicionamento dos usuários. O sistema WAAS foi projetado especificamente para atender acurácia, integridade, a continuidade e padrões de disponibilidade aos usuários da aviação, mas também é um serviço aberto que tem a capacidade de suporte a outras aplicações, como o posicionamento preciso (FAA, 2008).

Segundo a FAA, 2008 (Federal Aviation Administration) o sistema WAAS tem atualmente 25 estações de referência espalhadas pelo território americano. Cada estação de referência WAAS (WRS - WAAS Reference Station) inclui três receptores GPS, de modo que as falhas no receptor podem ser facilmente 
detectadas. Nestas estações de referência WAAS, os receptores são de dupla frequência. A cada segundo, são realizadas medições de fase e pseudodistância do GPS (WALTER et al., 2006).

A arquitetura do sistema WAAS consiste nos segmentos de controle, espacial e de usuários. O segmento de controle é composto por estações de referência terrestre (WRS), que estão representadas na Figura 2 pelo círculo, e também pelas estações mestras de referência (WMS- WAAS Master Stations), que são representadas pelas estrelas, além das estações de envio de dados (uplink) representadas pelas antenas:

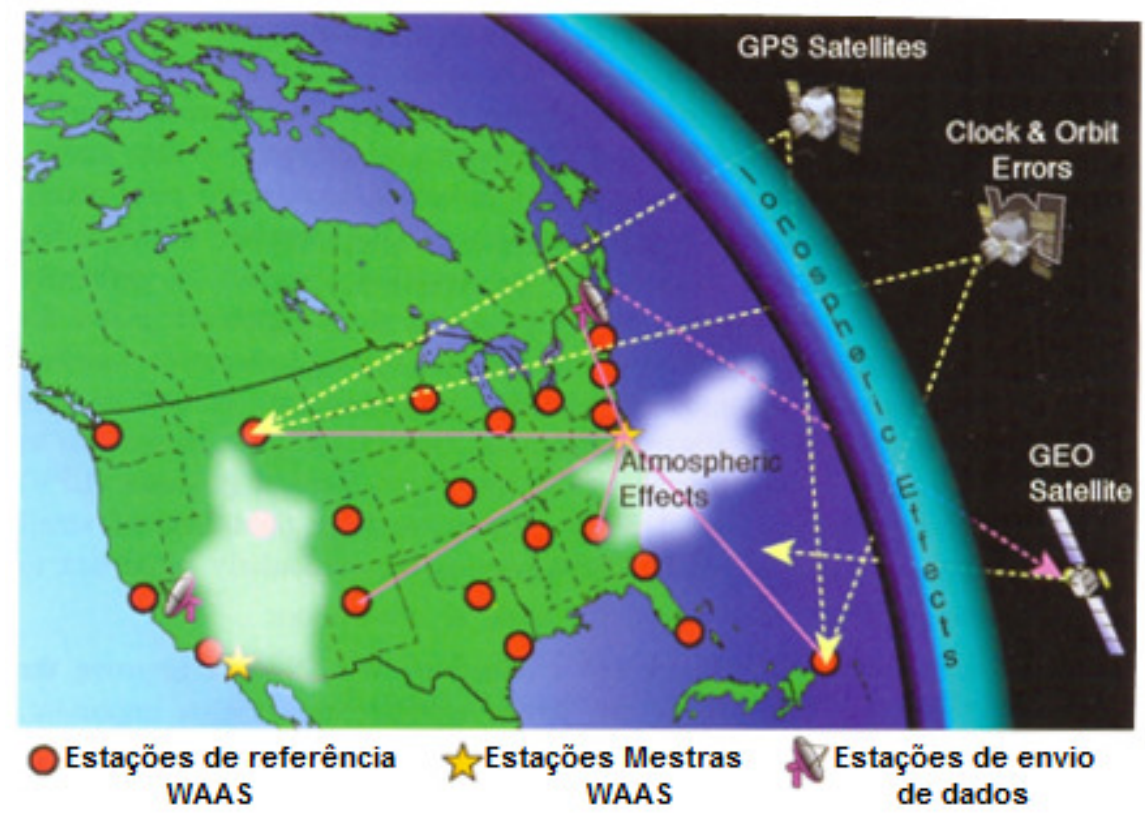

Figura 2: Estações de referência WAAS (WALTER et.al, 2006)

As estações de referência WAAS monitoram os dados dos satélites GPS (L1 e L1/L2) e os dados dos satélites geoestacionários WAAS. Estes dados são enviados para as WMS, onde as mensagens com as correções vetoriais e mensagens de integridade são geradas. Estas correções vetoriais são geradas para a deriva do relógio e efemérides de cada satélite e o erro devido à ionosfera. As mensagens de integridade são mensagens de informação sobre o nível de confiança associada às informações das correções.

Estas mensagens são enviadas para o segmento espacial, composto por três satélites, estes, por sua vez, retransmitem as mensagens geradas pelo sistema de controle aos usuários, em uma frequência igual à portadora L1 do GPS. Os satélites WAAS possuem código PRN (Pseudorandom noise) 122, 135 e 138, conforme 
Tabela 1.

Tabela 1: Satélites e posição WAAS (The Wide-Area Augmentation System)

\begin{tabular}{lccc}
\hline Nome & $\begin{array}{c}\text { Código } \\
\text { PRN }\end{array}$ & $\begin{array}{c}\text { Posição } \\
\text { (longitude) }\end{array}$ & $\begin{array}{c}\text { Constelação } \\
\text { SBAS }\end{array}$ \\
\hline AOR-W & 122 & $53^{\circ} \mathrm{W}$ & WAAS \\
LMRPS & 135 & $133^{\circ} \mathrm{W}$ & WAAS \\
ANIK & 138 & $107^{\circ} \mathrm{W}$ & WAAS \\
\hline
\end{tabular}

Além destas informações o sistema WAAS disponibiliza também informações sobre o cálculo da pseudodistância para os satélites geoestacionários, DOP (Dilution of Precision) e disponibilidade do sistema GPS e WAAS.

A composição do sistema WAAS está representada na Figura 3: satélites (GEO), estações de referência (Reference Stations), estação Mestra (Master Station), estações de envio de dados (Uplink), que são responsáveis pelo envio de informações de integridade e correções para os satélites WAAS.

\subsubsection{O sinal WAAS}

O sinal WAAS segue o padrão dos sistemas SBAS (WALTER et.al, 2006):

$$
\mathrm{s}(\mathrm{t})=\sqrt{2 \mathrm{CX}(\mathrm{t}) \mathrm{D}(\mathrm{t}) \cos (2 \pi f \mathrm{~L} 1(\mathrm{t})+\theta(\mathrm{t}))}
$$

onde :

$s(t)$ : Sinal WAAS

C: potência do sinal recebido

$\mathrm{D}(\mathrm{t})$ : sinal modulado com correção diferencial

fL1: frequência $L 1$

$\theta(\mathrm{t})$ : fase onda portadora

$\mathrm{X}(\mathrm{t})$ : código de propagação. 


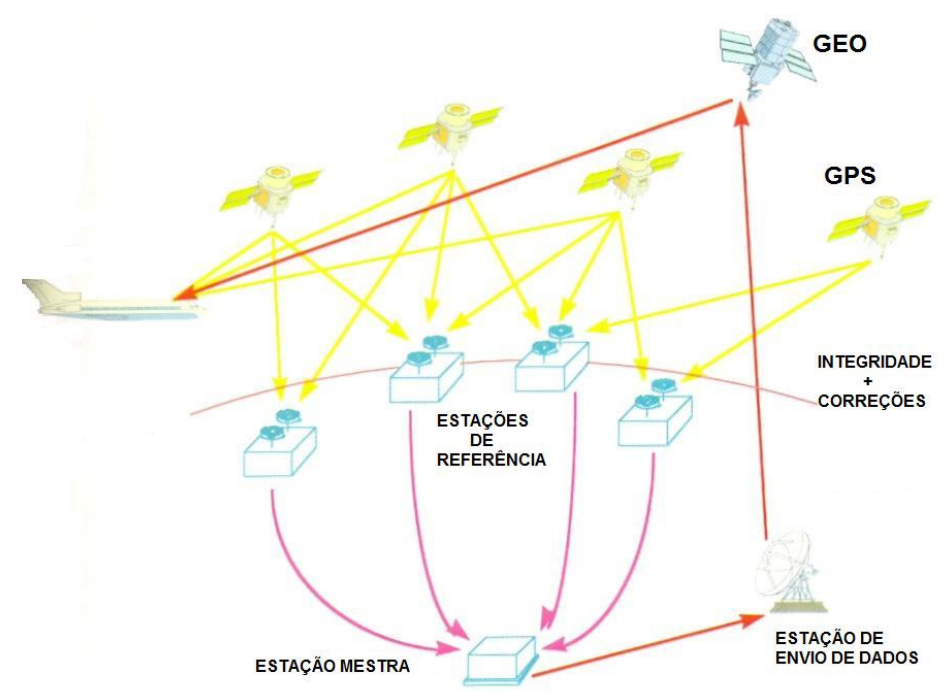

Figura 3: Sistema WAAS (WALTER et.al, 2006)

$\mathrm{Na}$ equação (1), C é a potência do sinal recebido. A fase da onda portadora $\theta(\mathrm{t})$ tem a frequência $f \mathrm{~L} 1=1575,42 \mathrm{MHz}$, que é igual a do GPS. O sinal é modulado com os dados que incluem as correções diferenciais $(D(t))$, nas quais estes dados são transmitidos a uma taxa de 250 bps (bits por segundo). Cada um destes sinais também é modulado com um código de propagação, $\mathrm{X}(\mathrm{t})$, igualmente ao código $\mathrm{C} / \mathrm{A}$ do GPS, este código é uma seqüência pseudo-aleatória de \pm 1 com uma taxa de 1.023MHz (WALTER et al., 2006).

Os códigos fazem com que o sinal WAAS tenha um espectro mais amplo do que a largura de banda necessária para enviar os dados por si só. Este diferencial de modulação de espectro permite medições precisas, que serão realizados na presença de ruído, sinais refletidos e interferências.

As medições de pseudodistância WAAS podem ser adicionadas ao conjunto de receptores GPS, porque o código $(\mathrm{X}(\mathrm{t}))$ e a portadora $(\theta(\mathrm{t}))$ do sinal WAAS estão sincronizados com o GPS. As medições adicionais proporcionam melhorias importantes para a continuidade e disponibilidade do tempo de navegação por satélite para a aviação, por exemplo durante a rota de vôo (WALTER et al.,2006).

\subsubsection{Sistema EGNOS}

O EGNOS é o sistema europeu de aumento baseado em satélites. Foi criado para incrementar o sinal dos sistemas GPS e GLONASS, baseado na transmissão 
de informações através dos satélites geoestacionários, com o objetivo de fornecer correção diferencial e informações sobre integridade, de tal forma que o novo sinal pode ser usado para aplicações críticas como pouso de aeronaves, que requer grande precisão (FLAMENT et al., 2006).

A arquitetura do EGNOS é bastante complexa e tem alta redundância. É composta por 47 elementos (estações de referência) implantados em 41 locais em 22 países. O EGNOS foi concebido para satisfazer as normas internacionais SBAS e realizar as seguintes tarefas: receber os dados dos satélites GPS, GLONASS e GEO, estimar os dados de integridade e as correções para a área de serviço, transmitir aos usuários, através dos satélites GEO, o sinal GPS-Like de integridade e correção.

O sistema EGNOS é formado por quatro segmentos: espacial, de usuários, terrestre e de suporte (FLAMENT et al., 2006). O segmento terrestre calcula as correções diferenciais e faz com que toda essa informação esteja disponível para os usuários através de uma transmissão pelo segmento espacial, que utiliza três satélites (GEO) que proporcionam redundância na transmissão da mensagem EGNOS aos usuários, que contém as correções diferenciais associadas com as informações de integridade. O segmento do usuário é feito de receptores que utilizam-se dos dados do sistema EGNOS, que permitem aos seus usuários calcular com acurácia a sua posição. O seguimento de suporte é composto de três partes (FLAMENT et al., 2006):

(a) PACF (Performance Assessment and System Checkout Facility) fornece suporte para as operações do EGNOS nas áreas de análise de desempenho, solução de problemas, procedimentos operacionais e de apoio à manutenção;

(b) ASQF (Application Specific Qualification Facility) - fornece ferramentas para qualificar, validar e certificar as diferentes aplicações do EGNOS, para a aviação civil e certificações aeronáuticas;

(c) DVP (Development Verification Platform) - utilizados para validar e verificar os requisitos EGNOS durante a fase de projeto. 


\subsubsection{Arquitetura Funcional do Sistema EGNOS}

O sistema EGNOS fornece os seguintes serviços (VENTURA-TRAVESET et al, 2006):

- Transmissão de correções através de três satélites, aumentando, assim, a disponibilidade de satélites para a navegação na região;

- Disponibilidade de informações de integridade, proporcionará uma navegação segura até os níveis exigidos para aviação civil;

- Disponibilidade de correções diferenciais, aumentando o serviço de navegação, até os níveis necessários para uma aproximação de pouso preciso.

Neste contexto (www.essp.be/about_egnos.html), o EGNOS fornece maior desempenho a partir de quatro parâmetros: acurácia, disponibilidade, continuidade e integridade:

$\checkmark$ Acurácia - Com relação à acurácia de um sistema de navegação, esta é normalmente apresentada como uma medida estatística do erro do sistema em conjunto com um nível de confiança (por exemplo, 95\%) refletindo a probabilidade do valor apresentado (WALTER; ENGE, 2006);

$\checkmark$ Integridade - A integridade diz respeito à confiança que pode ser colocada na correção da informação fornecida pelo sistema de navegação, que inclui a capacidade do sistema fornecer avisos oportunos ao usuário, quando o sistema ou os dados fornecidos por este sistema não devem ser utilizados para a navegação;

$\checkmark$ Continuidade - A continuidade do serviço de navegação é definida como a probabilidade de que os requisitos de acurácia e integridade será apoiada pelo sistema de navegação durante uma operação de vôo;

$\checkmark$ Disponibilidade - Disponibilidade do serviço de navegação é a probabilidade de que os serviços de posicionamento, integridade e de monitoração estão disponíveis para proporcionar acurácia, integridade e continuidade necessárias.

$\mathrm{Na}$ Tabela 2 são apresentados os satélites que formam a constelação 
EGNOS, e na Figura 4 são indicadas as posições dos satélites, respectivamente.

Tabela 2: Satélites e posição EGNOS (www.essp.be/about_egnos.html)

\begin{tabular}{lccc}
\hline Nome & $\begin{array}{c}\text { Código } \\
\text { PRN }\end{array}$ & $\begin{array}{c}\text { Posição } \\
\text { (longitude) }\end{array}$ & $\begin{array}{c}\text { Constelação } \\
\text { SBAS }\end{array}$ \\
\hline AOR-E & 120 & $15.5^{\circ} \mathrm{W}$ & EGNOS \\
IOR-W & 126 & $25^{\circ} \mathrm{E}$ & EGNOS \\
ARTEMIS & 124 & $21.5^{\circ} \mathrm{E}$ & EGNOS \\
\hline
\end{tabular}

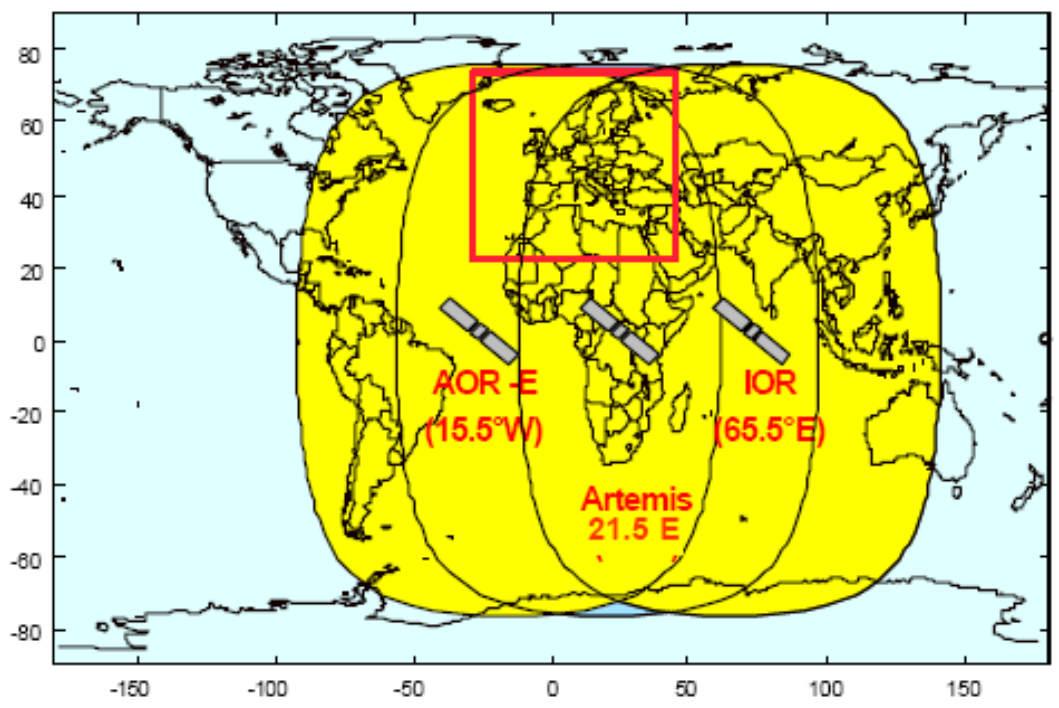

Figura 4: Posição dos satélites do Sistema EGNOS (FLAMENT et al., 2006).

\subsubsection{Interoperabilidade dos sistemas SBAS}

Como mencionado no item 2.1.4, existem vários sistemas de aumento baseados em satélites (SBAS), são eles: WAAS, EGNOS, MSAS e GAGAN, americano, europeu, japonês e indiano, respectivamente.

Embora todos os SBAS estejam atualmente definidos como sistema de aumento em suas regiões é, geralmente reconhecido que existe uma necessidade de estabelecer uma cooperação adequada entre os diferentes sistemas de aumento, de modo que sua aplicação se torne mais eficaz e faça parte de um sistema de navegação mundial (VENTURA-TRAVESET et al., 2006).

Para garantir o fornecimento contínuo do sinal deste sistema global é essencial que os sistemas de aumento existentes satisfaçam alguns requisitos 
comuns de interoperabilidade e desempenho.

Os prestadores de serviço para os sistemas de aumento EGNOS, WAAS e MSAS, se reúnem regularmente nos chamados grupos de trabalho de interoperabilidade (Interoperability Working Group), cuja principal finalidade é harmonizar e esclarecer questões relativas à aplicações técnicas, que poderão ter um impacto sobre a interoperabilidade entre estes sistemas SBAS (VENTURATRAVESET et al., 2006).

\subsection{Erros sistemáticos envolvidos nas observáveis}

O GNSS é um dos sistemas mais confiáveis para a realização do posicionamento espacial, no entanto suas observações contêm os invitáveis erros

observacionais (erros sistemáticos, aleatórios e grosseiros), cujo tratamento é importante para obtenção de resultados precisos, desta forma, as fontes de erros envolvidas devem ser bem conhecidas (MONICO, 2008). Os erros sistemáticos podem ser modelados ou reduzidos (até mesmo eliminados) através de técnicas apropriadas de observação ou de processamento. Quanto aos erros aleatórios, estes não apresentam qualquer relação funcional com as medidas e são, em geral, as discrepâncias remanescentes nas observações, depois que os erros sistemáticos e grosseiros forem eliminados ou minimizados. Eles são considerados uma propriedade inerente da observação.

Dentre os erros envolvidos, pode-se citar os erros devido a deriva do relógio do satélite, orbitais, efeitos atmosféricos, relatividade, erro da deriva do relógio do receptor e efeito do multicaminho. Tais erros deterioram a qualidade das observáveis GNSS (código e fase da onda portadora) e precisam ser tratados adequadamente, para que seja possível realizar posicionamento de ordem centimétrica. A maioria dos erros envolvidos pode ser minimizada no posicionamento relativo através de combinações lineares na modelagem funcional. Entretanto, o efeito do multicaminho, o qual ocorre devido às reflexões do sinal em superfícies (por exemplo, edificações) antes de chegar ao receptor não pode ser eliminado. Pois o multicaminho é um efeito altamente dependente da localização de cada receptor (MONICO, 2008).

As possíveis fontes e erros das observáveis GNSS estão relacionados na 
Tabela 3.

Tabela 3: Erros envolvidos nas observações GPS (MONICO, 2008)

\begin{tabular}{ll}
\hline Fonte & Erros \\
\hline \multirow{3}{*}{ Satélite } & Erro da órbita \\
& Erro do relógio \\
& Relatividade \\
& Atraso entre as duas portadoras no hardware satélite \\
\hline & Refração troposférica \\
& Refração ionosférica \\
Propagação do Sinal & Perdas de ciclos \\
& Multicaminho \\
& Rotação da Terra \\
\hline \multirow{3}{*}{ Receptor/Antena } & Erro do relógio \\
& Erro entre os canais \\
& Centro de fase da antena \\
\hline & Erro nas coordenadas \\
& Multicaminho \\
& Marés terrestres \\
Estação & Movimento do pólo \\
& Carga dos oceanos \\
& Pressão da atmosfera
\end{tabular}

\subsubsection{Geometria dos satélites}

A distribuição espacial dos satélites, no instante das observações, tem muita influência na qualidade do posicionamento e na propagação dos erros. Dependendo do momento da observação, a geometria dos satélites pode não ser adequada para a realização do posicionamento. Quanto mais distribuídos espacialmente os satélites estiverem, mais adequada é a geometria dos satélites e melhor a precisão das observações (SOUZA, 2006). O DOP (Dilution of Precision) auxilia na indicação da precisão dos resultados que serão obtidos. As combinações do DOP são apresentadas na Tabela 4.

A melhor geometria ocorre quando o volume do tetraedro formado entre a posição do observador e quatro satélites for máxima, assim o PDOP será mínimo, o mesmo ocorre para o contrário, quando o PDOP for máximo, o volume do tetraedro será mínimo. Assim, se um receptor GPS estiver recebendo sinais de quatro 
satélites posicionados na mesma região do céu, sua geometria é inadequada para o posicionamento (Figura 5) (MONICO, 2008).

Tabela 4: Variação do DOP (adaptado de SEEBER, 2003)

\begin{tabular}{lll}
\hline HDOP & Horizontal DOP & posicionamento horizontal; \\
VDOP & Vertical DOP & posicionamento vertical; \\
PDOP & Position DOP & posicionamento tridimensional; \\
TDOP & Time DOP & determinação do tempo; \\
GDOP & Geometrical DOP & posicionamento tridimensional e tempo; \\
RDOP Relative DOP & posicionamento relativo.
\end{tabular}

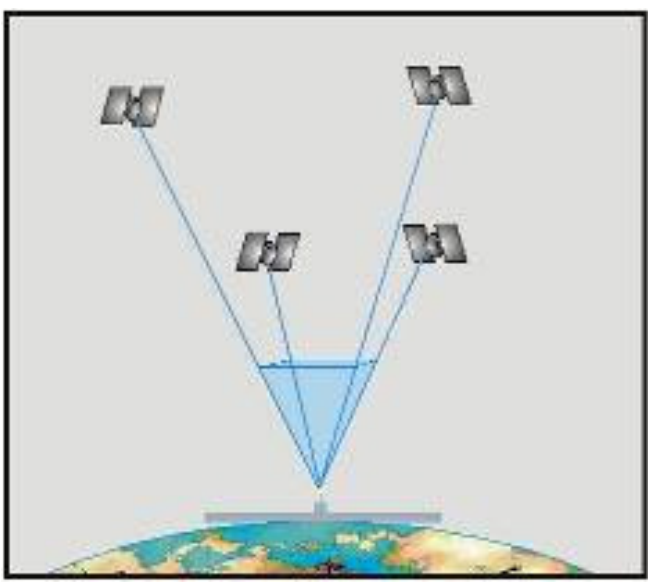

Geometria ruim

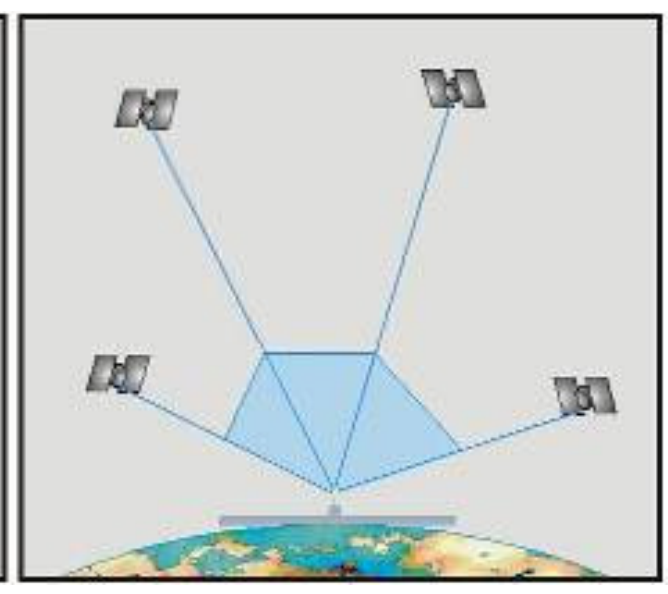

Geometria boa

Figura 5: Distribuição dos satélites (SOUZA, 2006)

A combinação da posição tridimensional e do tempo é o que chamamos de GDOP, que possui a seguinte expressão (MONICO, 2008):

$$
\mathrm{GDOP}=\sqrt{(\mathrm{PDOP})^{2}+(\mathrm{TDOP})^{2}}
$$

onde:

$$
\mathrm{PDOP}=\frac{1}{\mathrm{~V}} \text { e } \mathrm{V}=\text { volume do tetraedro }
$$

O que significa dizer que o PDOP é o inverso do volume do tetraedro formado entre a posição de quatro satélites e o receptor GPS (MONICO, 2008).

A MVC (Matriz Variância Covariância) dos parâmetros a estimar será dada aproximadamente por (SEEBER, 1993 e MONICO, 2008):

$$
C_{X X}=\left(A^{T} A\right)^{-1}
$$


que contém os seguintes elementos:

$$
C_{x X}=\left(\begin{array}{cccc}
q_{X X} & q_{X Y} & q_{X Z} & q_{X T} \\
q_{X Y} & q_{Y Y} & q_{Y Z} & q_{Y T} \\
q_{X Z} & q_{Y Z} & q_{Z Z} & q_{Z T} \\
q_{X T} & q_{Y T} & q_{Z T} & q_{T T}
\end{array}\right)
$$

A variância da estimativa de uma posição é dada por:

$$
\sigma_{P}^{2}=\sigma_{r}^{2}\left(\sigma_{x x}+\sigma_{y y}+\sigma_{z z}\right)
$$

que corresponde

$$
\sigma_{P}=\sigma_{r} P D O P
$$

de forma geral tem-se

$$
G D O P=\sqrt{\sum \operatorname{diag}\left(A^{T} A\right)^{-1}}
$$

Nas aplicações geodésicas, os valores dos DOP's são de menor importância, pois, atualmente, os receptores são capazes de rastrear todos os satélites visíveis, no entanto são importantes para as operações de planejamento dos levantamentos quando há possibilidade de ocorrer obstrução de sinal (MONICO, 2008).

Segundo SEEBER (1993), para o caso de posicionamento relativo o conceito de maior importância é o do RDOP:

$$
R D O P=\sqrt{\operatorname{tr}\left(A^{T} \sum^{-1} A\right)^{-1} / \sigma_{D D}^{2}}
$$

onde:

$\left(A^{T} \Sigma^{-1} A\right)^{-1}-$ matriz covariância;

$\sigma_{\mathrm{DD}}$ - incerteza da medição da dupla diferença;

$\Sigma$ - matriz de covariância da dupla diferença; 
A - matriz das derivadas parciais das duplas diferenças.

Os valores de RDOP podem ser calculados a priori, antes dos levantamentos, para fins de análise, mas a importância desta análise está diminuída uma vez que a constelação GPS está completa (SEEBER, 1993).

\subsubsection{Efeitos Atmosféricos}

Este efeito está ligado diretamente com a propagação do sinal GNSS pela atmosfera terrestre, na qual o mesmo atravessa camadas diferentes, troposfera e ionosfera, com características diferentes. Assim sendo, sofrem diferentes tipos de influência, que provocam variações na direção da propagação, velocidade de propagação, polarização e potência do sinal (SEEBER, 1993).

\subsubsection{Troposfera}

A Troposfera localiza-se entre a superfície terrestre e a ionosfera e possui uma espessura de $\cong 50 \mathrm{~km}$. Os atrasos da propagação do sinal na troposfera são críticos para o posicionamento de precisão e para a determinação de uma linha de base longa. A influência troposférica na medida da pseudodistância é decomposta em: componente seca (pressão, temperatura) e úmida (pressão do vapor d'água) (SEEBER, 1993).

\subsubsection{Ionosfera}

A ionosfera apresenta uma camada que se estende entre 50 a $1.000 \mathrm{~km}$ acima da superfície terrestre. Nessa camada, há a ionização dos gases devido à atividade solar, resultando em um meio ionizado, o qual provoca atrasos na propagação do sinal, esse fenômeno aparentemente aumenta o caminho percorrido 
pelo sinal transmitido (SOUZA, 2006). O erro associado à ionosfera é inversamente proporcional ao quadrado da frequência e diretamente proporcional ao conteúdo total de elétrons (TEC - Total Electron Content) presentes ao longo do caminho da trajetória percorrida pelo sinal através da ionosfera. O TEC varia no tempo e no espaço e é influenciado por diversas variáveis, tais como: ciclo solar, época do ano, hora do dia, localização geográfica, atividade geomagnética, entre outros (SKONE, 2000 apud CAMARGO e MATSUOKA, 2004).

\subsubsection{Multicaminho}

Os sinais transmitidos pelos satélites normalmente atingem a antena do receptor diretamente. No entanto, os objetos nas proximidades do receptor podem refletir alguns destes sinais antes de atingir a antena do receptor diretamente, fazendo com que sinais não desejados sejam captados pela antena (LEICK, 2003).

Em geral, não há um modelo para tratar o efeito do multicaminho, pois as situações geométricas de cada local variam de forma arbitrária, assim, em várias situações as observáveis da fase da onda portadora e pseudodistância são degradadas, o que afeta a qualidade do posicionamento (MONICO, 2008).

O modo de se evitar ou minimizar este erro é trabalhar em local aberto (sem obstruções) e utilizar antenas com tecnologia que minimizam este efeito, como exemplo as antenas do tipo choke ring ou pinwheel (MONICO, 2008).

O impacto do erro do multicaminho sobre a medida de fase da onda portadora é descrito a seguir (LEICK, 2004):

$\checkmark$ O erro máximo corresponde a um quarto do comprimento de onda, o que para a portadora L1 é de 4,8 cm;

$\checkmark$ A frequência do multicaminho é proporcional à distância perpendicular entre a superfície refletora e a antena do receptor, e inversamente proporcional ao comprimento de onda, além de ser função do ângulo de elevação do satélite;

$\checkmark$ A fase da onda portadora livre dos efeitos da ionosfera é de difícil modelagem quando sujeita ao multicaminhamento. 


\subsection{Posicionamento relativo}

O uso do GNSS aumentou consideravelmente, ao longo da última década. Várias são suas aplicações nas áreas de geodésia, topografia, meio ambiente, agricultura de precisão e inclusive nas aplicações menos precisas, como navegação veicular e levantamentos expeditos.

O objetivo do posicionamento relativo é a determinação das coordenadas de um ponto desconhecido em relação a um ponto de coordenadas conhecidas, ou seja, a determinação do vetor entre estes dois pontos (HOFMANN - LICHTENEGGER, 1997).

O conceito fundamental do posicionamento relativo é que dois ou mais receptores envolvidos rastreiem, simultaneamente, pelo menos dois satélites comuns (MONICO, 2008). No caso do usuário dispor de apenas um receptor, ele também poderá realizar posicionamento relativo, para isso deverá acessar os dados das redes ativas do Brasil como: RBMC (Rede Brasileira de Monitoramento Contínuo) e Ribac (Rede Incra de Bases Comunitárias do GPS) através do sítio do IBGE (Instituto Brasileiro de Geografia e Estatística) na internet (http://www.ibge.gov.br).

Neste tipo de posicionamento, utilizam-se as duplas diferenças das observáveis fundamentais (pseudodistância e fase da onda portadora). Dentro do método relativo tem-se: Posicionamento Estático, Estático rápido, Semi-Cinemático e Cinemático.

\subsubsection{Posicionamento relativo estático}

Neste tipo de posicionamento, dois ou mais receptores, rastreiam, simultaneamente, os satélites disponíveis, por um período de tempo que varia de 20 minutos a algumas horas (MONICO, 2008).

Geralmente, é utilizado como observável a fase da onda portadora, por ser mais precisa que a pseudodistância, mas esta não pode ser descartada por possuir informações do erro do relógio do satélite e permitir o cálculo do instante de transmissão do sinal pelo satélite. 


\subsection{Combinações lineares das observações GPS}

As observáveis podem ser combinadas entre diferentes estações, épocas e satélites (MONICO, 2008).

Existem dois grupos de correlações: as físicas e as matemáticas. As fases de um receptor/satélite em dois pontos estão correlacionadas fisicamente, uma vez que remetem para o mesmo satélite (HOFMANN-LICHTENEGGER, 2008). O principal interesse é direcionado para as correlações matemáticas introduzidas pelas diferenças.

\subsubsection{Dupla diferença}

A dupla diferença envolve dois receptores e dois satélites. A dupla diferença é a diferença entre duas simples diferenças. Ela é a observável mais utilizada no processamento GNSS utilizando a fase da onda portadora, assim o erro do relógio dos receptores e os termos que representam as combinações da fase inicial dos receptores são eliminados. Portanto, proporciona melhor relação entre o ruído resultante e a eliminação de erros sistemáticos envolvidos nas observáveis originais (MONICO, 2008).

As equações de dupla diferença para a pseudodistância são apresentadas nas equações 11 e 12.

$$
\Delta P D_{1,2}^{1,2}+v_{P R_{D D}}=\Delta \rho_{1,2}^{1,2}
$$

onde

$$
\Delta \rho_{1,2}^{1,2}=\Delta \rho_{1,2}^{1}-\Delta \rho_{1,2}^{2}
$$

Para o caso das equações envolvendo os sistemas GPS e GALILEO, nas quais as frequências são idênticas tem-se a equação 15. Em relação ao sistema GLONASS, no qual cada satélite possui uma frequência específica, tem-se a 
equação 13, na qual foi feita uma distinção entre as frequências de cada um dos satélites envolvidos $\left(f^{S 1}\right.$ e $\left.f^{S 2}\right)$ (MONICO, 2008).

Serão apresentadas as duas equações, envolvendo GLONASS (equação 13) e no caso de envolver GPS e GALILEO (equação 15).

$\Delta \phi_{1,2}^{1,2}=\frac{f^{S 1}}{c}\left(\Delta \rho_{1,2}^{1}\right)-\frac{f^{S 2}}{c}\left(\Delta \rho_{1,2}^{2}\right)+f^{S 1}\left(d t_{1}-d t_{2}\right)-f^{S 2}\left(d t_{1}-d t_{2}\right)+N_{1,2}^{1,2}+v_{\Phi_{D D}}$

com

$$
\begin{aligned}
& N_{1,2}^{1,2}=N_{1,2}^{1}-N_{1,2}^{2}=N_{1}^{1}-N_{2}^{1}-N_{1}^{2}+N_{2}^{2} \\
& \Delta \phi_{1,2}^{1,2}=\frac{f}{c}\left(\Delta \rho_{1,2}^{1,2}\right)+N_{1,2}^{1,2}+v_{\Phi_{D D}}
\end{aligned}
$$

onde:

$\Delta \rho_{1,2}^{1,2}=$ diferença entre a diferença das distâncias geométricas do receptor $\mathrm{R} 1$ aos satélites 1 e 2, e a diferença das distâncias geométricas do receptor R2 aos satélites; $\mathrm{N}_{1,2}^{1,2}=$ diferença entre a diferença de ambigüidade do receptor $\mathrm{R} 1$ aos satélites $1 \mathrm{e}$ 2, e a diferença de ambigüidade do receptor $\mathrm{R} 2$ aos satélites 1 e 2;

$\mathrm{N}_{1}^{2} \quad$ = ambigüidade do receptor $\mathrm{R} 1$ ao satélite 2;

$\mathrm{N}_{2}^{2} \quad$ = ambigüidade do receptor R2 ao satélite 2 . 


\section{DESCRIÇÃO DOS DADOS}

Os dados deste trabalho foram obtidos em rastreios realizados em distintas regiões do Brasil, variando em latitude e longitude, com o objetivo de analisar a disponibilidade das observáveis $L 1$, dos satélites SBAS. As cidades de realização do trabalho foram: Manaus - AM , Mossoró - RN; Nova Venécia - ES; Rio de Janeiro RJ e São Paulo - SP. Na figura 6 estão ilustradas as cidades de rastreio. No total, 90 pontos foram rastreados, gerando-se aproximadamente 4500 linhas de base entre GPS e GPS + SBAS, mas são apresentadas apenas os melhores resultados obtidos no processamento (1250 linhas de base). Nesta pesquisa foram utilizados os receptores GPS Promark3 e Promark500 da fabricante Magellan, o primeiro L1 e o segundo L1/L2. O programa de processamento utilizado foi o GNSS Solution v. 3.10.07 da mesma fabricante dos receptores.

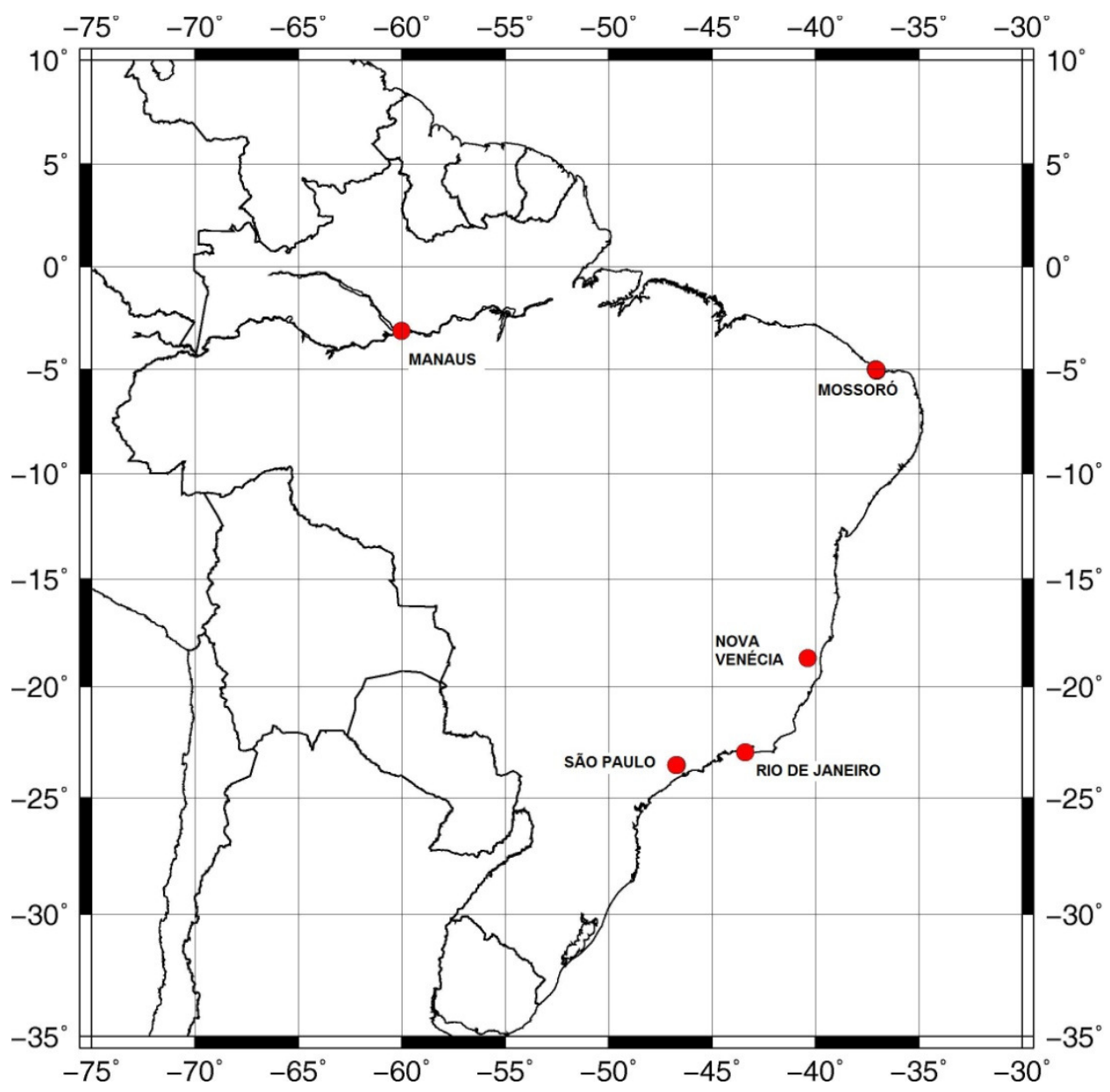

Figura 6: Locais de rastreios (o autor) 
A Tabela 5 mostra a data, o local, o tempo de rastreio, o horário e quantidade de satélites visualizados, e os satélites SBAS rastreados.

Tabela 5: Resumo do Rastreio de Campo (o autor)

\begin{tabular}{|c|c|c|c|c|c|}
\hline $\begin{array}{l}\text { Data do } \\
\text { Rastreio }\end{array}$ & $\begin{array}{l}\text { Local do } \\
\text { Rastreio }\end{array}$ & $\begin{array}{c}\text { Tempo de } \\
\text { Rastreio }\end{array}$ & $\begin{array}{l}\text { Horário de } \\
\text { início do } \\
\text { Rastreio }\end{array}$ & $\begin{array}{c}\text { SBAS (PRN) } \\
\text { Rastreado }\end{array}$ & $\begin{array}{c}\text { Número de } \\
\text { Satélites }\end{array}$ \\
\hline 04/04/2009 & São Paulo (SP) & 30 minutos & 08 horas & S38 (Anik) & $\begin{array}{l}11 \text { GPS e } \\
07 \text { Glonass }\end{array}$ \\
\hline 06/06/2009 & São Paulo (SP) & 30 minutos & 08 horas & S38 (Anik) & 10 GPS \\
\hline $22 / 04 / 2009$ & Nova Venécia (ES) & 02 horas & 15horas & $\begin{array}{l}\text { S20 (AOR/E) } \\
\text { S24 (Artemis) }\end{array}$ & 12 GPS \\
\hline 23/04/2009 & Nova Venécia (ES) & 03 horas & 16 horas & $\begin{array}{l}\text { S20 (AOR/E) } \\
\text { S24 (Artemis) }\end{array}$ & 10 GPS \\
\hline 02/07/2009 & Rio de Janeiro (RJ) & 02 horas & $15 \mathrm{~h} 40 \mathrm{~min}$ & S38 (Anik) & 12 GPS \\
\hline 03/07/2009 & Rio de Janeiro (RJ) & 08 horas & 09h00min & S38 (Anik) & 12 GPS \\
\hline 04/07/2009 & Rio de Janeiro (RJ) & 03 horas & 13h30min & S38 (Anik) & 12 GPS \\
\hline 07/10/2009 & Mossoró (RN) & 03 horas & 09 horas & S24 (Artemis) & 10 GPS \\
\hline $21 / 10 / 2009$ & Nova Venécia (ES) & 55 minutos & 16 horas & S20 (AOR/E) & 10 GPS \\
\hline 23/10/2009 & Nova Venécia (ES) & 06 horas & $14 \mathrm{~h} 34 \mathrm{~min}$ & S20 (AOR/E) & 15 GPS \\
\hline 26/10/2009 & Nova Venécia (ES) & 03 horas & 17 horas & $\begin{array}{l}\text { S20 (AOR/E) } \\
\text { S24 (Artemis) }\end{array}$ & 14 GPS \\
\hline $04 / 11 / 2009$ & Nova Venécia (ES & 01 hora & $14 \mathrm{~h} 58 \mathrm{~min}$ & S20 (AOR/E) & 12 GPS \\
\hline $24 / 03 / 2010$ & Manaus (AM) & 15 minutos & $12 \mathrm{~h} 30 \mathrm{~min}$ & $\begin{array}{c}\text { S20 (AOR/E) } \\
\text { S38 (Anik) }\end{array}$ & 18 GPS \\
\hline $01 / 05 / 2010$ & Nova Venécia (ES) & 02 horas & 16 horas & S20 (AOR/E) & 12 GPS \\
\hline 05/05/2010 & Nova Venécia (ES) & 30 minutos & 09h30min & $\begin{array}{c}\text { S20 (AOR/E) } \\
\text { S38 (Anik) }\end{array}$ & 11 GPS \\
\hline 06/05/2010 & Nova Venécia (ES) & 30 minutos & 09h30min & $\begin{array}{c}\text { S20 (AOR/E) } \\
\text { S38 (Anik) }\end{array}$ & 10 GPS \\
\hline 07/05/2010 & Nova Venécia (ES) & 30 minutos & 09h30min & $\begin{array}{c}\text { S20 (AOR/E) } \\
\text { S38 (Anik) }\end{array}$ & 10 GPS \\
\hline $14 / 12 / 2010$ & São Paulo (SP) & 60 minutos & 12 horas & $\begin{array}{c}\text { S20 (AOR/E) } \\
\text { S38 (Anik) }\end{array}$ & 11 GPS \\
\hline $15 / 12 / 2010$ & São Paulo (SP) & 40 horas & 15 horas & $\begin{array}{l}\text { S38 (Anik) } \\
\text { S33 (AMR) }\end{array}$ & 09 GPS \\
\hline
\end{tabular}




\subsection{Planejamento de campo}

O planejamento precede os levantamentos de campo propriamente dito, utilizando-se dos dados de almanaque enviados pelos satélites GPS para se obter uma previsão. Cada conjunto de dados de almanaque fornece os parâmetros orbitais para toda a constelação GPS. Nesta fase, é possível definir uma série de condições necessárias para o trabalho de campo, como exemplo: tempo de rastreio, melhor horário para a coleta, obstruções, etc.

Todos os planejamentos foram realizados nos programas Trimble Office v. 2.8 (Trimble) e Occupation Planning (JAVAD). O Ocuppation Planning foi utilizado para o cálculo do RDOP, enquanto o Trimble Office v. 2.8 foi utilizado para o planejamento. Assim, foram verificadas as informações pertinentes ao rastreio, tais como: horário ideal, número de satélites disponível, diluição da precisão (PDOP e RDOP) e elevação dos satélites, conforme exemplo das Figuras 7 e 8.

Com exceção dos rastreio realizados nas cidades do Rio de Janeiro, Mossoró e Manaus, para todos os outros foram realizados os planejamentos antes do início dos rastreios, nas cidades onde não se realizou previamente o planejamento, as condições em que os dados foram coletados foram reconstituídos utilizando-se o almanaque obtido no próprio rastreio.

Lembrando que os receptores utilizados em todos os rastreios, apenas dispõem de dois canais para rastreio da constelação SBAS, assim não foi possível rastrear mais que dois destes satélites simultaneamente.

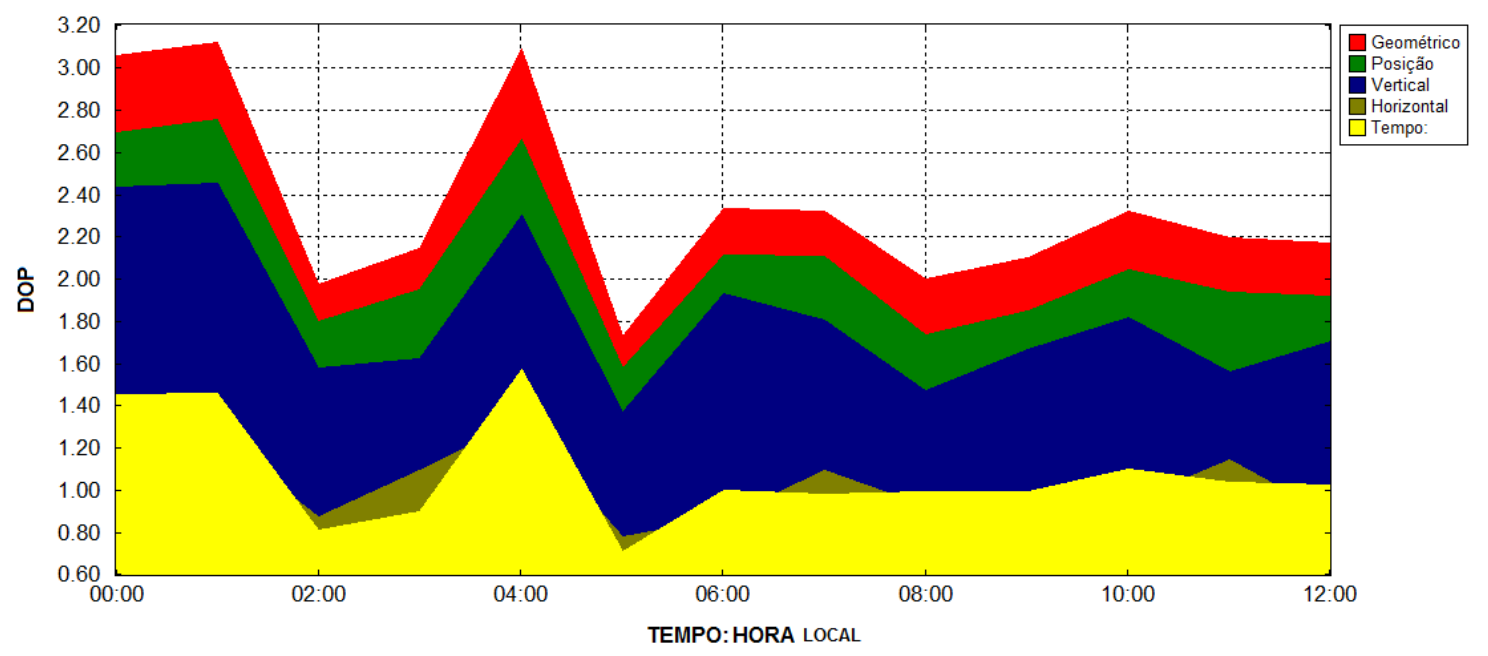

Figura 7: DOP (Diluição da Precisão) - Trimble Geo Office 


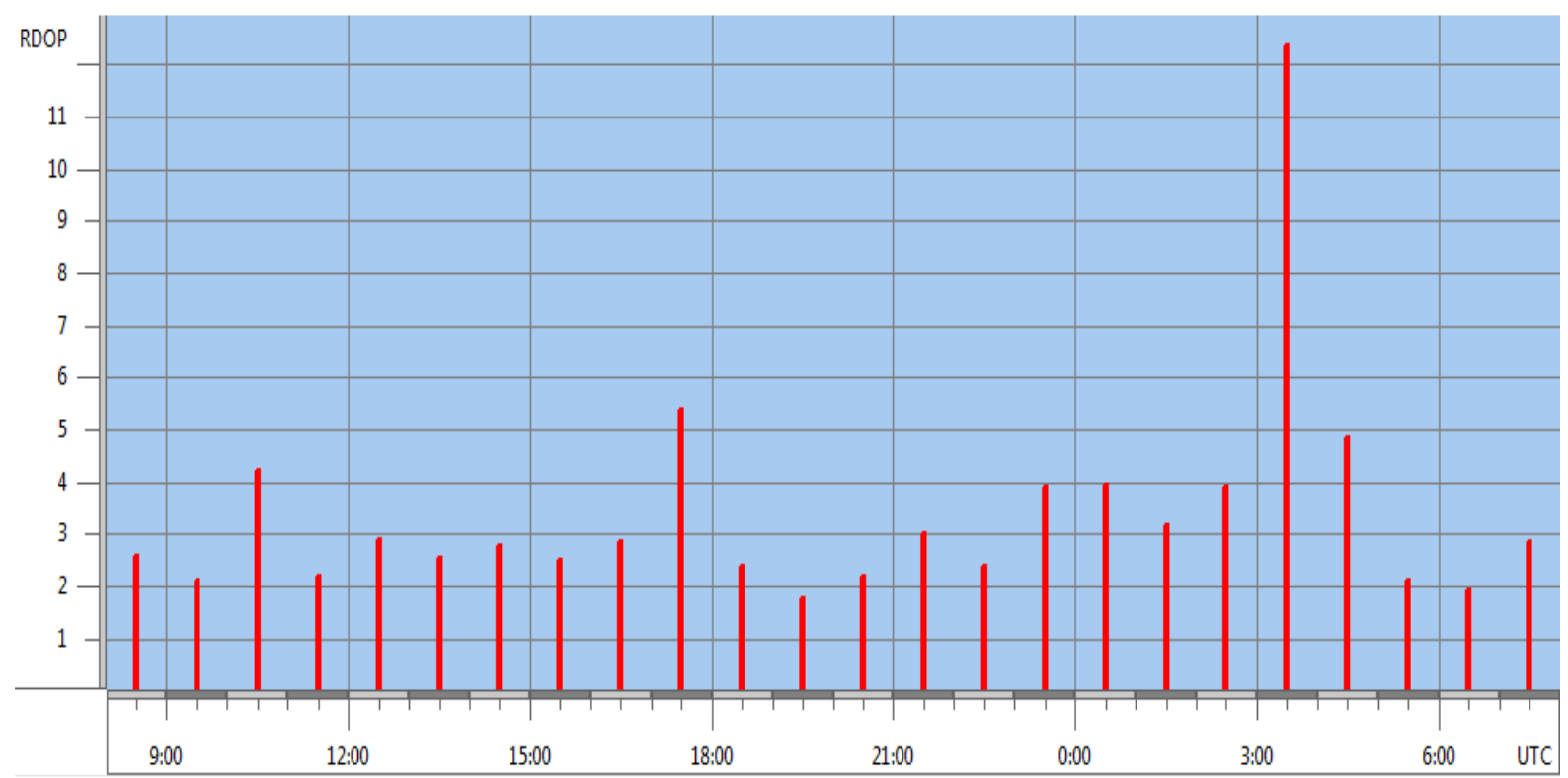

Figura 8: RDOP (Hora Local) - Occupation Planning

\subsubsection{Trabalho de campo - primeiro rastreio com GPS L1/L2}

Previamente a ida ao campo, para a realização do rastreio, foi elaborado o planejamento de campo. As Figuras 9 e 10 mostram respectivamente a elevação dos satélites SBAS na cidade de São Paulo e a disposição dos satélites no espaço, a Figura 10 será utilizada na seleção dos satélites para o processamento, o valor máximo do PDOP e RDOP para o horário do rastreio foi 4. A legenda da Figura 9 é representada pelos satélites PRN 120, 124 e 138, respectivamente. A taxa de gravação foi padronizada em todos os rastreios e foi utilizado um segundo.

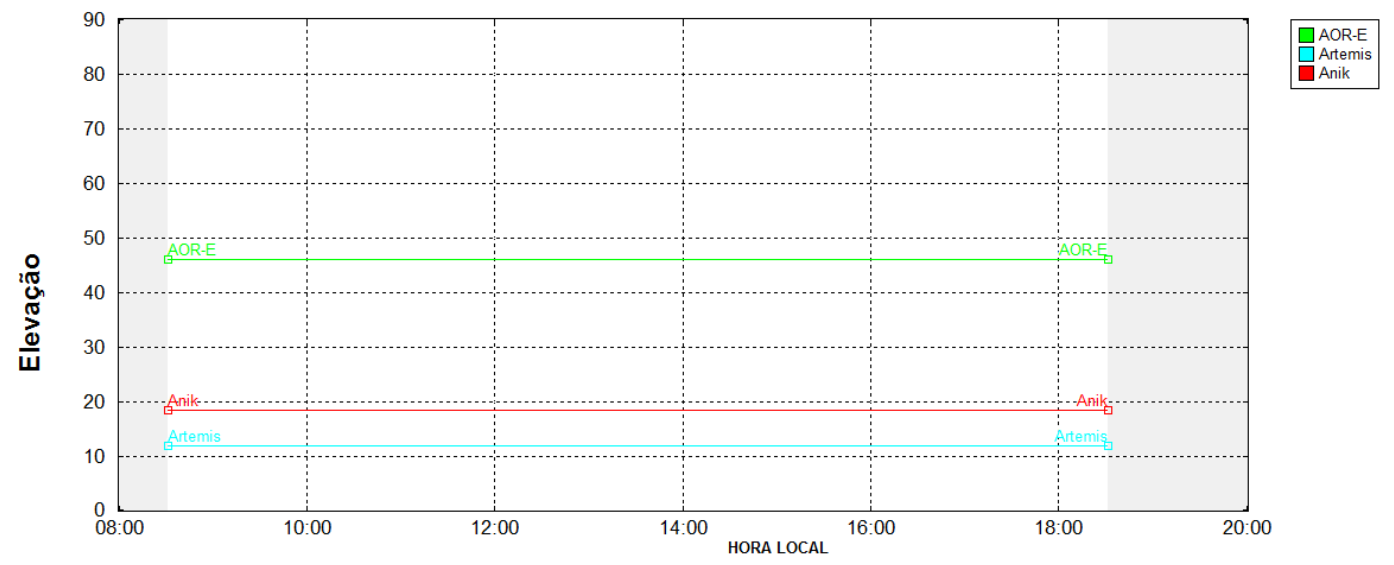

Figura 9: Elevação dos Satélites do SBAS - SP 


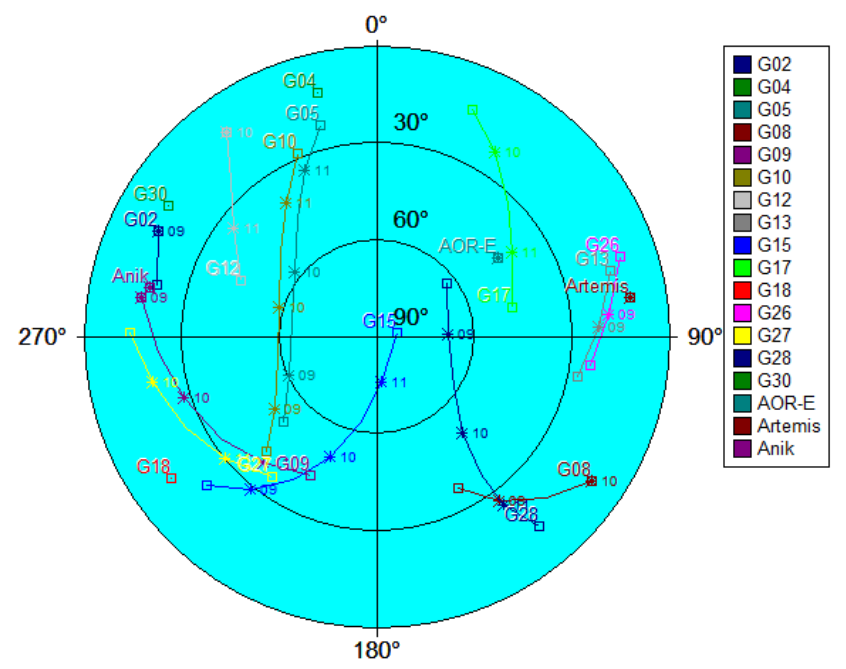

Figura 10: Disposição dos satélites GPS e SBAS - SP

Para a realização do rastreio foi utilizado como ponto base o pilar geodésico denominado de P1 da raia olímpica da USP (Universidade de São Paulo), cujas coordenadas são conhecidas e bem determinadas.

O planejamento foi elaborado para que um receptor GNSS estivesse estacionado no pilar base P1 e o receptor móvel percorresse os demais pilares geodésicos espalhados pela raia olímpica da USP (P2, P3, etc.), com um tempo mínimo de rastreio em cada ponto de 30 minutos. Este tempo foi estipulado para que as constelações GPS e GLONASS se alterassem de modo a se ter dados da portadora L1 suficientes para se inferir sobre a contribuição ou não dos dados dos satélites SBAS no posicionamento.

Neste primeiro rastreio, foram utilizados os marcos P2, P3C e P4, por estarem em distâncias diferentes e por se localizar em lugares abertos e sem muitas obstruções. A Figura 11 ilustra o local do rastreio, onde os pontos verdes são os pilares. 


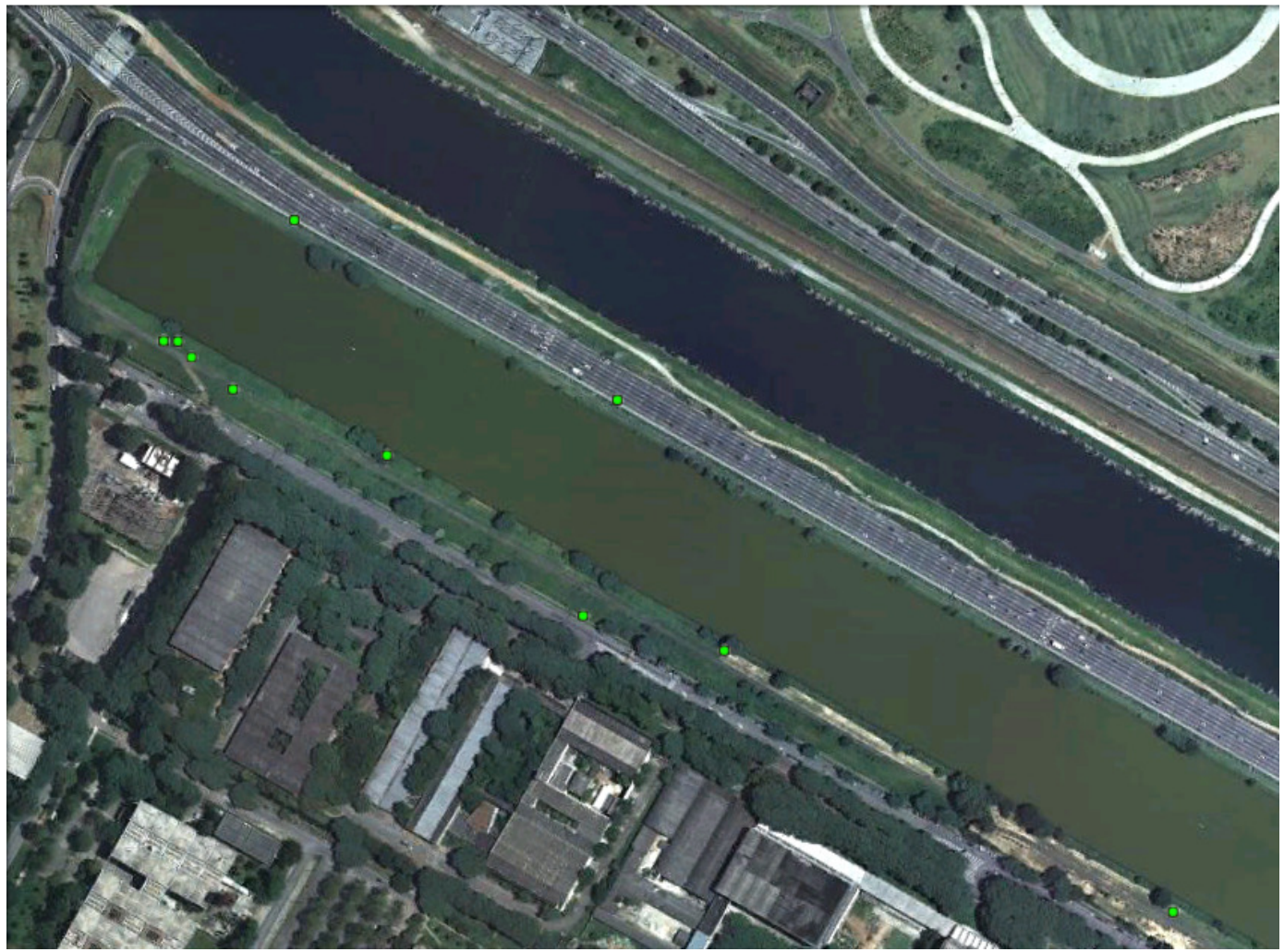

Figura 11: Local do rastreio em São Paulo - Raia da USP (Google Earth, 2010)

Depois de instalado o receptor no pilar P1, o receptor móvel foi instalado nos outros pilares selecionados, onde a primeira linha de base (P1 para P2) foi de aproximadamente 50 metros, a segunda linha de base (P1 para P3C) foi de aproximadamente 165 metros e a última (P1 para P4) foi de aproximadamente 450 metros e o tempo de rastreio foi de aproximadamente 30 a 35 minutos em todos os pontos, conforme o planejamento inicial.

Os satélites SBAS rastreados foram os de PRN 120 (S20) e 138 (S38), contudo, o satélite S20 não foi rastreado simultaneamente nos receptores GNSS base e móvel.

\subsubsection{Trabalho de Campo - Segundo rastreio GPS L1}

As informações obtidas no planejamento foram levadas em consideração, conforme as Figuras 12 e 13, onde pode-se verificar a elevação dos satélites SBAS naquela região, e a distribuição predita dos satélites no espaço, quanto ao PDOP, este não ultrapassa o valor de 3,5 durante todo o rastreio, o mesmo acontece com o 
RDOP onde seu valor chega ao máximo de 4,0.

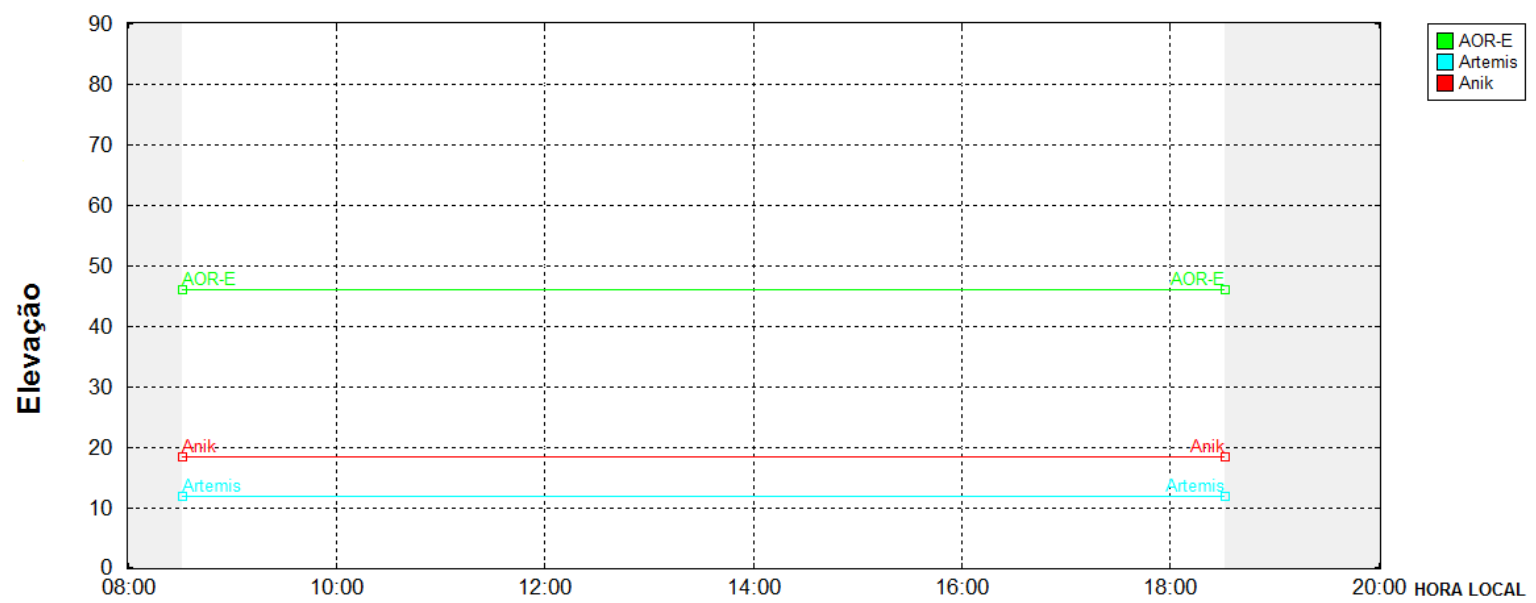

Figura 12: Elevação dos satélites SBAS - ES

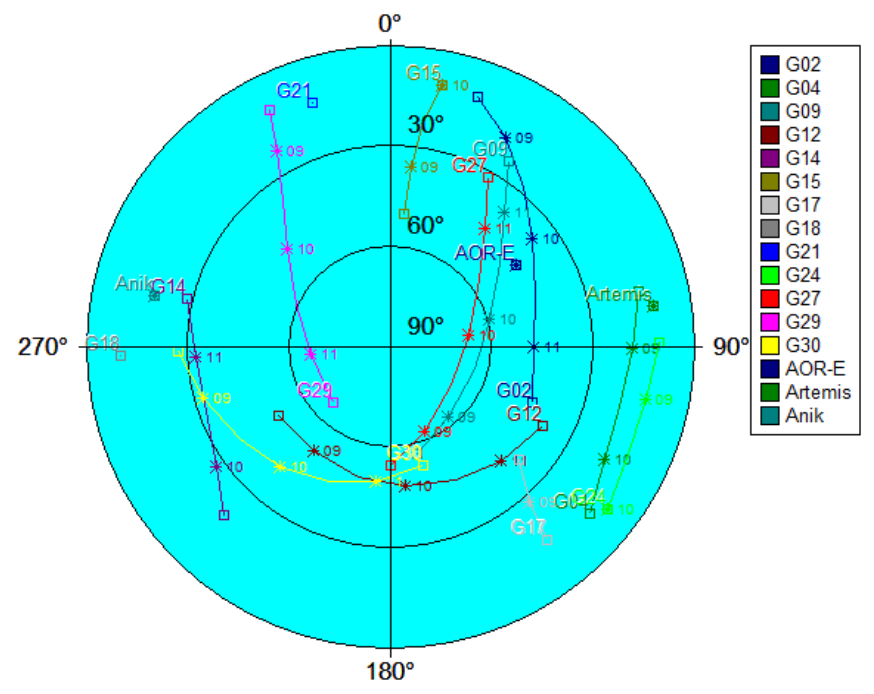

Figura 13: Disposição dos satélites GPS e SBAS - ES

Realizaram-se dois rastreios nos dias 22 e 23/04/2009 em Nova Venécia ES. O rastreio foi realizado dentro do IFES (Instituto Federal do Espírito Santo - Campus Nova Venécia). O tempo de rastreio foi de 02 horas, para verificar quais dos satélites SBAS (PRN) seriam rastreados, e se haveria alternância entre os satélites SBAS.

Verificou-se que os satélites SBAS rastreados foram os de PRN 120 (S20) e 124 (S24), mas os dados do satélite S24 não têm simultaneidade entre base e móvel, sendo rastreado apenas em um dos receptores.

Para a realização de mais experimentos envolvendo os satélites SBAS, oito novos rastreios foram realizados, conforme Tabela 5, mas em um local com menos obstruções (árvores, prédios, etc.) aumentando assim a possibilidade de rastreio dos 
satélites SBAS. Uma das dificuldades de se rastrear os satélites SBAS é representado pela Figura 12 onde verifica-se que os satélites PRN 138 e o PRN 124 possuem baixa elevação respectivamente $19^{\circ}$ e $12^{\circ}$, o que compromete seu rastreio em locais com muitas obstruções.

Nestes novos rastreios os receptores GPS foram colocados em pilares do IBGE e do CREA - ES, que estão localizados em locais abertos e sem obstruções, além de terem suas coordenadas conhecidas e bem definidas.

Os nomes apresentados na legenda da Figura 12 são os PRN dos satélites SBAS, conforme descrição AOR-E (PRN 120), Artemis (PRN 124) e Anik (PRN138).

\subsubsection{Trabalho de campo - Terceiro Rastreio GPS L1/L2 e L1}

O planejamento foi elaborado para que se obtivessem os melhores resultados no rastreio, levando em consideração os DOP's, a disponibilidade e elevação dos satélites, entre outros itens já citados, conforme mostra as Figuras 14 e 15.

Um dado importante neste rastreio é a elevação dos satélites SBAS, pois existem obstruções que podem atrapalhar o rastreio destes satélites, além de verificar qual o melhor ângulo a ser selecionado no receptor GPS para a máscara de elevação, que normalmente é de $15^{\circ}$.

Pela Figura 14 pode-se verificar que a elevação dos satélites SBAS, Artemis (PRN124), Anik (PRN 138) e AOR-E (PRN 120) possuem elevação acima de $10^{\circ}$. Assim a máscara de elevação deverá ser no máximo de $10^{\circ}$. Para o dia 06/06/2009, o PDOP estava abaixo de 3 para todo o período do rastreio e o RDOP com o valor máximo de 4,4 para o período do rastreio. O tempo de rastreio para cada pontos foi entre 30 e 40 minutos. 


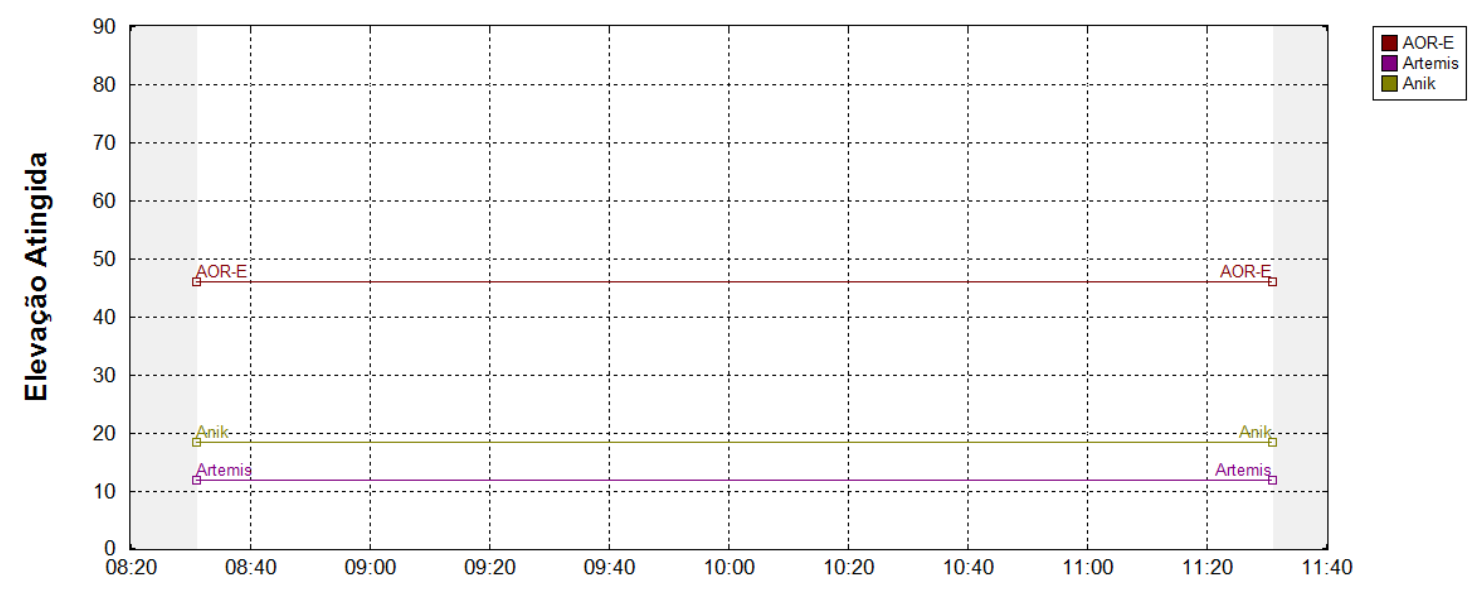

Figura 14: Elevação satélites SBAS - SP

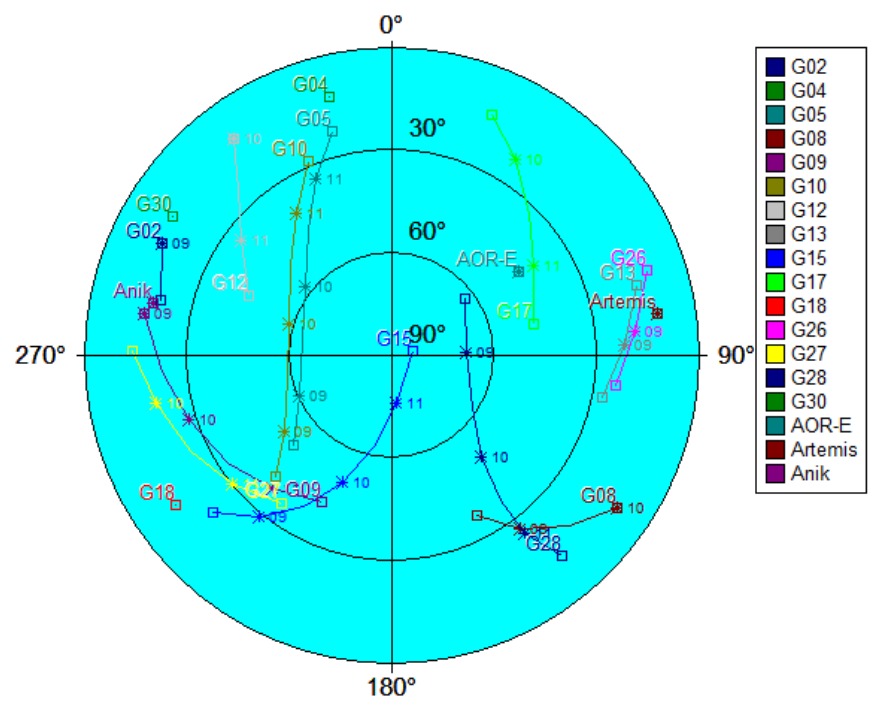

Figura 15: Disposição dos satélites GPS e SBAS - SP

$\mathrm{Na}$ realização do terceiro rastreio utilizou-se como ponto base o pilar P1 e como pontos móveis os pilares P11, PIII e P4. A escolha destes pilares adotou duas variáveis: 1) a distância entre eles; 2) por estarem em locais com poucas obstruções, como muros e árvores em sua volta, assim tem-se situações diferentes (sem obstruções) dos rastreios anteriores. Tais obstruções não impediam o rastreio, apenas provocaram algumas dificuldades, assim poder-se verificar o comportamento dos satélites SBAS (perda de ciclos) durante o rastreio.

Neste rastreio, os satélites SBAS rastreados foram os de PRN 120, 124 e 138, mas apenas o satélite PRN 138 obteve dados simultâneos entre estação base e móvel, o satélite PRN 120 apresentou um período muito curto de rastreio e seus dados estavam bastante prejudicados, apresentando muita perda de ciclos, quanto ao PRN 124, ele apenas foi rastreado no móvel, mesmo assim, por apenas alguns ALBARICI, F. L. "POSICIONAMENTO RELATIVO: ANÁLISE DOS RESULTADOS COMBINANDO AS OBSERVÁVEIS L1 DOS SATÉLITES GPS E SBAS" 
segundos. Os fatos ocorridos nos satélites PRN 120 e PRN 124, confirmam as dúvidas, que ao se ter qualquer obstruções, mesmo que poucas, os dados coletados apresentam muitos problemas de perda de ciclos. Dois novos rastreios foram realizados nos dias 14 e 15/12/2010, um com uma hora e outro com quarenta horas, respectivamente, assim realizou-se novos experimentos.

\subsubsection{Trabalho de Campo - Quarto Rastreio GPS L1/L2}

Para este rastreio, especificamente, não foi realizado o planejamento de campo, pois foram aproveitados os dados de um trabalho realizado na cidade do Rio de Janeiro. A situação do local onde foram instalados os receptores GPS é excelente, não tendo nenhuma obstrução. Para melhor elucidar as condições em que foram realizados os rastreios, as Figuras 16 e 17 são apresentadas, onde verifica-se a elevação dos satélites SBAS e a distribuição dos satélites no espaço, o PDOP tem valor abaixo de 4,0 e o RDOP para aquela data estava abaixo de 4,4 durante todo o período de rastreio. Os satélites SBAS PRN 138 e 124 possuem praticamente a mesma elevação, aproximadamente $15^{\circ}$ acima do horizonte enquanto que o PRN 120 possui elevação de 50 (Figura 16), mas apenas o PRN 138 foi rastreado de forma simultânea nos dois receptores. As datas dos rastreios foram dias 02, 03 e 04/07/2009.

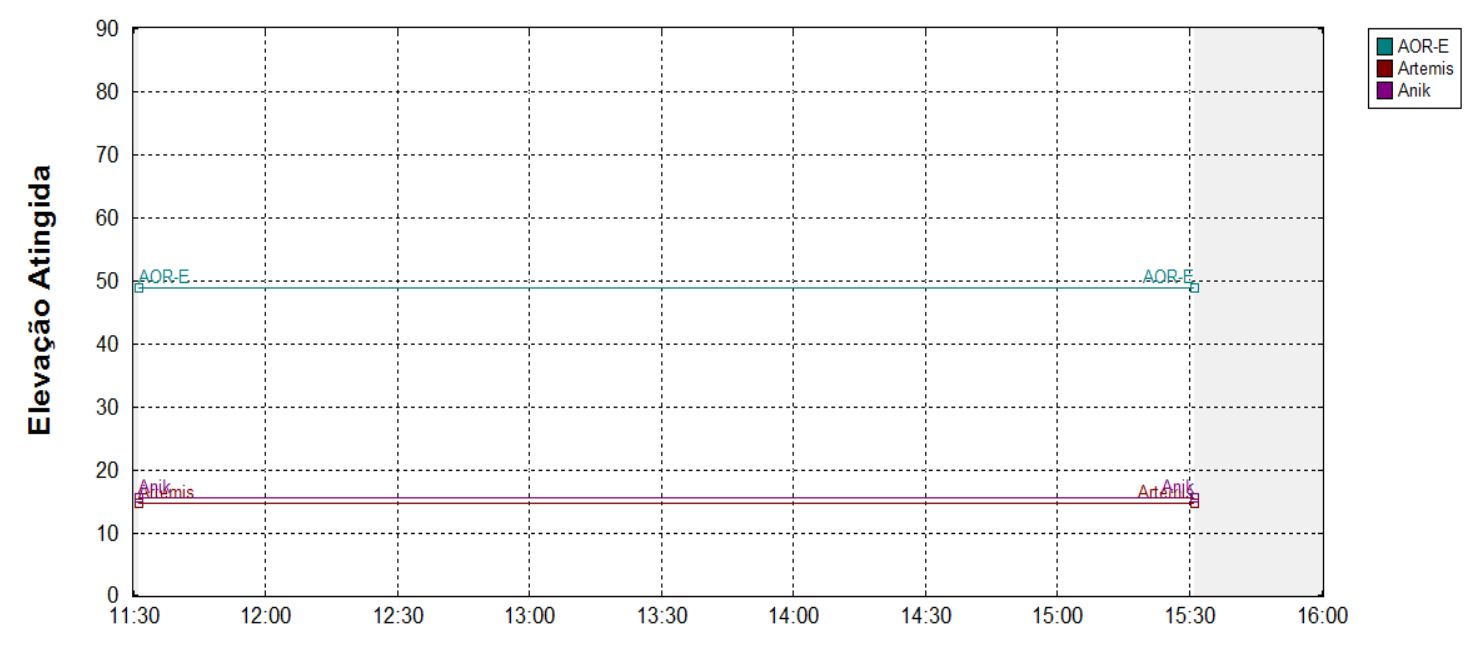

Figura 16: Elevação dos SBAS - RJ 


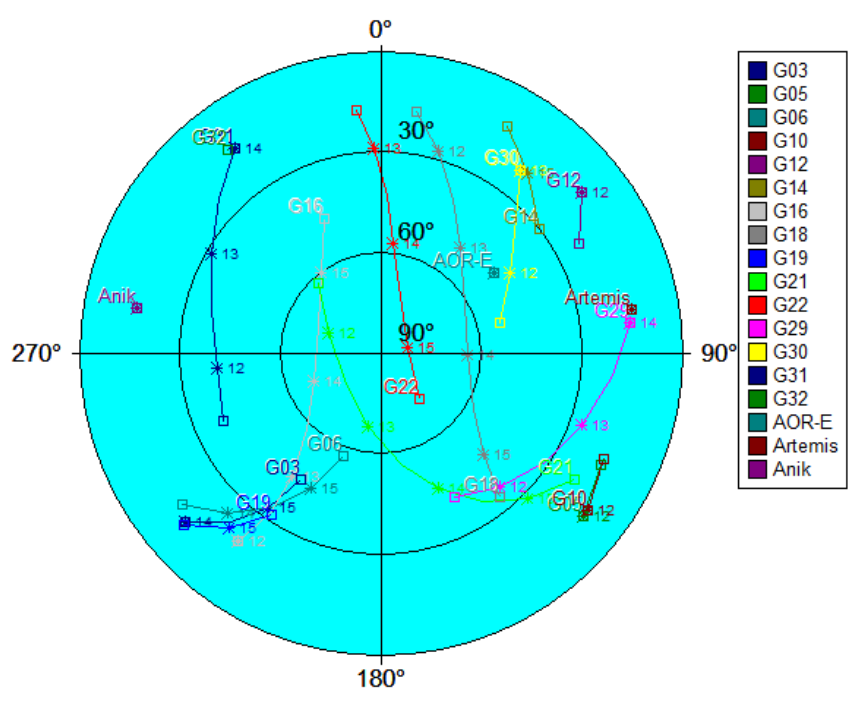

Figura 17: Disposição dos satélites GPS e SBAS - RJ

Os pontos base foram transportados para a torre de controle do autódromo, conforme ilustra a Figura 18, onde constata-se que o local não possui obstruções que comprometa o rastreio dos satélites SBAS.

Utilizou-se os dados GPS e SBAS dos dias 182, 183 e 184 para realizar o pós-processamento, dois com quase 02 (duas) horas de rastreio e outro com 08 (oito) horas de rastreio ininterruptos, respectivamente. A distância entre o par de receptores GPS foi de aproximadamente 1,2 metros.
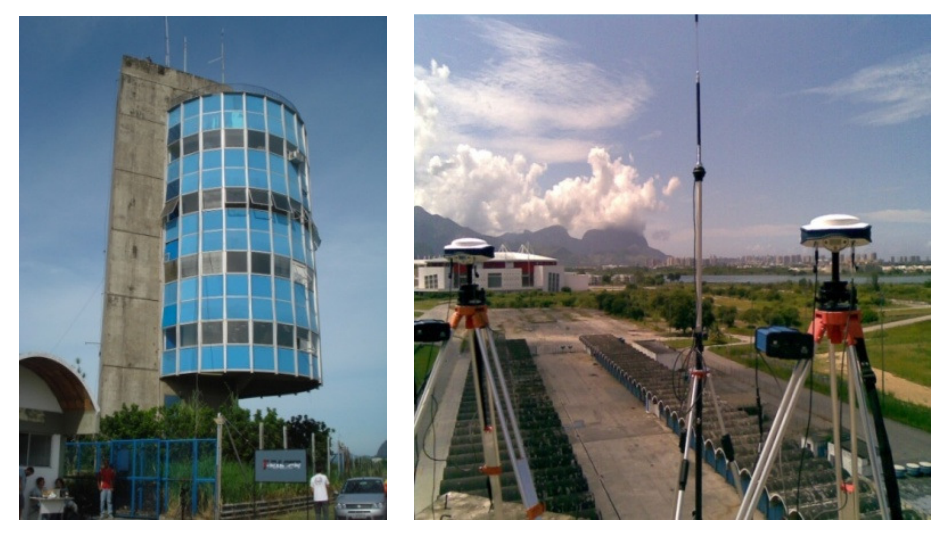

Figura 18: Vista da torre de controle e dos receptores instalados 


\subsubsection{Trabalho de Campo - Quinto Rastreio GPS L1}

O quinto rastreio foi realizado na cidade de Mossoró - RN no dia 07/10/2009. Nesta etapa os dados utilizados foram de um projeto existente na região Nordeste do Brasil, tendo um total de 47 pontos rastreados.

Os pilares rastreados não tem coordenadas conhecidas para uma eventual comparação e o tempo de ocupação dos pontos foi de apenas cinco minutos. Para verificar as informações sobre as condições do rastreio foram utilizados os programas Trimble Office e Occupation Planning.

A elevação dos satélites SBAS no local do rastreio e a disposição dos satélites estão ilustradas nas Figuras 19 e 20, respectivamente, os valores do PDOP durante o rastreio ficam abaixo de 2,5 enquanto que o RDOP está com valor máximo de 2,9. Os pontos rastreados neste local estão mais próximos da linha do Equador e também os mais a leste que se obteve os dados. Para a leitura da legenda utiliza-se a descrição AOR-E (PRN 120), Artemis (PRN 124) e IOR-W (PRN126), todos com elevação acima de $30^{\circ}$.

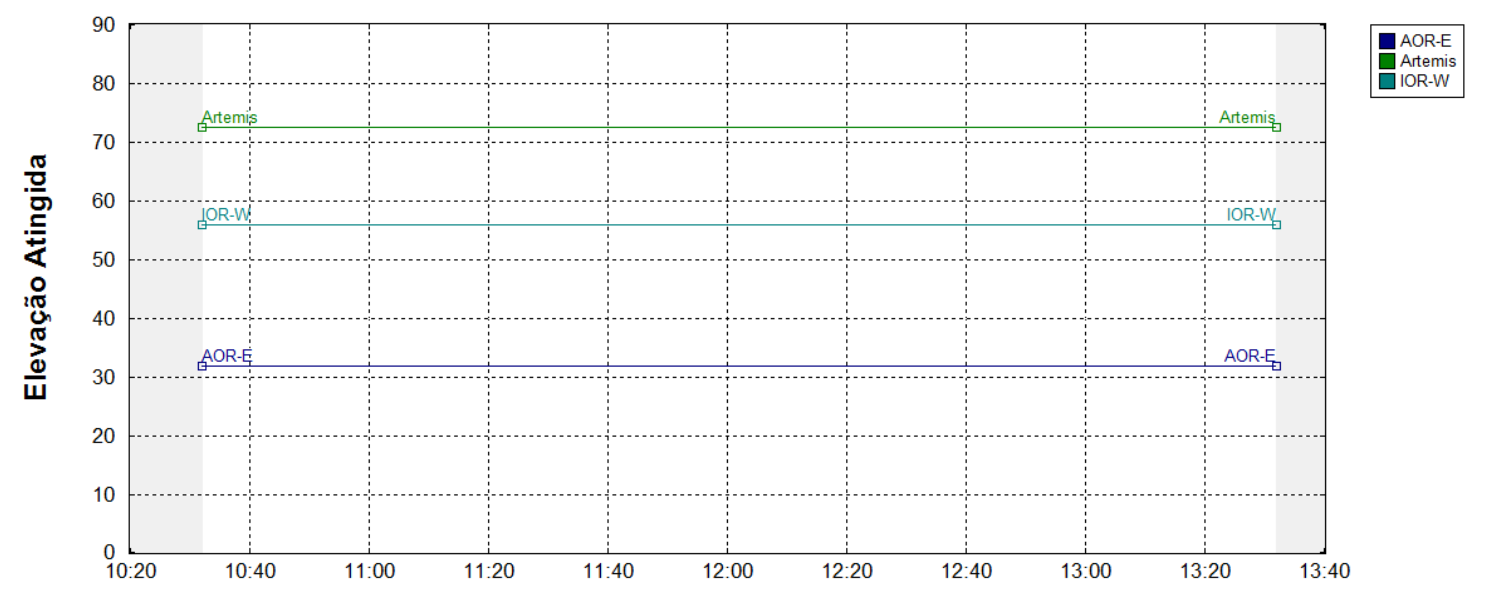

Figura 19: Altitude dos satélites SBAS em Mossoró RN 


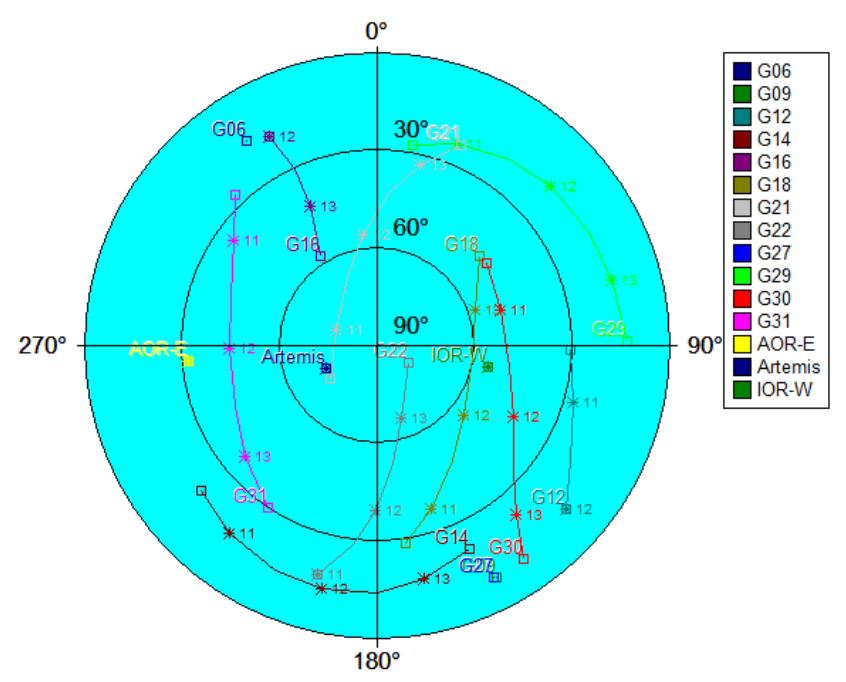

Figura 20: Disposição dos satélites GPS e SBAS - Mossoró - RN

\subsubsection{Trabalho de Campo - Sexto Rastreio GPS L1/L2}

No sexto rastreio, realizado na cidade de Manaus - AM, no dia 24/03/2010, apesar de não se realizar o planejamento de campo antecipadamente, utilizou-se o almanaque para verificar as condições em que o rastreio foi realizado. $\mathrm{Na}$ reconstituição do cenário verificou-se que o PDOP não ultrapassou o valor de 2,25 durante todo o período e o RDOP teve um valor máximo de 2,5. As Figuras 21 e 22 indicam a elevação dos satélites SBAS e a disposição dos satélites no espaço, respectivamente.

Os pilares rastreados não possuem coordenadas conhecidas e o tempo de ocupação foi de quinze minutos. Foram rastreados dois pontos e após o download dos dados foi verificado que os satélites SBAS visíveis foram o PRN 120 e 138. Os dados do satélite PRN 138 apresentaram problemas, isto é, ocorreram muitas perdas de ciclos e apenas uma parte do tempo ficou disponível, o que o inviabilizou no processamento. Apenas os dados do satélite PRN 120 foram aproveitados nos experimentos descritos no Capítulo 4. 


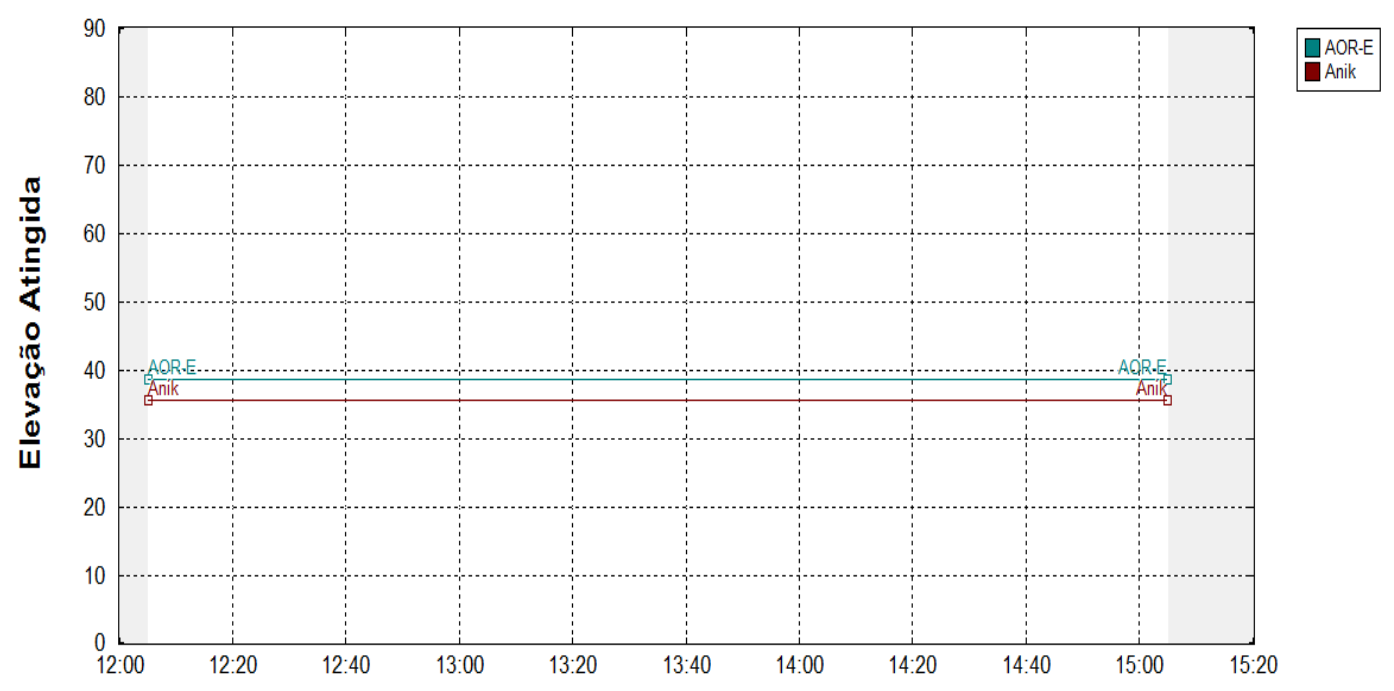

Figura 21: Elevação dos satélites SBAS - Manaus - AM

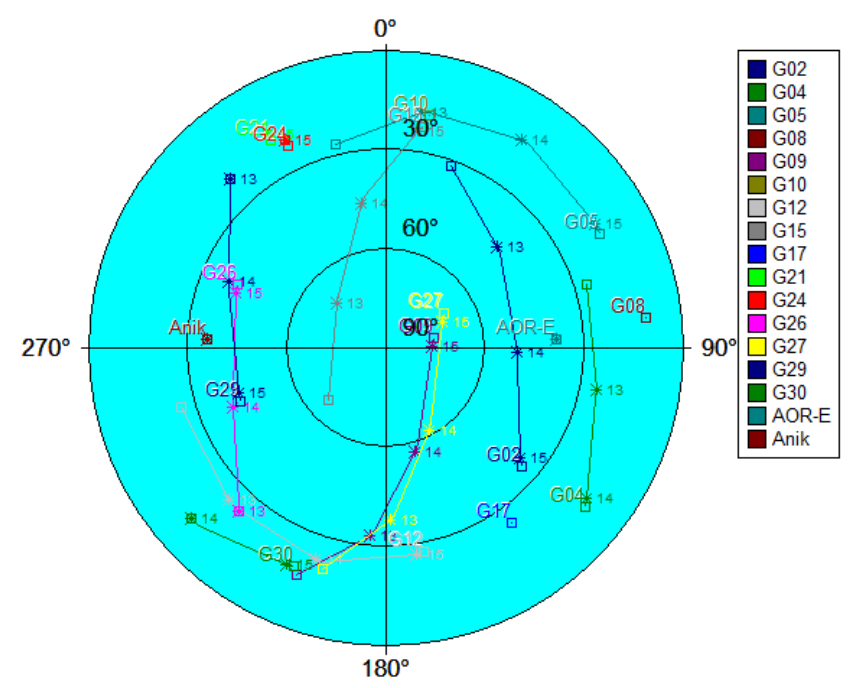

Figura 22: Disposição dos satélites GPS e SBAS - Manaus - AM 


\section{METODOLOGIA}

Neste capítulo são apresentados os principais aspectos metodológicos envolvidos no trabalho de pesquisa desenvolvido. As etapas abrangentes da metodologia empregada foram: coleta e processamento dos dados, análise do processamento, geração de gráficos e análise estatística.

O estudo está direcionado para os satélites SBAS de PRN 120 (S20), 124 (S24) e 138 (S38), sendo os dois primeiros do sistema EGNOS e o seguinte do sistema WAAS, respectivamente. Isto se deu ao fato, pois estes satélites foram rastreados com maior frequência em todos as coletas deste trabalho, ora dois simultaneamente, ora apenas um deles.

A Tabela 6 resume as informações pertinentes a estes satélites para cada local e também enumera cada um dos experimentos realizados para um melhor o entendimento dos resultados (Capítulo 6).

Tabela 6: Informações dos satélites SBAS (o autor)

\begin{tabular}{|c|c|c|c|c|c|}
\hline Local do Rastreio & $\begin{array}{l}\text { SBAS (PRN) } \\
\text { Rastreado }\end{array}$ & $\begin{array}{c}\text { Posição no } \\
\text { espaço } \\
\text { (SBAS) } \\
\end{array}$ & Azimute & Elevação & Experimentos \\
\hline São Paulo (SP) & S38 (Anik - WAAS) & $107.3^{\circ} \mathrm{W}$ & $282^{\circ}$ & $18^{\circ}$ & 1 \\
\hline Nova Venécia (ES) & $\begin{array}{l}\text { S20 (AOR-E - EGNOS) } \\
\text { S24 (Artemis - EGNOS) }\end{array}$ & $\begin{array}{l}15.5^{\circ} \mathrm{W} \\
21.5^{\circ} \mathrm{E}\end{array}$ & $\begin{array}{l}56^{\circ} \\
80^{\circ}\end{array}$ & $\begin{array}{l}55^{\circ} \\
12^{\circ}\end{array}$ & 2 \\
\hline Rio de Janeiro (RJ) & S38 (Anik - WAAS) & $107.3^{\circ} \mathrm{W}$ & $280^{\circ}$ & $15^{\circ}$ & 3 \\
\hline Mossoró (RN) & $\begin{array}{l}\text { S24 (Artemis - EGNOS) } \\
\text { S20 (AOR-E - EGNOS) }\end{array}$ & $\begin{array}{l}21.5^{\circ} \mathrm{E} \\
15.5^{\circ} \mathrm{W}\end{array}$ & $\begin{array}{l}87^{\circ} \\
56^{\circ}\end{array}$ & $\begin{array}{l}23^{\circ} \\
32^{\circ}\end{array}$ & 4 \\
\hline Manaus (AM) & $\begin{array}{l}\text { S20 (AOR-E - EGNOS) } \\
\text { S38 (Anik - WAAS) }\end{array}$ & $\begin{array}{l}15.5^{\circ} \mathrm{W} \\
107.3^{\circ} \mathrm{W}\end{array}$ & $\begin{array}{r}87^{\circ} \\
273^{\circ}\end{array}$ & $\begin{array}{l}39^{\circ} \\
36^{\circ}\end{array}$ & 5 \\
\hline
\end{tabular}

Uma questão a ser observada é que os dados foram processados em apenas um programa comercial, o GNSS Solution $v$ 3.10.07. Isso ocorreu devido a impossibilidade de se obter outros softwares de outras fabricantes que realizassem o processamento, das observáveis $L 1$, dos satélites SBAS. Assim realizar comparações entre eles. 


\subsection{Processamento dos dados}

Após as etapas de planejamento e dos rastreios em diferentes datas e locais, o próximo passo foi o processamento dos dados obtidos.

Os dados brutos, no formato Atom (formato da fabricante) e Rinex, obtidos nos diversos rastreios foram importados para o software GNSS Solution, onde foram processados, utilizando-se das efemérides transmitidas, e realizados vários experimentos (neste contexto entenda-se por experimentos; exclusão de satélites, reprocessamento dos dados, corte nos dados com perdas de ciclos). Um exemplo do arquivo Rinex, de navegação SBAS, é apresentado no Apêndice A.

O programa GNSS Solution foi configurado para o processamento dos dados no sistema de referência SAD 69 (South American Datum 1969), na projeção UTM (Universal Transversa de Mercator), como os rastreios foram realizados em locais diferentes, os fusos da projeção UTM variaram para cada local.

Na primeira etapa, os dados foram processados diretamente, ou seja, sem a preocupação de uma pré-análise de como se comportaram os satélites rastreados, apenas sendo informadas as coordenadas e seus respectivos desvios-padrão para o ponto considerado como base.

Esta primeira etapa foi realizada para detecção de erros grosseiros no processamento, como por exemplo, digitação das coordenadas da base erroneamente, erro na altura da antena, etc

A segunda etapa do processamento foi realizar os experimentos com conjuntos diferentes de satélites, ou seja, excluir alguns dos satélites GPS e SBAS, e reprocessar os dados, verificando a variação das coordenadas dos pontos e também seus respectivos resíduos, além do PDOP e RDOP.

Para um melhor entendimento dos detalhes de cada experimento, será descrita a metodologia aplicada na seleção dos satélites escolhidos para fazer parte do processamento dos dados.

Para a seleção dos satélites que foram utilizados no processamento das linhas de base, primeiramente, verificaram-se quais satélites (PRN) foram rastreados em cada ponto através do software GNSS Solution e, depois, verificou-se a qualidade das efemérides obtidas através do gráfico de residuais do mesmo programa. Assim, os satélites com resíduos mais próximo a zero foram selecionados. 
Este critério foi adotado, pois os resíduos mais discrepantes possuem maior probabilidade de estarem com erros nas observáveis, o que dificultaria o processamento, prejudicando a acurácia das coordenadas. A Figura 23 mostra esta situação:

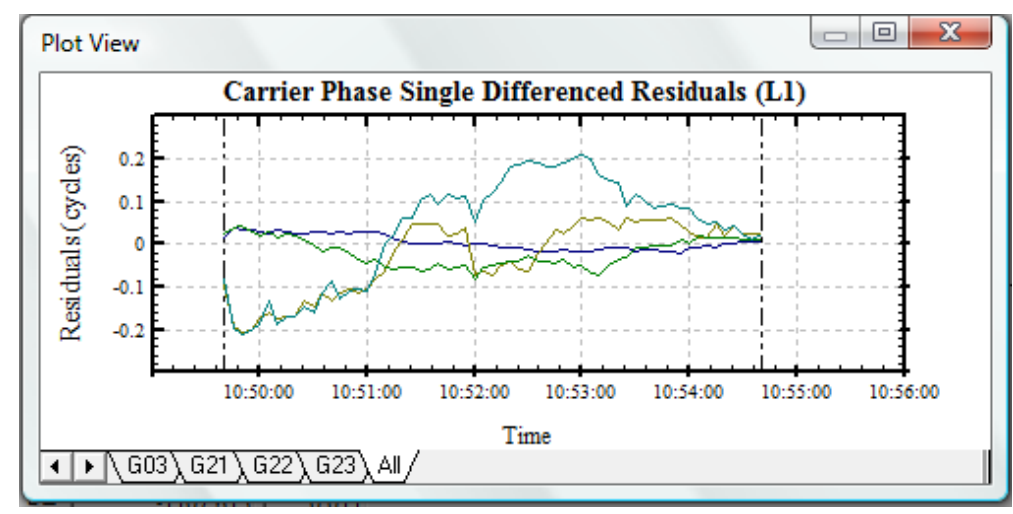

Figura 23: Residuais dos Satélites

As informações podem ser determinadas para cada satélite separadamente, ou para todos os satélites que foram rastreados, neste exemplo estão selecionados todos os satélites (AII) como mostra a Figura 24.

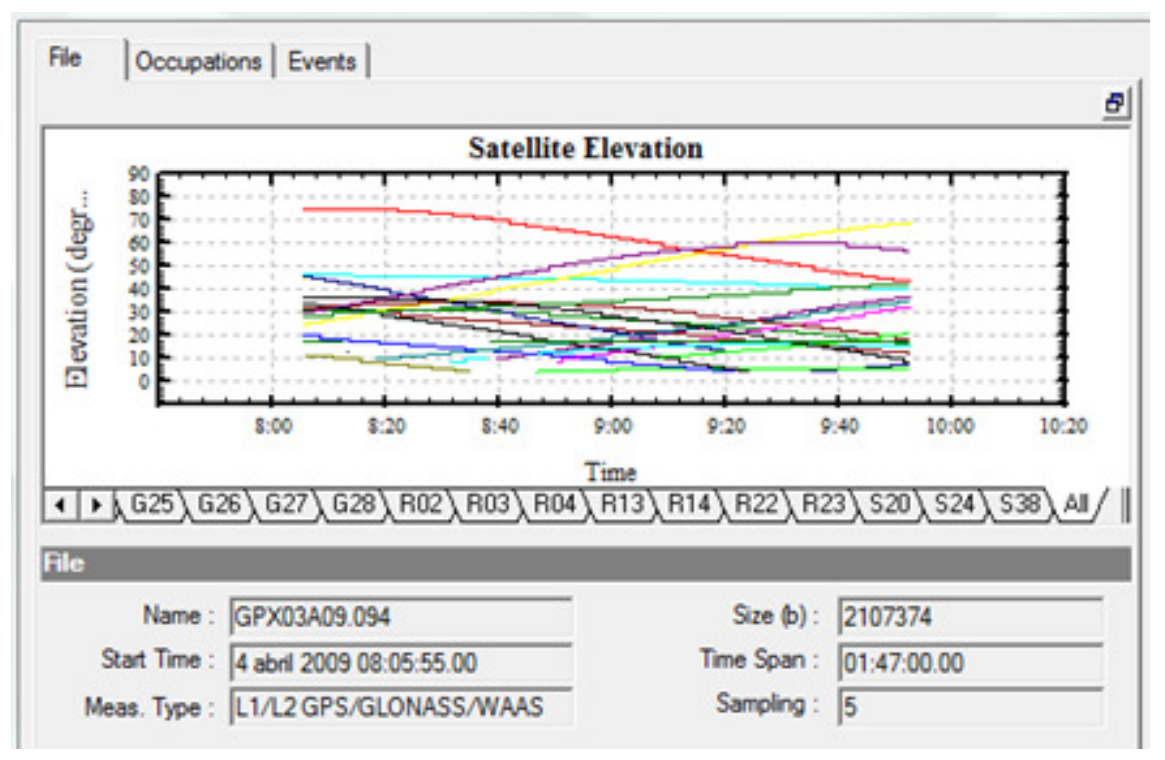

Figura 24: Elevação de todos os Satélites Rastreados.

Outra análise é referente à elevação dos satélites rastreados, para a seleção verificou-se quais satélites estão com a maior elevação, evitando, assim, selecionar satélites que estejam muito baixo. A Figura 25 mostra os satélites PRN 19 e o PRN 26, respectivamente, um saindo no horizonte, ficando abaixo da linha de visada do receptor e outro entrando no horizonte, aumentando sua elevação com o passar do ALBARICI, F. L. "POSICIONAMENTO RELATIVO: ANÁLISE DOS RESULTADOS COMBINANDO AS OBSERVÁVEIS L1 DOS SATÉLITES GPS E SBAS" 
tempo, ficando acima da linha de visada do horizonte do receptor.

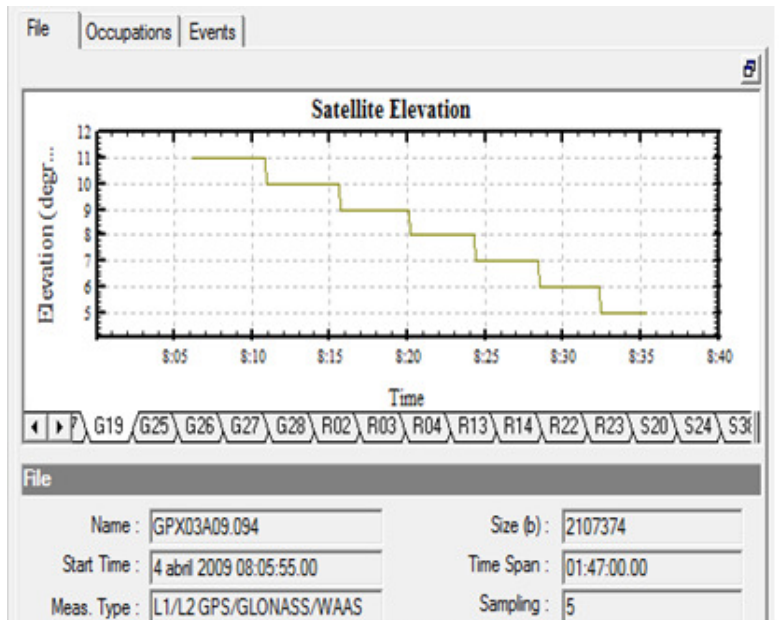

Satélite PRN 19

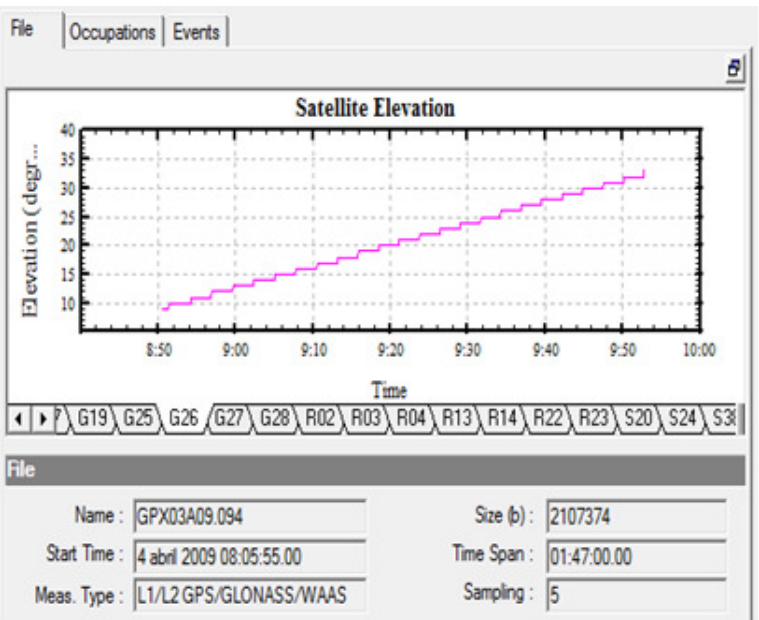

Satélite PRN 20

Figura 25: Elevação dos Satélites rastreados.

A Figura 26 ilustra a elevação do satélite S24 (EGNOS), que é constante $\left(13^{\circ}\right)$ na cidade de São Paulo. Todos os satélites rastreados, GPS, GLONASS e SBAS, aparecem nesta tela, para se obter as informações, os satélites podem ser selecionados um a um ou todos de uma só vez.

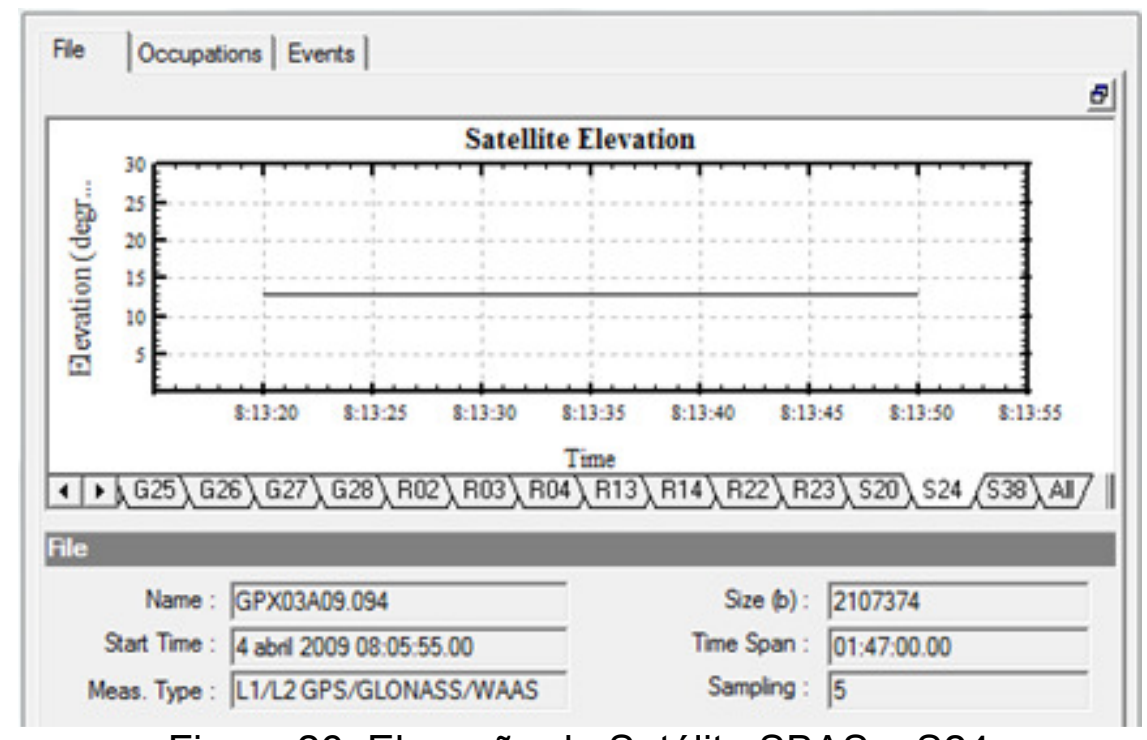

Figura 26: Elevação do Satélite SBAS - S24

Outro parâmetro levado em consideração para a seleção dos satélites é a relação sinal ruído. A qualidade do sinal recebido pode ser avaliada através da relação sinal-ruído $(S / N)$, que pode ser definida como sendo a relação entre a potência do sinal recebido do satélite e a potência de ruído que acompanha o sinal. 
O ruído pode ser causado pelo próprio receptor, por fenômenos naturais (radiações atmosféricas capturadas pela antena) ou por transmissores de sinais interferentes. (SOUZA et al. 2005).

Portanto, quanto menor for a relação de sinal ruído, maior o risco de haver problemas nos dados rastreados, o sinal recebido deve ser igual ou superior a sensibilidade do receptor.

A Tabela 7 foi adaptada do manual do receptor Promark3 e mostra a sensibilidade do receptor para o sinal ruído.

Tabela 7: Sinal - Ruído do receptor da fabricante Magellan (adaptado <FTP Magellan acesso: 24 mar. 2010>)

\begin{tabular}{cc}
\hline Sinal Ruído (SNR) & Qualidade de recepção dos dados GPS \\
\hline SNR $<10 \mathrm{~dB}$ & Muito Crítico: dados instáveis \\
$10<\mathrm{SNR}<20 \mathrm{~dB}$ & Bom mas ainda Crítico: sinal se deteriora ligeiramente. \\
SNR $>20 \mathrm{~dB}$ & Excelente: sinal em nível excelente \\
\hline
\end{tabular}

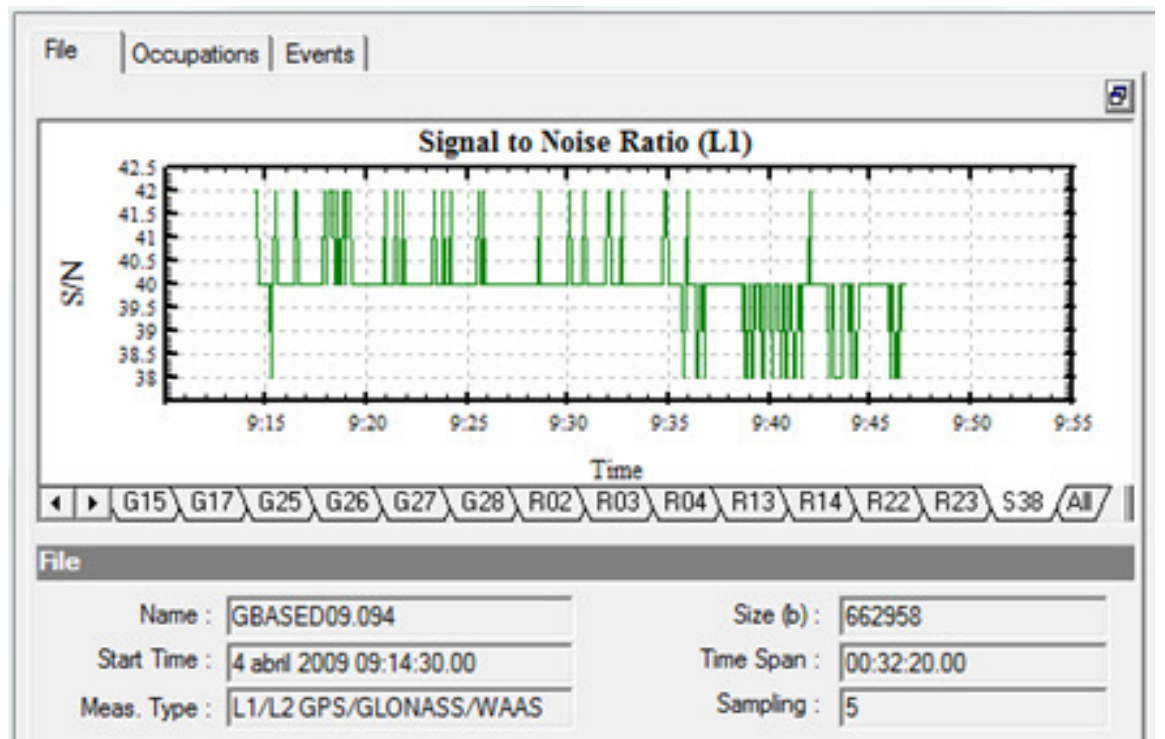

Figura 27: Sinal ruído satélite WAAS PRN 138

O satélite PRN 138 (Figura 27) possui uma razão de sinal ruído considerada alta (oscila entre 38 e $42 \mathrm{~dB}$ ), que segundo a tabela 6, é excelente e o risco de haver problemas com os dados rastreados é mínimo.

Até o momento, foram apresentados os parâmetros utilizados para a seleção dos satélites a serem utilizados no processamento. Após tais análises e selecionados os satélites com os melhores parâmetros, utilizou-se outro software para visualizar estes satélites a partir do arquivo do almanaque. 
$\mathrm{Na}$ análise da seleção dos satélites (PRN) que foram utilizados no processamento dos dados, utilizou-se o arquivo de almanaque no programa Trimble Office para visualizar a posição de cada satélite no momento da captura dos dados. No capítulo 3 foram apresentados os Skyplot (Disposição dos satélites) de cada local de rastreio, que são utilizados nesta etapa de escolha dos satélites. Assim, com esta ferramenta pode-se verificar quais satélites (Figura 28) proporcionarão em uma melhor geometria, pois a utilização de uma geometria (RDOP) ruim pode mascarar os resultados, degradando a qualidade do posicionamento.

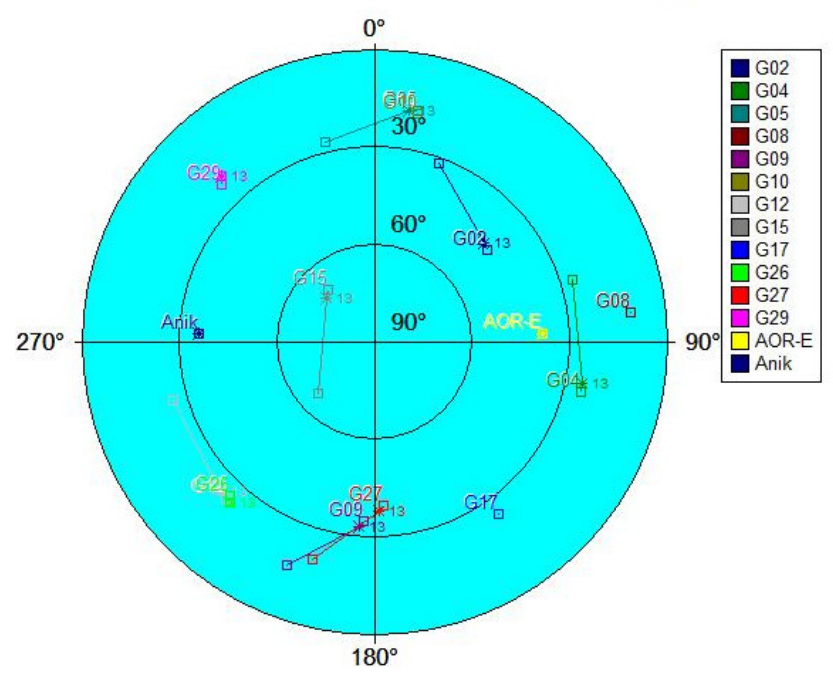

Figura 28: Exemplo de Skyplot - Manaus - AM

Esta ferramenta foi utilizada em cada um dos rastreios realizados para verificar qual a melhor geometria possível.

A estratégia utilizada no processamento dos dados tem a finalidade de selecionar os mesmos satélites rastreados para todos os pontos, ou seja, verificamse quais satélites GPS (PRN) foram rastreados em cada ponto e utilizam-se os mesmos para fazer o processamento relativo, assim, poder-se-á verificar a variação da constelação e se fazer uma análise mais coerente dos resultados obtidos. Caso não seja possível utilizar os mesmos satélites, serão utilizados os que melhor contribuírem na geometria da constelação.

O processamento foi realizado em duas partes: uma somente com os satélites GPS e outra com a adição dos satélites geoestacionários.

Para isso, realizou-se experimentos no processamento, desde a parte que se chamou de ideal, onde estão à disposição todos satélites GPS e SBAS rastreados, 
até a pior condição, onde os dados foram processados com apenas 04 satélites GPS (o programa não realiza o processamento com número inferior a 04 satélites), que foi chamada de situação crítica.

Quando realiza-se o processamento que se denominou de ideal, adicionamse as observáveis dos satélites SBAS para averiguar se a inclusão de tais satélites realmente alteram a geometria, melhorando, assim, o PDOP e RDOP, e conseqüentemente, a acurácia das coordenadas.

Ao partir da situação ideal, retiram-se, gradativamente, um a um os satélites GPS e adicionam-se os satélites SBAS ao processamento, até chegar-se na situação critica, onde se tem apenas quatro satélites GPS e adicionam-se as observáveis do satélite SBAS ao processamento.

Essa etapa foi realizada exaustivamente, para que se conseguisse chegar a conclusões sobre a contribuição das observáveis dos satélites SBAS no processamento, e até onde estas observáveis afetam positivamente ou negativamente no posicionamento relativo, ou mesmo se sua contribuição é nula.

Os rastreios foram realizados na região Sudeste, mas em Estados diferentes, e também na região Nordeste e Norte, o que ajudará a analisar a disponibilidade de obtenção da observável L1 dos satélites SBAS em diferentes regiões do país, e sobre a utilização ou não das observáveis dos satélites SBAS em cada local.

No processamento dos dados, que foram realizados nas cidades de Manaus e Mossoró não foram utilizadas as coordenadas verdadeiras do ponto, pois os receptores GPS não foram colocados em pilares de coordenadas conhecidas. Assim, no processamento daqueles dados, o ponto de controle (base) foi determinado em relação a RBMC e adotou-se para os pontos rastreados, como coordenadas verdadeiras, o melhor resultado obtido no processamento.

\subsubsection{Análise do processamento}

Como descrito no item 4.1, vários experimentos foram realizados no processamento dos dados. Para a análise dos resultados obtidos foram estipulados os seguintes critérios: 
$\checkmark$ Verificação das coordenadas obtidas no processamento relativo e seus resíduos, nos vários experimentos realizados;

$\checkmark$ Comparação das coordenadas obtidas no processamento relativo com as consideradas "verdadeiras";

$\checkmark$ Verificação do tipo de solução do ponto (Fixed ou Float),

$\checkmark$ Verificação da melhoria da geometria dos satélites através do RDOP, ao ser adicionado ao processamento os dados dos satélites SBAS.

Uma linha de base com uma solução do tipo Float indica que nem todas as ambigüidades foram resolvidas. Na maioria dos casos, um vetor com um tipo de solução Float pode ser ruim em qualidade. Caso haja uma solução Float em um vetor curto, provavelmente haverá problemas com os dados utilizados para calcular aquele vetor (Magellan, 2010).

\subsubsection{Geração dos gráficos}

Para um melhor entendimento dos critérios utilizados, foram gerados gráficos no programa Microcal Origin 6.0.

$\checkmark$ Gráfico das discrepâncias e desvio padrão;

Foram visualizadas as coordenadas $\mathrm{N}, \mathrm{E}$ e $\mathrm{h}$ de cada ponto processado $\mathrm{e}$ comparados com as verdadeiras, assim, se obteve a discrepância, em metros, para cada coordenada e seus respectivos desvios padrão.

$\checkmark$ Gráfico das Análises estatísticas;

Foram gerados gráficos do erro médio quadrático (RMS) das coordenadas N, E e h.

\subsection{Análise estatística}

A análise de tendência e precisão deve ser feita a partir da análise das discrepâncias obtidas entre as coordenadas consideradas verdadeiras e as coordenadas obtidas no processamento. Para a análise de tendência, utiliza-se o 
teste $t$ de Student .

De acordo com CHAVES (1998) e CAMARGO (2000), a discrepância do ponto, a discrepância média e sua variância são determinados a partir das Equações 16.a, 16.b e 16.c, respectivamente.

$$
\begin{aligned}
& \Delta X_{i}=X_{i}-X_{i}^{r} \\
& \overline{\Delta X}=\frac{1}{n} \sum_{i=1}^{n} \Delta X_{i} \\
& S_{\Delta X}^{2}=\frac{1}{n} \sum_{i=1}^{n}\left(\Delta X_{i}-\overline{\Delta X}\right)^{2}
\end{aligned}
$$

onde:

$\Delta X_{i}$ : discrepância no ponto $(i)$;

$\overline{\Delta X}$ : média das discrepâncias;

$S_{\Delta x}^{2}$ : variância da discrepância;

$n$ : número de observações.

Nas Equações 16.a, 16.b e 16.c , ao denominar-se $X$ para um ponto, entendese que esta nomenclatura seja válida para as coordenadas $\mathrm{N}$ e E. Nelas, as coordenadas com índice $(r)$ são referentes às coordenadas obtidas através do levantamento GPS e as outras são relativas às coordenadas verdadeiras.

\subsubsection{Análise de tendência}

Para realizar o teste de tendência, podem ser utilizadas as seguintes hipóteses (GALO e CAMARGO., 1994):

$$
H_{0}: \overline{\Delta X}=0 ; \quad H_{1}: \overline{\Delta X} \neq 0
$$

Na equação $17 H_{0}$ corresponde à hipótese básica e $H_{1}$ à hipótese alternativa. 
Em seguida, calcula-se a estatística amostral $t$, e verifica-se se o mesmo encontrase dentro do intervalo de aceitação ou rejeição da hipótese nula. O cálculo da estatística amostral $\left(t_{X}\right)$ é dado pela Equação 18.

$$
t_{X}=\frac{\overline{\Delta X}}{s_{\Delta X}} n^{1 / 2}
$$

o intervalo de confiança por:

$$
\left|t_{X}\right|<t_{\left(n-1, \frac{\alpha}{2}\right)}
$$

onde:

n: número de observações;

$\alpha$ : nível de significância.

Se a estatística $t$ amostral não satisfaz a desigualdade, rejeita-se a hipótese nula, ou seja, as coordenadas possuem tendência significativa para um determinado nível de confiança. A detecção de tendência em alguma direção informa a ocorrência de problemas de natureza sistemática.

\subsubsection{Análise de erro médio quadrático}

O erro médio quadrático $(E M Q)$ de um estimador é o valor esperado do quadrado da diferença entre o estimador e o parâmetro (MONTGOMERY et al., 1999), ele indica a acurácia absoluta, pois não utiliza a média, resultando em um valor absoluto em relação a referência (MACHADO, 2008). Portanto, consiste em analisar o grau de concordância entre o valor estimado e o valor de referência, isto é, analisar a acurácia entre os valores obtidos com o rastreio GPS e os valores considerados verdadeiros (SOUZA, 2006). 


$$
R M S=\sqrt{\frac{\sum_{i=1}^{m}\left(\Delta N_{i}-\Delta \widehat{N}_{i}\right)^{2}}{n}}
$$

onde:

n: número de observações;

$\Delta \widehat{N}_{i}:$ componente verdadeira; e

$\Delta N_{i}$ : componente observada através do rastreio GPS. 


\section{RESULTADOS}

Neste capítulo, são apresentados os resultados obtidos no desenvolvimento do trabalho. Inicialmente, nas seções 5.1 a 5.5 são apresentados os resultados de cada processamento realizado, apresenta-se em forma de gráficos e tabelas as diferenças nas coordenadas N, E e h. Na Seção 5.6, é realizada uma análise estatística dos resultados, na qual foram obtidos os resultados da aplicação dos testes de tendência e erro médio quadrático (RMS). Outros gráficos comparativos das componentes $\mathrm{N}, \mathrm{E}$ e $\mathrm{h}$ por local onde realizou-se os rastreios estão representados no Anexo A.

\subsection{Experimento 1}

Quando processado apenas com as observáveis L1 do sistema GPS, as precisões dos pontos, analisadas e comparadas com as verdadeiras, apresentam diferenças milimétricas. Porém, quando foram adicionados as observáveis L1 do sistema SBAS, as precisões das coordenadas apresentam diferenças acima das consideradas ideais, ou seja, estas diferenças chegaram a ser centimétricas, principalmente nos casos considerados críticos (pouca disponibilidade de satélites). Esta situação aconteceu em todos os rastreios realizados na cidade de São Paulo. A Tabela 8 mostra as coordenadas $\mathrm{N}, \mathrm{E}$ e $\mathrm{h}$ (altitude geométrica) obtidas nas monografias dos pontos utilizados na cidade de São Paulo.

\begin{tabular}{ccccc}
\multicolumn{5}{c}{ Tabela 8: Coordenadas dos pontos da Raia USP (o autor) } \\
\hline Pilares & $\mathbf{N}(\mathbf{m})$ & $\mathbf{E}(\mathbf{m})$ & Altitude $\mathbf{h}(\mathbf{m})$ & $\begin{array}{c}\text { Linha de } \\
\text { base }(\mathbf{m})\end{array}$ \\
\hline P1 & $7.394 .477,887$ & $323.300,162$ & 724,84 & ----- \\
P2 & $7.394 .455,737$ & $323.343,354$ & 724,79 & 48,540 \\
P3C & $7.394 .402,502$ & $323.447,118$ & 724,76 & 165,188 \\
P4 & $7.394 .272,909$ & $323.699,782$ & 724,92 & 449,180 \\
P11 & $7.394 .573,225$ & $323.378,605$ & 725,4 & 113,006 \\
PIII & $7.394 .450,260$ & $323.617,255$ & 725,17 & 306,19 \\
P2A & $7.394 .473,243$ & $323.309,232$ & 724,82 & 10,178 \\
\hline
\end{tabular}


Para os dados do rastreio realizado no dia 04/04/2009, a metodologia de seleção dos satélites foi utilizada para obtenção dos melhores resultados nos processamentos realizados.

Os resultados dos dados processados no primeiro rastreio são apresentados nas Tabelas 09, 10, 11 e 12.

Tabela 9: Coordenadas Processadas - Situação ideal - Com SBAS/P (o autor)

\begin{tabular}{ccccccccc}
\hline Nome & Experimento & $\mathbf{N}(\mathbf{m})$ & $\mathbf{E}(\mathbf{m})$ & Altitude $(\mathbf{m})$ & SVS & PDOP & RDOP & Solução \\
\hline P1 & GPS+Glonass+S38 & $7.394 .477,887$ & $323.300,162$ & 724,841 & 16 & 1,6 & 1,00 & Base \\
P2 & GPS+Glonass+S38 & $7.394 .455,742$ & $323.343,354$ & 724,783 & 14 & 1,6 & 1,00 & Fixa \\
P3C & GPS+Glonass+S38 & $7.394 .402,478$ & $323.447,110$ & 724,745 & 16 & 1,5 & 1,00 & Fixa \\
P4 & GPS+Glonass+S38 & $7.394 .272,916$ & $323.699,783$ & 724,906 & 16 & 1,4 & 1,00 & Fixa \\
\hline
\end{tabular}

Tabela 10: Coordenadas Processadas - Situação Ideal - Sem SBAS/ SP (o autor)

\begin{tabular}{ccccccccc}
\hline Nome & Experimento & $\mathbf{N}(\mathbf{m})$ & $\mathbf{E}(\mathbf{m})$ & Altitude $(\mathbf{m})$ & SVS & PDOP & RDOP & Solução \\
\hline P1 & GPS+Glonass & $7.394 .477,887$ & $323.300,162$ & 724,841 & 16 & 1,6 & 1,00 & Base \\
P2 & GPS+Glonass & $7.394 .455,742$ & $323.343,354$ & 724,783 & 14 & 1,6 & 1,00 & Fixa \\
P3C & GPS+Glonass & $7.394 .402,478$ & $323.447,110$ & 724,745 & 16 & 1,5 & 1,00 & Fixa \\
P4 & GPS+Glonass & $7.394 .272,916$ & $323.699,783$ & 724,906 & 16 & 1,4 & 1,00 & Fixa \\
\hline
\end{tabular}

Tabela 11: Coordenadas Processadas - Situação Crítica - Com SBAS /SP(o autor)

\begin{tabular}{ccccccccc}
\hline Nome & Experimento & $\mathbf{N}(\mathbf{m})$ & $\mathbf{E}(\mathbf{m})$ & Altitude $(\mathbf{m})$ & SVS & PDOP & RDOP & Solução \\
\hline P1 & 04GPS+S38 & $7.394 .477,887$ & $323.300,162$ & 724,841 & 5 & 5,4 & 1,00 & Base \\
P2 & 04GPS+S38 & $7.394 .455,744$ & $323.343,354$ & 724,791 & 5 & 5,4 & 1,00 & Fixa \\
P3C & 04GPS+S38 & $7.394 .402,482$ & $323.447,112$ & 724,741 & 5 & 5,3 & 1,00 & Fixa \\
P4 & 04GPS+S38 & $7.394 .272,915$ & $323.699,783$ & 724,911 & 5 & 4,2 & 1,00 & Fixa \\
\hline
\end{tabular}

Tabela 12: Coordenadas Processadas - Situação Crítica - Sem SBAS/SP(o autor)

\begin{tabular}{ccccccccc}
\hline Nome & Experimento & $\mathbf{N}(\mathbf{m})$ & $\mathbf{E}(\mathbf{m})$ & Altitude $(\mathbf{m})$ & sVS & PDOP & RDOP & Solução \\
\hline P1 & 04GPS & $7.394 .477,887$ & $323.300,162$ & 724,841 & 4 & 7,0 & 1,00 & Base \\
P2 & 04GPS & $7.394 .455,741$ & $323.343,353$ & 724,777 & 4 & 7,0 & 1,00 & Fixa \\
P3C & 04GPS & $7.394 .402,475$ & $323.447,109$ & 724,733 & 4 & 5,5 & 1,00 & Fixa \\
P4 & 04GPS & $7.394 .272,914$ & $323.699,784$ & 724,901 & 4 & 4,3 & 1,00 & Fixa \\
\hline
\end{tabular}

Analisando-se as coordenadas dos pontos, nota-se que quanto maior a disponibilidade de satélites, mais próxima das coordenadas verdadeiras (Tabela 8) elas se encontram. Quando a disponibilidade de satélites diminui de forma acentuada, as coordenadas apresentam discrepâncias maiores.

Ao se comparar as coordenadas do marco P2 com as consideradas verdadeiras, verifica-se que quando a disponibilidade de satélites é abundante 
(situação ideal), as discrepâncias ficam milimétricas, no entanto quando a disponibilidade é mínima (situação crítica), a discrepância fica centimétrica na componente h, apesar do PDOP e RDOP serem considerados baixos.

As observáveis L1 do satélite PRN 138 foram utilizadas no processamento, mas não interferiram no processamento de forma positiva, ou seja, melhorando de forma significativa a acurácia das coordenadas. A adição deste satélite na presença de uma grande disponibilidade de satélites GPS, não interfere nas coordenadas, bem como no PDOP, mas quando se tem pouca disponibilidade de satélites GPS (04 GPS + S38) ele ajuda na melhoria do PDOP de forma discreta, mas não na acurácia das coordenadas.

Por outro lado, quando se adiciona neste mesmo processamento mais um satélite GPS e retira-se o satélite SBAS (PRN 138), ficando assim com 05 satélites GPS, as discrepâncias das coordenadas diminuem de forma acentuada, tornando-se milimétricas. Neste mesmo processamento, ao inserir o SBAS ficando com 05 GPS + S38, as coordenadas não se alteram, o mesmo acontece quando se aumenta o número de satélites GPS e faz-se o mesmo teste. A Tabela 13 mostra que os resultados encontrados praticamente não se alteram. O Gráfico 1 mostra a discrepância e o desvio padrão das coordenadas N, E e h (altitude geométrica).

No gráfico 1, a componente das coordenadas $E$ não apresentam problemas na situação descrita como crítica na metodologia (04 GPS + S38), apenas as componentes $\mathrm{N}$ e h apresenta maior discrepância. Os dados dos satélites SBAS não melhoraram a acurácia das coordenadas, entretanto as mantiveram próximas das verdadeiras. Analisando-se os desvios padrão, nota-se que estes apresentam-se com valores baixos, e estão condizentes com a literatura, onde o comportamento dos desvios padrão nas componentes $\mathrm{E}$ e $\mathrm{N}$ são menores do que na componente $\mathrm{h}$. Para um melhor entendimento, a Tabela 13 demonstra os valores do gráfico 1. 


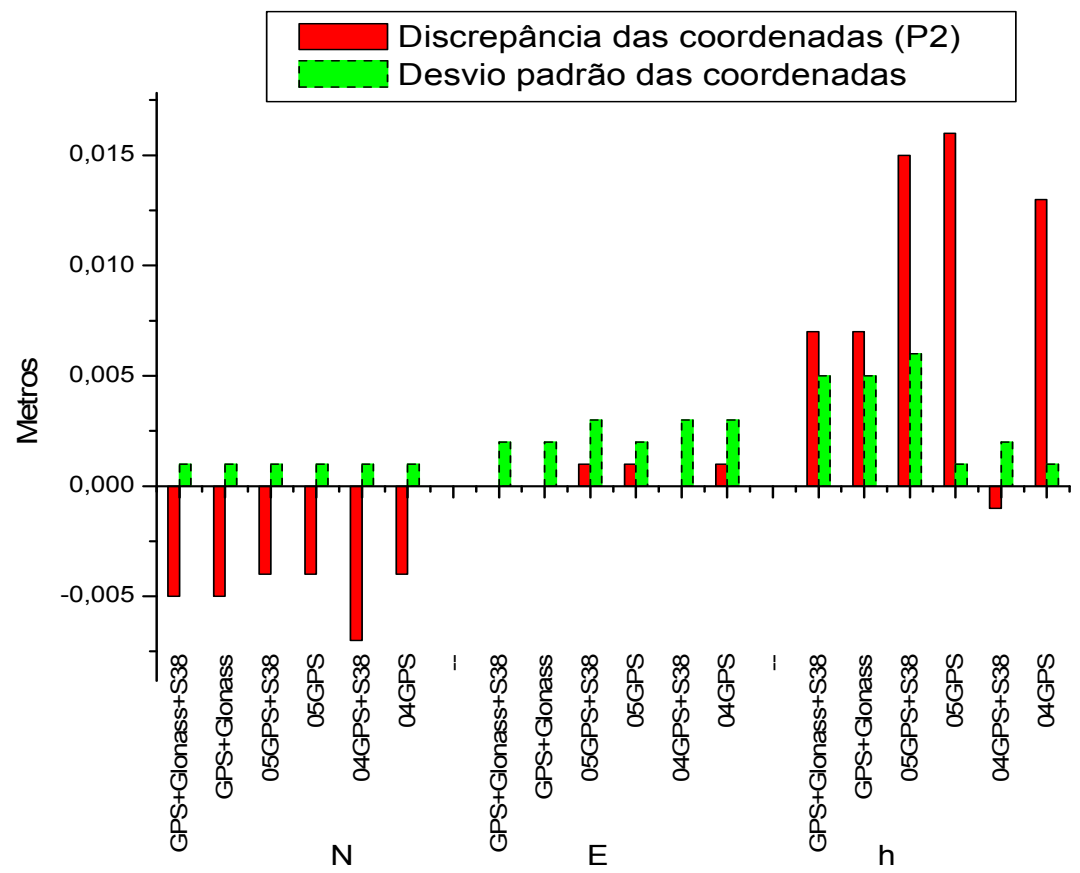

Gráfico 1: Discrepância e Desvio padrão - P2 (N, E,h) (o autor)

Tabela 13: Discrepância - P2 (o autor)

\begin{tabular}{cccc}
\hline Experimento & $\mathbf{N}(\mathbf{m})$ & $\mathbf{E}(\mathbf{m})$ & $\mathbf{h}(\mathbf{m})$ \\
\hline GPS + Glonass +S38 & $-0,005$ & 0,001 & 0,007 \\
05 GPS + S38 & $-0,004$ & 0,001 & 0,015 \\
04 GPS + S38 & $-0,007$ & 0,001 & 0,001 \\
\hline
\end{tabular}

No caso do pilar P3C (linha de base de aproximadamente 165 metros), as coordenadas obtidas com o processamento, utilizando-se a situação ideal ao ser comparada com as coordenadas verdadeiras, têm uma diferença centimétrica (Tabela 14). Ao contrário do que aconteceu no pilar P2, as coordenadas ficam mais distantes das verdadeiras, quando a situação chamada de crítica é apresentada (04 GPS + S38)

Quando adiciona-se os satélites GPS ao processamento, o PDOP passa de 5,5 na situação crítica, regressivamente, chegando em 1,5 quando se tem a situação ideal, conforme a Tabela 9. Quanto mais se adiciona satélites GPS ao processamento, menos se tem a contribuição das observáveis L1 dos satélites SBAS. O Gráfico 2 ilustra as discrepâncias e os desvios-padrão das coordenadas N, E e h. 
Ao analisar as diferenças das coordenadas do ponto P3C, conferimos que a diferença é centimétrica em todos os experimentos realizados. Na Tabela 14 verificase os valores:

\begin{tabular}{cccc}
\multicolumn{4}{c}{ Tabela 14: Discrepância - P3C (o autor) } \\
\hline Experimento & $\mathbf{N}(\mathbf{m})$ & $\mathbf{E}(\mathbf{m})$ & $\mathbf{h}(\mathbf{m})$ \\
\hline GPS + Glonass +S38 & 0,024 & 0,008 & 0,015 \\
05 GPS + S38 & 0,029 & 0,010 & 0,028 \\
04 GPS + S38 & 0,020 & 0,006 & 0,019 \\
\hline
\end{tabular}

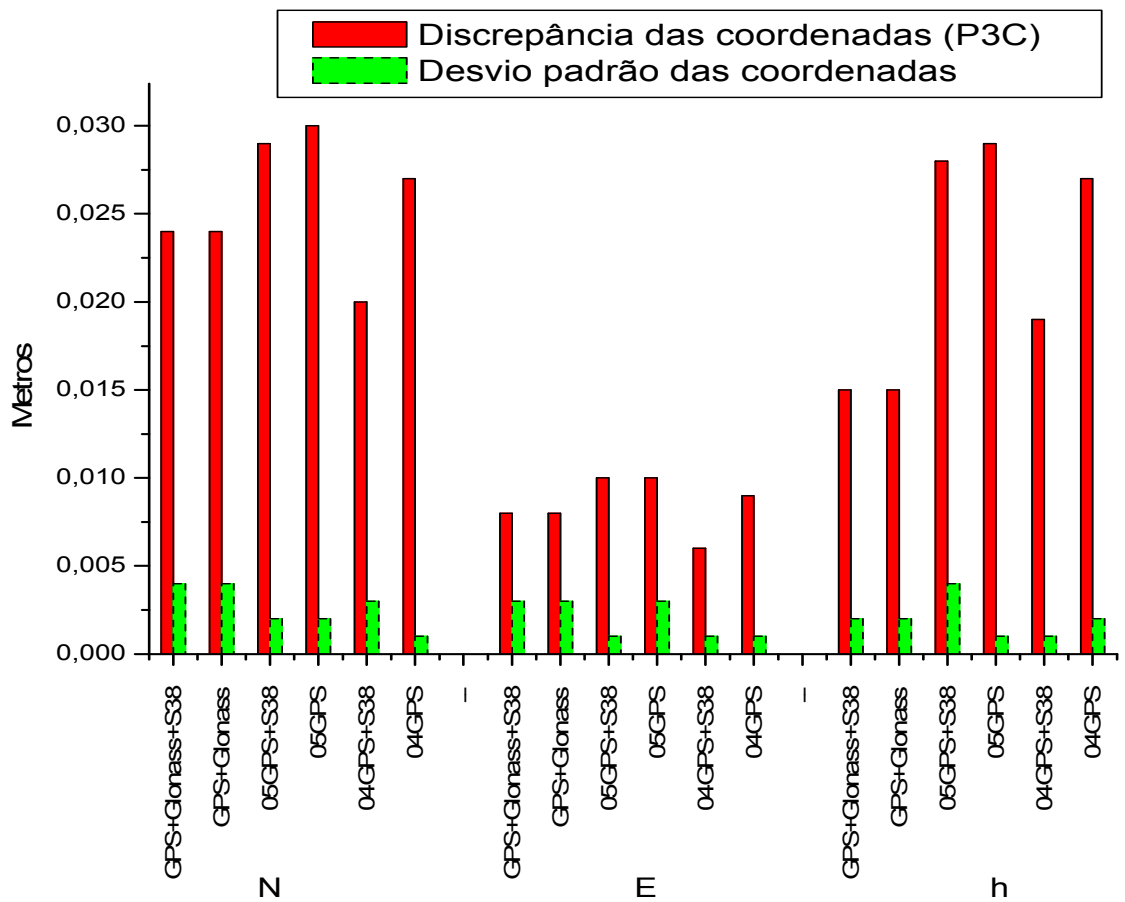

Gráfico 2: Diferenças e Desvio padrão - P3C (N, E, h) (o autor)

No pilar P4, ao se comparar as coordenadas oriundas do processamento com as coordenadas verdadeiras, pode-se verificar que as diferenças são pequenas e que diferem ao milímetro em relação à verdadeira, mesmo em situação considerada crítica 04 GPS + S38, conforme a Tabela 15. As maiores discrepâncias encontramse na componente h que tem valores de aproximadamente 1,5 centímetros.

O PDOP, na situação crítica, é considerado alto, ficando com valor de 4,3 (Tabela 12), mas ao se adicionar, gradativamente, os satélites GPS ao processamento, com isso aumentando a disponibilidade de satélites, ele passa para 
1,4 (Tabela 9). Os valores do RDOP não se alteram se mantendo constante em 1,0, conforme os valores das tabelas, 9, 1011 e 12. O Gráfico 3 esboça a discrepância das coordenadas e seus respectivos desvios-padrão.

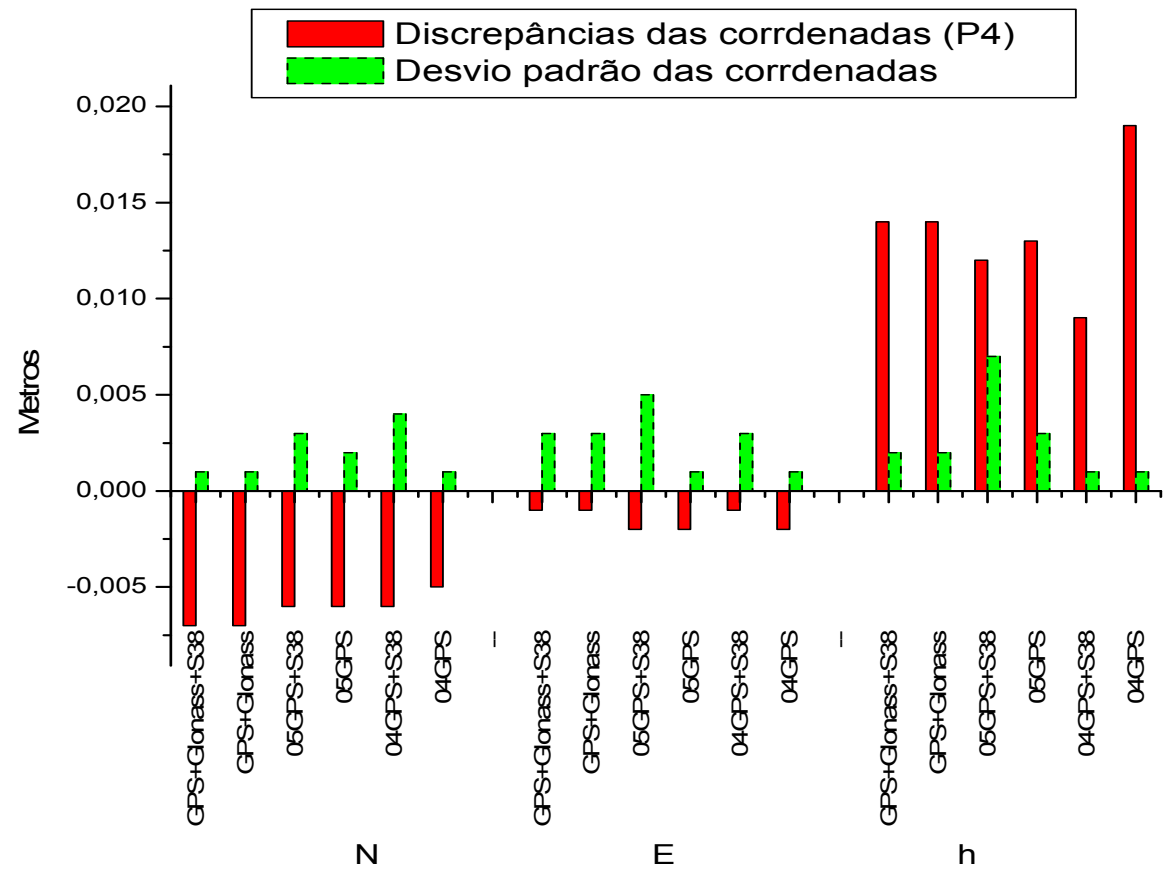

Gráfico 3: Discrepância e Desvio padrão - P4 (N, E, h) (o autor)

Ao se analisar o gráfico 3 , incluindo-se ao processamento o satélite SBAS PRN 138 (S38), nota-se que as coordenadas ficam bem próximas das verdadeiras, quando comparadas às coordenadas verdadeiras. A Tabela 15 elucida as discrepâncias.

\begin{tabular}{cccc}
\multicolumn{4}{c}{ Tabela 15: Discrepância - P4 (o autor) } \\
\hline Experimento & $\mathbf{N}$ & $\mathbf{E}$ & $\mathbf{h}$ \\
\hline GPS + Glonass +S38 & $-0,007$ & $-0,001$ & $-0,014$ \\
05 GPS + S38 & $-0,006$ & $-0,002$ & 0,012 \\
04 GPS + S38 & 0,006 & 0,001 & 0,000 \\
\hline
\end{tabular}

De todos os pilares rastreados, apenas no pilar denominado P3C observou-se "problemas" com as componentes das coordenadas, mesmo quando utilizou-se todos os satélites disponíveis no processamento, ficando as discrepâncias na ordem de centímetros. 
Analisando-se os resultados apresentados até o momento, nota-se que a inclusão das observáveis L1 dos satélites SBAS (PRN 138) ao processamento, foi importante, quando simulou-se o rastreio com o mínimo de satélites, mas não foi determinante para a melhoria da geometria e da acurácia das coordenadas do ponto. Ou seja, esperava-se que ao se adicionar as observáveis L1 dos satélites SBAS ao processamento em conjunto com os observáveis L1 GPS, a qualidade das coordenadas, o PDOP e o RDOP seriam melhores que as coordenadas processadas apenas com os satélites GPS.

Um novo rastreio foi realizado na cidade de São Paulo no dia 06/06/2009, na raia da USP, foram rastreados então os pilares $\mathrm{P} 4$, PIII e P11.

Neste rastreio especificamente, as condições estavam boas, local dos pontos rastreados aberto, com poucas obstruções e com tempo de coleta de 40 minutos para cada pilar.

Ao realizar-se o processamento, verificou-se que no pilar PIII não foram rastreados os satélites SBAS em sua totalidade, acarretando em dados com muita perda de ciclos, assim, não existindo dados suficientes para a realização dos experimentos. Uma possível explicação para não rastrear os satélites SBAS é pelo fato deste ponto estar bem próximo a um muro de aproximadamente 3 metros de altura.

Apenas o rastreio realizado no pilar P4 não apresentou problemas, rastreando durante todo o tempo o satélite SBAS, e suas coordenadas oficiais estão no sítio do IBGE. A Tabela 16 apresenta as coordenadas processadas com diferentes experimentos.

Tabela 16: Coordenadas do Ponto P4 (o autor)

\begin{tabular}{ccccccccc}
\hline Nome & Experimento & $\mathbf{E}(\mathbf{m})$ & $\mathbf{N}(\mathbf{m})$ & Altitude $(\mathbf{m})$ & $\mathbf{S V s}$ & PDOP & RDOP & Solução \\
\hline P4 & 09 GPS + S38 & $323.699,781$ & $7.394 .272,915$ & 724,929 & 10 & 1,8 & - & - \\
P4 & 09 GPS & $323.699,783$ & $7.394 .272,915$ & 724,934 & 9 & 1,9 & 1,00 & Fixa \\
P4 & 04 GPS + S38 & $323.699,779$ & $7.394 .272,912$ & 724,112 & 5 & 5,3 & 1,00 & Fixa \\
P4 & 04 GPS & $323.699,778$ & $7.394 .272,909$ & 724,121 & 4 & 5,5 & 1,00 & Fixa \\
\hline
\end{tabular}

O Gráfico 4 apresenta as diferenças entre as coordenadas processadas e seus desvios padrão e a Tabela 17 mostra os valores das discrepâncias. 


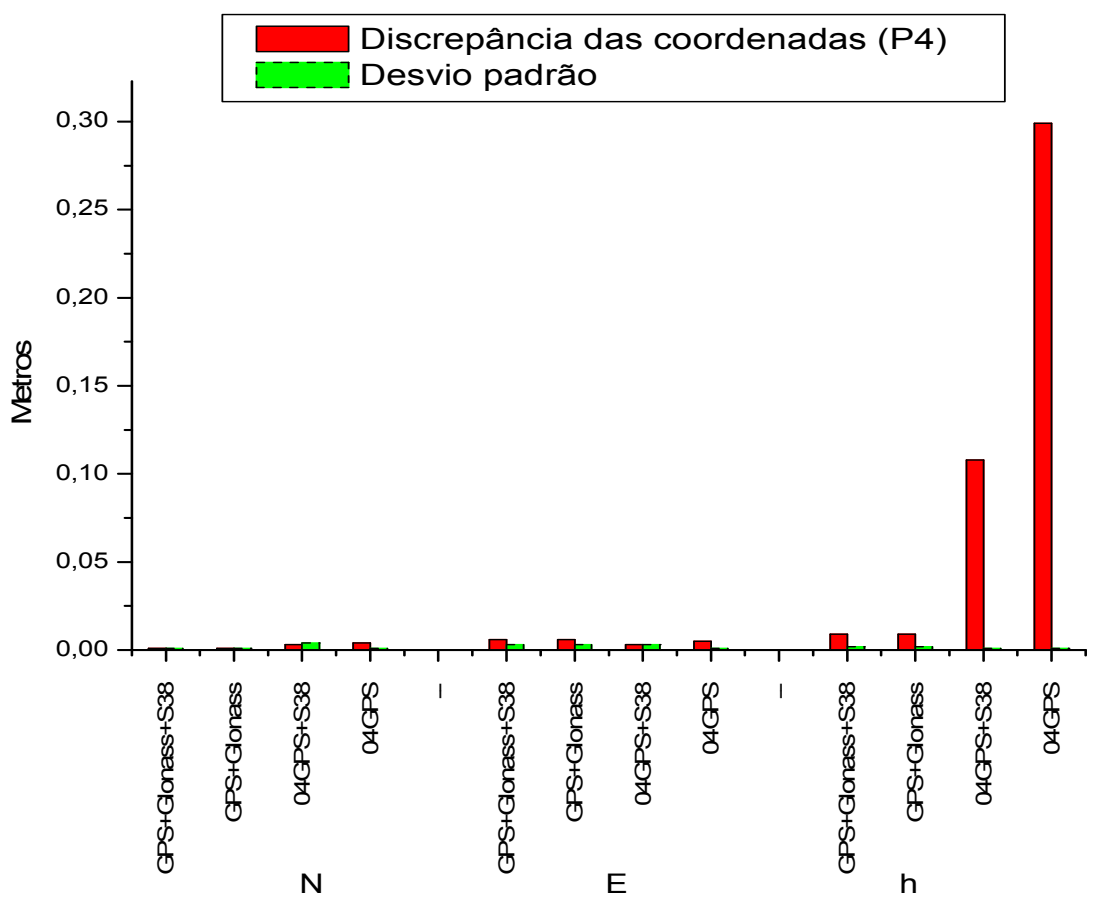

Gráfico 4: Discrepância e Desvio padrão - P4 (N, E, h) (o autor)

Tabela 17: Discrepância - P4 (o autor)

\begin{tabular}{cccc}
\hline Experimento & $\mathbf{N}(\mathbf{m})$ & $\mathbf{E}(\mathbf{m})$ & $\mathbf{h}(\mathbf{m})$ \\
\hline 09 GPS + S38 & 0,001 & $-0,006$ & $-0,009$ \\
09 GPS & $-0,001$ & $-0,006$ & $-0,014$ \\
04 GPS + S38 & 0,003 & $-0,003$ & 0,108 \\
04 GPS & 0,004 & 0,005 & 0,299 \\
\hline
\end{tabular}

Ao observar o gráfico 4 e a tabela 17, verifica-se nos resultados obtidos, nos quais há uma grande disponibilidade de satélites, que as diferenças são pequenas ou seja; muito próximas das coordenadas verdadeiras. Quando a disponibilidade de satélites diminui e adiciona-se as observáveis L1 do satélite SBAS, as diferenças diminuem na coordenada $h$, para 11 centímetros. As coordenadas $N$ e $E$, só apresentam problemas na situação crítica, na qual a quantidade de satélites GPS é precária e ao adicionar o satélite geoestacionário, este não influencia positivamente a acurácia.

No rastreio realizado no dia 14/12/2010, utilizou-se o pilar P2A, com a menor distância entre as linhas de base rastreadas. Ao analisar-se os arquivos obtidos no rastreio, verificou-se que os satélites SBAS PRN 138 e 120 foram rastreados, mas obteve-se dados simultâneos apenas do satélite PRN 138. Após o processamento dos dados obteve-se os valores para as coordenadas $\mathrm{N}, \mathrm{E}$ e $\mathrm{h}$, além do PDOP e ALBARICI, F. L. "POSICIONAMENTO RELATIVO: ANÁLISE DOS RESULTADOS COMBINANDO AS OBSERVÁVEIS L1 DOS SATÉLITES GPS E SBAS" 
RDOP. Verifica-se ao se comparar as coordenadas verdadeiras do ponto P2A na Tabela 8, com as processadas nas Tabelas 18 e 19, que os valores estão próximos das coordenadas verdadeiras, na situação considerada ideal, onde a maior discrepância se encontra na componente $\mathrm{h}$ tendo o seu valor aproximado de quatro centímetros, mas ao se adicionar as observáveis L1 dos satélites SBAS ao processamento os valores das discrepâncias aumentam (Tabela 20).

Tabela 18: Coordenadas Processadas - GPS - SP (o autor)

\begin{tabular}{ccccccccc}
\hline Nome & Descrição & $\mathbf{N}(\mathbf{m})$ & $\mathbf{E}(\mathbf{m})$ & Altitude $(\mathbf{m})$ & SVs & PDOP & RDOP & Solução \\
\hline P2A & 08GPS & $7.394 .473,256$ & $323.309,228$ & 724,836 & 8 & 2,1 & 1 & Fixa \\
P2A & 04 GPS & $7.394 .473,241$ & $323.309,227$ & 724,790 & 4 & 4,0 & 1 & Fixa \\
\hline
\end{tabular}

Tabela 19: Coordenadas Processadas - GPS + SBAS - SP (o autor)

\begin{tabular}{ccccccccc}
\hline Nome & Descrição & $\mathbf{N}(\mathbf{m})$ & $\mathbf{E}(\mathbf{m})$ & Altitude $(\mathbf{m})$ & SVs & PDOP & RDOP & Solução \\
\hline P2A & 08GPS+S38 & $7.394 .473,256$ & $323.309,228$ & 724,836 & 8 & 2,1 & 1 & Fixa \\
P2A & 04GPS+S38 & $7.394 .473,271$ & $323.309,217$ & 724,830 & 4 & 4,0 & 1 & Fixa \\
\hline
\end{tabular}

O Gráfico 5 mostra as discrepâncias obtidas e a Tabela 20 ilustra estes valores.

Quando se processa os dados com apenas cinco satélites GPS a discrepância da coordenada $\mathrm{N}$ é de 1,2 centímetros e ao adicionar os dados SBAS esse valor passa para 8,8 centímetros, o mesmo acontece quando se tem apenas quatro satélites GPS e adiciona-se os dados dos satélites SBAS, a discrepância aumenta de 2 milímetros para 2,8 centímetros. Para o mesmo processamento, na coordenada $\mathrm{E}$, a discrepância é a mesma para os processamentos realizados com a quantidade abundante de satélites GPS, mas ao se realizar o processamento simulando a uma situação de pouca disponibilidade de satélites GPS, ao se adicionar as observáveis SBAS, nota-se que a discrepância aumenta de 5 milímetros para 1,5 centímetros. 


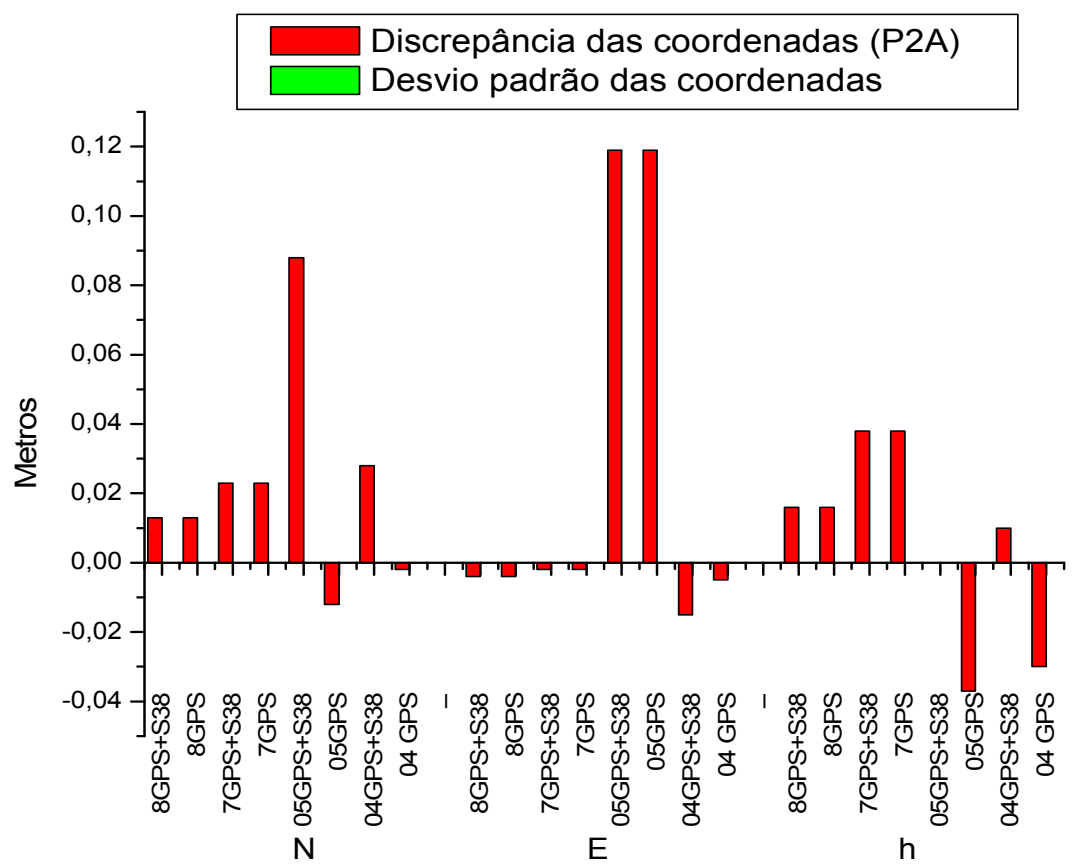

Gráfico 5: Discrepância e Desvio padrão - P2A (N, E, h) (o autor)

\begin{tabular}{cccc}
\multicolumn{2}{c}{ Tabela 20: Discrepância } & $-\mathrm{P} 2 \mathrm{~A}$ (o autor) \\
\hline Experimento & $\mathbf{N}(\mathbf{m})$ & $\mathbf{E}(\mathbf{m})$ & $\mathbf{h}(\mathbf{m})$ \\
\hline 8GPS+S38 & 0,013 & $-0,004$ & 0,016 \\
8GPS & 0,013 & $-0,004$ & 0,016 \\
7GPS+S38 & 0,023 & $-0,002$ & 0,038 \\
7GPS & 0,023 & $-0,002$ & 0,038 \\
05GPS+S38 & 0,088 & 0,119 & 0,000 \\
05GPS & $-0,012$ & 0,119 & $-0,037$ \\
04GPS+S38 & 0,028 & $-0,015$ & 0,010 \\
04 GPS & $-0,002$ & $-0,005$ & $-0,030$ \\
\hline
\end{tabular}

\subsection{Experimento 2}

Para os resultados obtidos dos rastreios na cidade de Nova Venécia - ES são apresentados os resultados de apenas dois rastreios, pois ficaria muito repetitiva a análise de todos os pontos coletados. Um destes rastreios foi realizado em pontos onde não se conhece as coordenadas oficiais, ou seja, não foi colocado em pilares de coordenadas conhecidas, e o outro rastreio que será apresentado, o receptor GPS foi colocado em pilares onde se conhece coordenadas verdadeiras. Para 
utilizar a mesma metodologia aplicada nos rastreios anteriores, as coordenadas obtidas no processamento, utilizando como base as estações da RBMC, serão consideradas como verdadeiras, isso para o caso do rastreio dos pontos que não se conhece as coordenadas oficiais, coordenadas estas obtidas no sitio do IBGE.

Para esta região, os dados se comportaram de maneira praticamente idêntica, pois apenas as observáveis L1 do satélite PRN 120 (EGNOS) foi rastreado na base e no móvel simultaneamente.

Um problema verificado é sobre a rastreabilidade dos satélites SBAS pelo receptor GPS, a Figura 29 mostra o local onde foi realizado o rastreio, pode-se notar que é um local aberto, sem obstruções e a antena está a dois metros de altura.

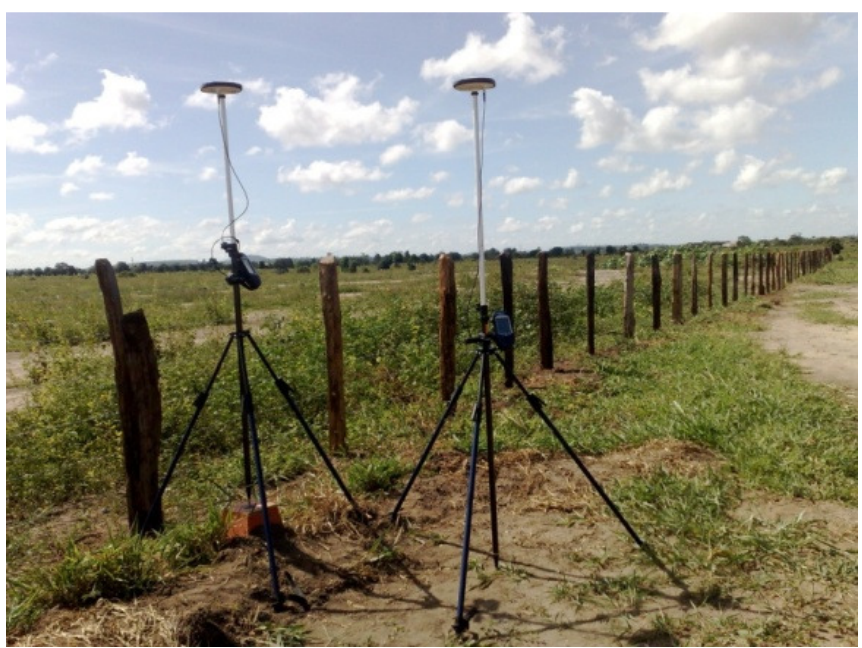

Figura 29 : Vista local rastreio Nova Venécia - ES

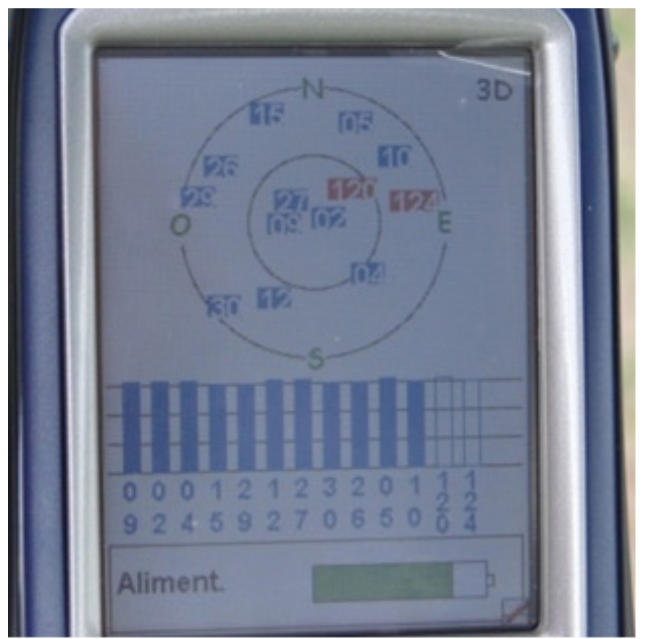

Base - Satélites PRN 120 e 124

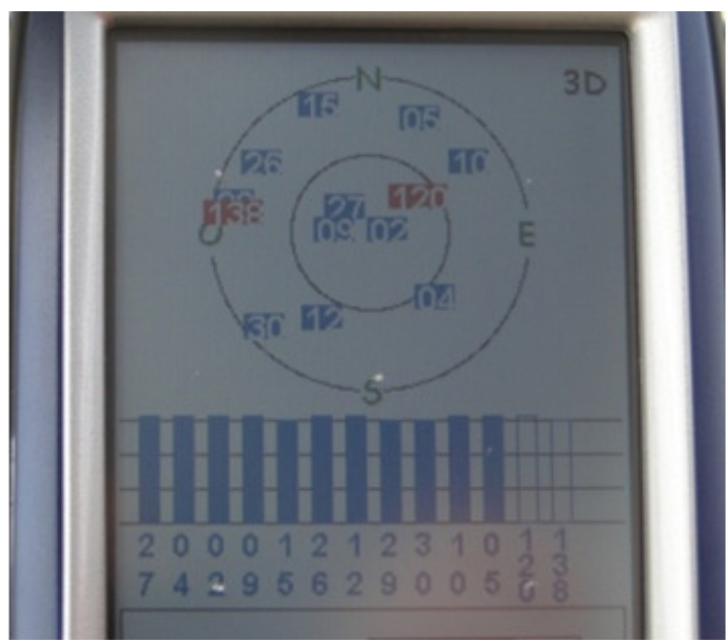

Móvel - Satélites PRN 120 e 138

Figura 30: Vista Receptor GPS 
A figura 30 ilustra os receptores GPS em campo no momento do rastreio, pode-se observar que eles rastreiam os mesmos satélites GPS. Entretanto, para o caso dos satélites SBAS é diferente, pois nota-se que eles apenas rastreiam o PRN 120 simultaneamente, já o PRN 124 e 138 não são rastreados simultaneamente, eles ficam sendo rastreados por certos períodos de tempo, não tendo dados suficientes e com muita perda de ciclos. Esse problema aconteceu em todos os rastreios realizados na cidade de Nova Venécia - ES. Algumas possíveis explicações são (informação verbal ${ }^{1}$ ): os receptores não possuírem a mesma versão de firmware (programa interno do receptor) e após cada rastreio, apagar todos os dados (reset) do receptor, para que não fique em sua memória dados sobre os satélites SBAS. Para estes rastreios em específico, a versão do firmware é a mesma nos dois receptores, sendo necessário novos rastreios para a realização de testes e estudos sobre este problema. Acredita-se que o receptor GPS, quando não se apagam os dados de sua memória, ao ser ligado para nova coleta de dados, rastreie primeiramente os satélites SBAS que estão em sua memória.

A Tabela 21 mostra as coordenadas verdadeiras dos pilares utilizados na cidade de Nova Venécia - ES (NV).

\begin{tabular}{ccccc}
\multicolumn{4}{c}{ Tabela 21: Coordenadas Verdadeiras - Nova Venécia (o autor) } \\
\hline Nome & $\mathbf{N}(\mathbf{m})$ & $\mathbf{E}(\mathbf{m})$ & Altitude $(\mathbf{m})$ & Linda de base $(\mathbf{m})$ \\
\hline P8114 & $7.932 .696,952$ & $349.437,655$ & 166,970 & Base \\
990A & $7.930 .345,915$ & $354.839,866$ & 73,957 & 65,525 \\
990B & $7.930 .274,740$ & $354.850,482$ & 72,722 & 111,646 \\
P001 & $7.933 .423,284$ & $350.511,842$ & 168,013 & $1.296,894$ \\
Deb1 & $7.932 .695,795$ & $349.437,104$ & 166,997 & $1.282,000$ \\
\hline \multicolumn{5}{c}{}
\end{tabular}

Os dados do processamento são apresentados nas Tabelas 22, 23, 24 e 25.

Tabela 22: Coordenadas Processadas - Situação ideal - Com SBAS / NV (o autor)

\begin{tabular}{ccccccccc}
\hline Nome & Experimento & $\mathbf{E}(\mathbf{m})$ & $\mathbf{N}(\mathbf{m})$ & Altitude $(\mathbf{m})$ & $\mathbf{S V s}$ & PDOP & RDOP & Solução \\
\hline 991A & 10GPS+S20 & $7.930 .360,468$ & $354.778,958$ & 93,224 & 11 & 1,7 & 1,76 & Base \\
991B & 10GPS+S20 & $7.930 .355,467$ & $354.776,162$ & 93,219 & 11 & 1,8 & 1,76 & Base \\
990A & 10GPS+S20 & $7.930 .345,915$ & $354.839,866$ & 73,957 & 11 & 1,7 & 1,76 & Fixa \\
990B & 10GPS+S20 & $7.930 .274,740$ & $354.850,482$ & 72,722 & 11 & 1,8 & 1,76 & Fixa \\
\hline
\end{tabular}

\footnotetext{
1 SASS., J. ( Magellan, USA) Conversa pessoal. Encontro dos representantes Magellan, 2009, São Paulo
} 
Tabela 23: Coordenadas Processadas - Situação Ideal - Sem SBAS / NV (o autor)

\begin{tabular}{ccccccccc}
\hline Nome & Experimento & $\mathbf{E}(\mathbf{m})$ & $\mathbf{N}(\mathbf{m})$ & Altitude $(\mathbf{m})$ & $\mathbf{S V s}$ & PDOP & RDOP & Solução \\
\hline 991A & 10GPS & $7.930 .360,468$ & $354.778,958$ & 93,224 & 11 & 1,7 & 1,76 & Base \\
991B & 10GPS & $7.930 .355,467$ & $354.776,162$ & 93,219 & 11 & 1,8 & 1,76 & Base \\
990A & 10GPS & $7.930 .345,915$ & $354.839,866$ & 73,957 & 11 & 1,7 & 1,76 & Fixa \\
990B & 10GPS & $7.930 .274,740$ & $354.850,482$ & 72,722 & 11 & 1,8 & 1,76 & Fixa \\
\hline
\end{tabular}

Tabela 24: Coordenadas Processadas - Situação Crítica - Com SBAS /NV (o autor)

\begin{tabular}{ccccccccc}
\hline Nome & Experimento & $\mathbf{E}(\mathbf{m})$ & $\mathbf{N}(\mathbf{m})$ & Altitude $(\mathbf{m})$ & $\mathbf{S V s}$ & PDOP & RDOP & Solução \\
\hline 991A & 04GPS+S20 & $7.930 .360,468$ & $354.778,958$ & 93,224 & 4 & 6,0 & 2,03 & Base \\
991B & 04GPS+S20 & $7.930 .355,467$ & $354.776,162$ & 93,219 & 4 & 6,1 & 2,03 & Base \\
990A & 04GPS+S20 & $7.930 .346,214$ & $354.840,134$ & 74,060 & 4 & 6,0 & 2,03 & Fixa \\
990B & 04GPS+S20 & $7.930 .275,040$ & $354.850,757$ & 72,797 & 4 & 6,1 & 2,03 & Fixa \\
\hline
\end{tabular}

Tabela 25: Coordenadas Processadas - Situação Crítica - Sem SBAS / NV (o autor)

\begin{tabular}{ccccccccc}
\hline Nome & Experimento & $\mathbf{E}(\mathbf{m})$ & $\mathbf{N}(\mathbf{m})$ & Altitude $(\mathbf{m})$ & $\mathbf{S V s}$ & PDOP & RDOP & Solução \\
\hline 991A & 04GPS & $7.930 .360,468$ & $354.778,958$ & 93,224 & 4 & 6,0 & 2,03 & Base \\
991B & 04GPS & $7.930 .355,467$ & $354.776,162$ & 93,219 & 4 & 6,1 & 2,03 & Base \\
990A & 04GPS & $7.930 .346,214$ & $354.840,134$ & 74,060 & 4 & 6,0 & 2,03 & Fixa \\
990B & 04GPS & $7.930 .275,040$ & $354.850,757$ & 72,797 & 4 & 6,1 & 2,03 & Fixa \\
\hline
\end{tabular}

Constatou-se nos experimentos efetuados que as coordenadas não se alteram, com a adição das observáveis L1 do satélite PRN 120, há uma diferença de 30 centímetros na coordenada N e 27 centímetros na coordenada E (Tabela 26), na situação crítica, quando comparada à coordenada verdadeira.

Quando se dispõe de apenas 04 satélites GPS e adiciona-se as observáveis do satélite PRN 120 para que se tivesse no mínimo 05 satélites para processamento, o software não contabilizava o satélite SBAS no número de satélites utilizados, o mesmo aconteceu quando havia 10 satélites GPS e era inserido as observáveis do satélite SBAS ao processamento. Com base nesta análise e verificando que as coordenadas não se alteram, com ou sem a utilização dos satélites SBAS, pode-se dizer que as observáveis L1 do satélite PRN 120 (EGNOS) não foi utilizado no processamento, ou que estas observáveis não contribuíram no posicionamento nem positiva nem negativamente.

Em todas as coordenadas, a adição das observáveis L1 do satélite PRN 120 não provocou melhoria na acurácia do posicionamento, no RDOP e no PDOP. Ao se verificar os gráficos, nota-se que as coordenadas estão próximas as consideradas verdadeiras, mas na situação crítica, as diferenças são acentuadas.

Para elucidar estas diferenças, são apresentados os gráficos 6 e 7 e também as Tabelas 26 e 27. 


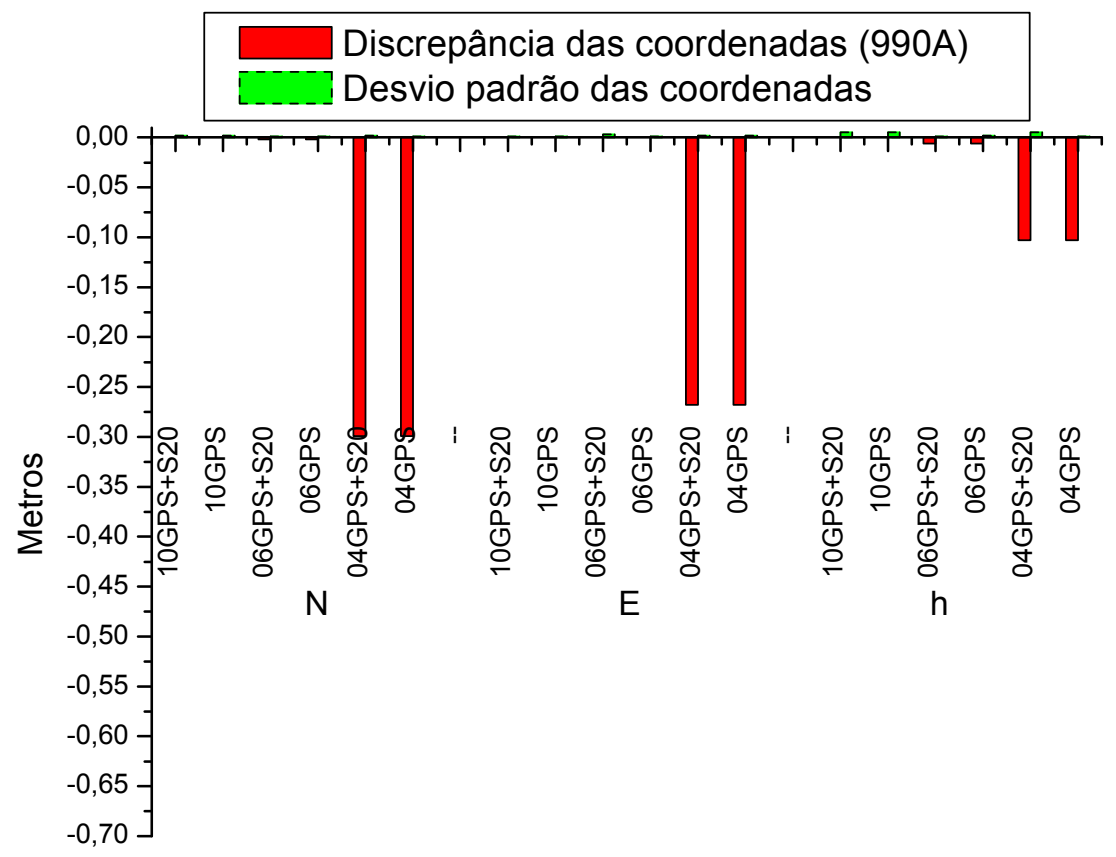

Gráfico 6: Discrepâncias e desvio padrão- P990A (N, E, h) (o autor)

Tabela 26: Discrepância - Nova Venécia (o autor)

\begin{tabular}{cccc}
\hline Experimento & $\mathbf{N}(\mathbf{m})$ & $\mathbf{E}(\mathbf{m})$ & $\mathbf{h}(\mathbf{m})$ \\
\hline 10 GPS & 0,000 & 0,000 & 0,000 \\
06GPS+S20 & $-0,002$ & 0,000 & $-0,006$ \\
06GPS & $-0,002$ & 0,000 & $-0,006$ \\
04 GPS +S20 & $-0,299$ & $-0,268$ & $-0,103$ \\
04 GPS & $-0,299$ & $-0,268$ & $-0,103$ \\
\hline
\end{tabular}

Nota-se nos gráficos 6 e 7, e é verificado nas tabelas 26 e 27, que não há diferenças entre os dados processados com e sem as observáveis SBAS. Ou seja, após o processamento com as observáveis L1 dos satélites GPS, ao adicionar no processamento as observáveis L1 do satélite PRN 120, as coordenadas não se alteraram, e ao se comparar os resultados obtidos nos dois processamentos (apenas GPS e GPS+SBAS) com as coordenadas verdadeiras as discrepâncias são as mesmas. 


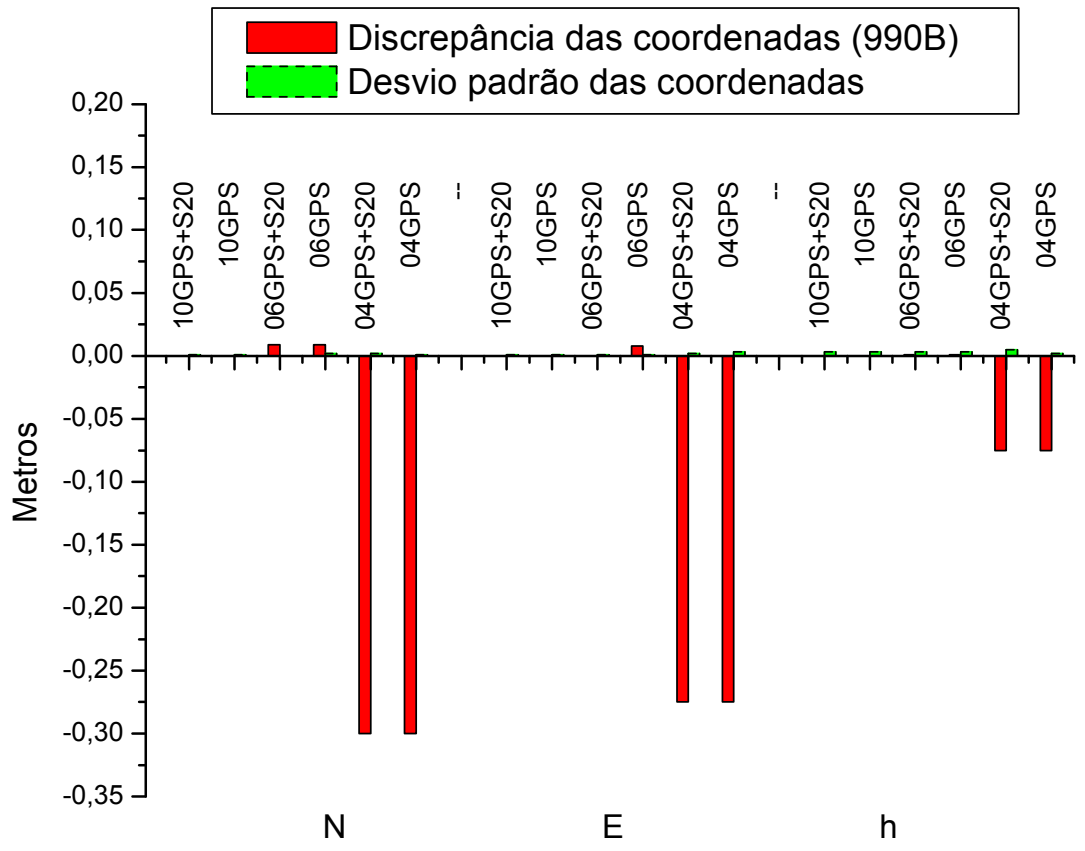

Gráfico 7: Discrepâncias e desvio padrão-P990B (N, E, h) (o autor)

\begin{tabular}{cccc}
\multicolumn{4}{c}{ Tabela 27: Discrepância - P990B (o autor) } \\
\hline Experimento & $\mathbf{N}$ & $\mathbf{E}$ & $\mathbf{h}$ \\
\hline 10GPS+S20 & 0,000 & 0,000 & 0,000 \\
10GPS & 0,000 & 0,000 & 0,000 \\
06GPS+S20 & 0,009 & 0,000 & 0,001 \\
06GPS & 0,009 & 0,008 & 0,001 \\
04GPS+S20 & $-0,300$ & $-0,275$ & $-0,075$ \\
04GPS & $-0,300$ & $-0,275$ & $-0,075$ \\
\hline
\end{tabular}

Os resultados obtidos nos processamentos realizados em Nova Venécia ES, nos quais os receptores GPS foram instalados em pilares de coordenadas conhecidas são apresentados nas tabelas 28 a 31 com a situação ideal e a crítica, respectivamente. Os Gráficos 8 e 9 indicam as discrepâncias das coordenadas N, E e $\mathrm{h}$ bem como seus desvios-padrão, com e sem a utilização das observáveis SBAS.

Tabela 28: Coordenadas Processadas situação ideal - Com SBAS - P001 e Deb1 (o autor)

\begin{tabular}{ccccccccc}
\hline Nome & Experimento & $\mathbf{E}(\mathbf{m})$ & $\mathbf{N}(\mathbf{m})$ & Altitude $(\mathbf{m})$ & SVs & PDOP & RDOP & Solução \\
\hline P8114 & 11GPS+S20 & $7.932 .696,952$ & $349.437,655$ & 166,970 & 11 & 1,5 & 1,44 & Base \\
P001 & 11GPS+S20 & $7.933 .423,284$ & $350.511,842$ & 168,013 & 11 & 1,5 & 1,44 & Fixo \\
Deb1 & 11GPS+S20 & $7.932 .695,795$ & $349.437,104$ & 166,997 & 11 & 1,3 & 1,44 & Fixo \\
\hline
\end{tabular}


Tabela 29: Coordenadas Processadas situação ideal - Sem SBAS - P001 e Deb1 (o autor)

\begin{tabular}{ccccccccc}
\hline Nome & Experimento & $\mathbf{E}(\mathbf{m})$ & $\mathbf{N}(\mathbf{m})$ & Altitude $(\mathbf{m})$ & $\mathbf{S V s}$ & PDOP & RDOP & Solução \\
\hline P8114 & 11GPS & $7.932 .696,952$ & $349.437,655$ & 166,970 & 11 & 1,5 & 1,44 & Base \\
P001 & 11GPS & $7.933 .423,284$ & $350.511,842$ & 168,013 & 11 & 1,5 & 1,44 & Fixo \\
Deb1 & 11GPS & $7.932 .695,795$ & $349.437,104$ & 166,997 & 11 & 1,3 & 1,44 & Fixo \\
\hline
\end{tabular}

Tabela 30: Coordenadas Processadas situação crítica - Com SBAS - P001 e Deb1(o autor)

\begin{tabular}{ccccccccc}
\hline Nome & Experimento & $\mathbf{E}(\mathbf{m})$ & $\mathbf{N}(\mathbf{m})$ & Altitude $(\mathbf{m})$ & SVs & PDOP & RDOP & Solução \\
\hline P8114 & 04GPS+S20 & $7.932 .696,952$ & $349.437,655$ & 166,970 & 4 & 3,2 & 2,03 & Base \\
P001 & 04GPS+S20 & $7.933 .423,264$ & $350.511,847$ & 168,032 & 4 & 3,2 & 2,03 & Fixo \\
Deb1 & 04GPS+S20 & $7.932 .695,798$ & $349.437,102$ & 167,000 & 4 & 5,5 & 2,03 & Fixo \\
\hline
\end{tabular}

Tabela 31: Coordenadas Processadas situação crítica - Sem SBAS - P001 e Deb1(o autor)

\begin{tabular}{ccccccccc}
\hline Nome & Experimento & $\mathbf{E}(\mathbf{m})$ & $\mathbf{N}(\mathbf{m})$ & Altitude $(\mathbf{m})$ & SVs & PDOP & RDOP & Solução \\
\hline P8114 & 04GPS & $7.932 .696,952$ & $349.437,655$ & 166,970 & 4 & 3,2 & 2,03 & Base \\
P001 & 04GPS & $7.933 .423,264$ & $350.511,847$ & 168,032 & 4 & 3,2 & 2,03 & Fixo \\
Deb1 & 04GPS & $7.932 .695,798$ & $349.437,102$ & 167,000 & 4 & 5,5 & 2,03 & Fixo \\
\hline
\end{tabular}

Observa-se nos gráficos 8 e 9, que os resultados possuem comportamentos semelhantes, o que significa dizer que as observáveis L1 do satélite PRN 120 ao serem adicionados ao processamento em conjunto com as observáveis dos satélites GPS não influenciaram na acurácia das coordenadas, nem na melhoria das condições do rastreio (PDOP e RDOP), tanto na situação ideal, quanto na situação crítica, isto é, a utilização das observáveis SBAS não se traduziu em melhora ou piora das coordenadas. As Tabelas 32 e 33 apresentam as discrepâncias encontradas no processamento.

\begin{tabular}{|c|c|c|c|}
\hline Experimento & $\mathbf{N}(\mathbf{m})$ & $E(m)$ & $h(m)$ \\
\hline $11 \mathrm{GPS}+\mathrm{S} 20$ & 0,000 & 0,000 & 0,000 \\
\hline 11GPS & 0,000 & 0,000 & 0,000 \\
\hline 05GPS+S20 & $-0,005$ & 0,001 & $-0,004$ \\
\hline 05GPS & $-0,005$ & 0,001 & $-0,004$ \\
\hline 04GPS+S20 & $-0,003$ & 0,002 & $-0,003$ \\
\hline 04GPS & $-0,003$ & 0,002 & $-0,003$ \\
\hline
\end{tabular}




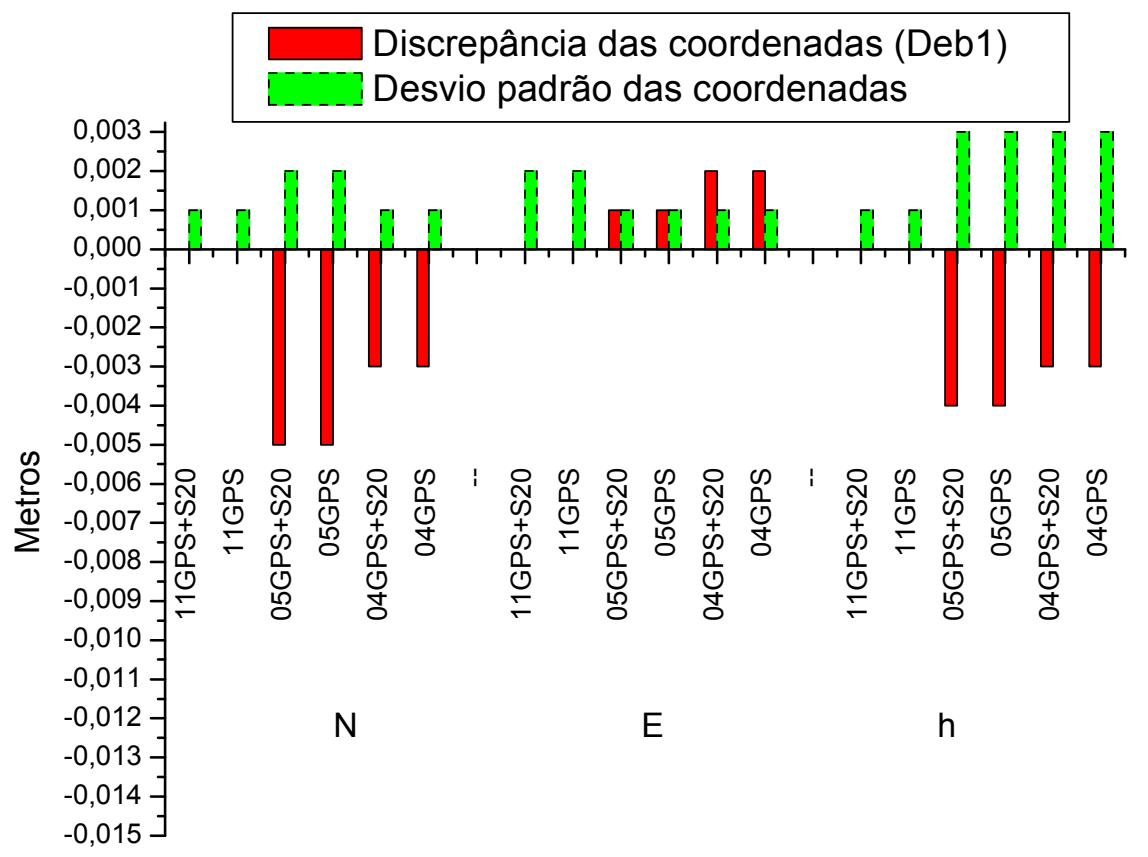

Gráfico 8: Discrepância e desvio padrão - PDeb1 (N, E, h) (o autor)

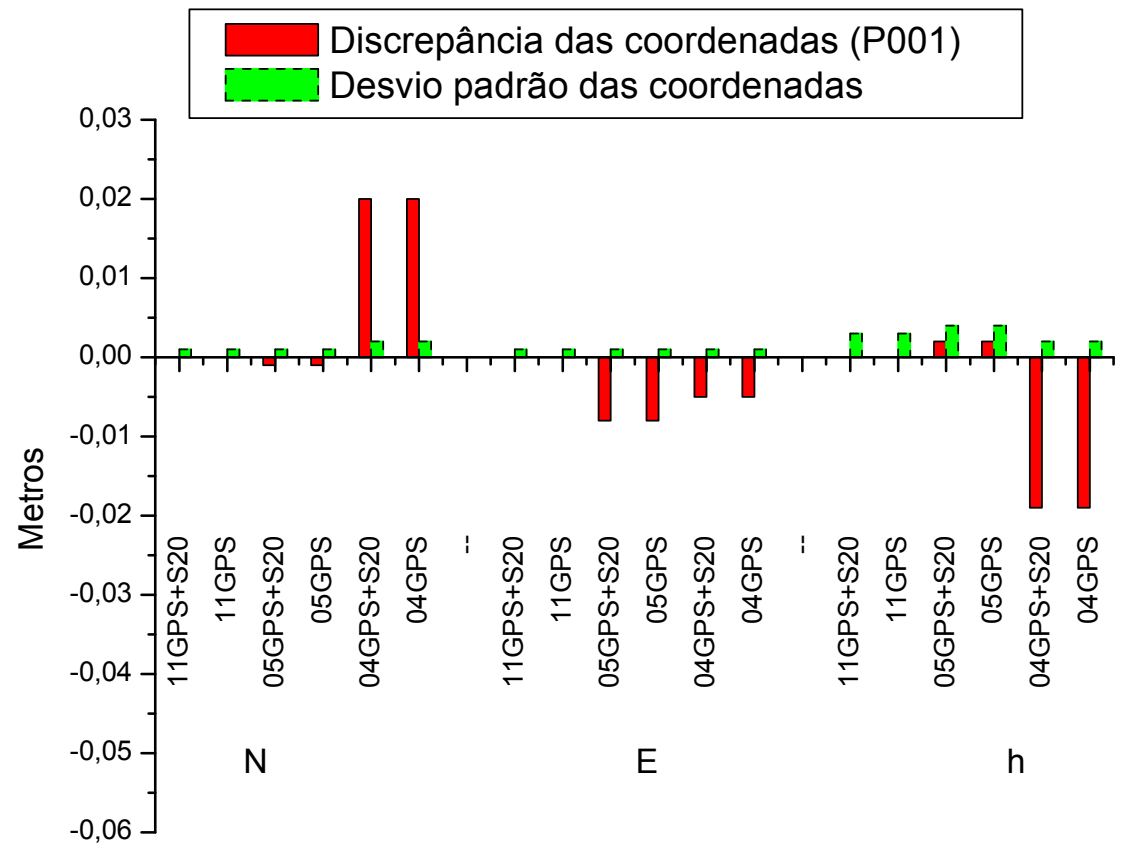

Gráfico 9: Discrepância e desvio padrão- P001 (N, E, h) (o autor) 
Tabela 33: Discrepância - Ponto P001 (o autor)

\begin{tabular}{cccc}
\hline Experimento & $\mathbf{N}(\mathbf{m})$ & $\mathbf{E}(\mathbf{m})$ & $\mathbf{h}(\mathbf{m})$ \\
\hline 11GPS+S20 & 0,000 & 0,000 & 0,000 \\
11GPS & 0,000 & 0,000 & 0,000 \\
05GPS+S20 & $-0,001$ & $-0,008$ & 0,002 \\
05GPS & $-0,001$ & $-0,008$ & 0,002 \\
04GPS+S20 & 0,020 & $-0,005$ & $-0,019$ \\
04GPS & 0,020 & $-0,005$ & $-0,019$ \\
\hline
\end{tabular}

\subsection{Experimento 3}

No rastreio realizado na cidade do Rio de Janeiro, o ponto base foi transportado para a torre de controle do autódromo e os dados foram importados para o GNSS Solution. No processamento realizado foi utilizado como base o ponto 1016, cujas coordenadas são conhecidas. A Tabela 34 mostra as coordenadas verdadeiras.

Tabela 34: Coordenadas Verdadeiras - Rio de Janeiro (o autor)

\begin{tabular}{ccccc}
\hline Nome & $\mathbf{N}(\mathbf{m})$ & $\mathbf{E}(\mathbf{m})$ & Altitude $(\mathbf{m})$ & Vetor $(\mathbf{m})$ \\
\hline 1016 & $7.458 .350,663$ & $664.343,226$ & 34,510 & 1,138 \\
8002 & $7.458 .351,430$ & $664.344,082$ & 34,648 & 1,138 \\
\hline
\end{tabular}

Os dados processados na cidade do Rio de Janeiro serão apresentados nas Tabelas 35, 36, 37 e 38, respectivamente.

Tabela 35: Coordenadas Processadas situação ideal - Com SBAS /RJ (o autor)

\begin{tabular}{ccccccccc}
\hline Nome & Experimento & $\mathbf{E}(\mathbf{m})$ & $\mathbf{N}(\mathbf{m})$ & Altitude $(\mathbf{m})$ & $\mathbf{S V s}$ & PDOP & RDOP & Solução \\
\hline 1016 & $11 \mathrm{GPS}+S 38$ & $7.458 .350,66$ & $664.343,25$ & 34,51 & 11 & 1,4 & -1 & 1,138 \\
8002 & $11 \mathrm{GPS}+\mathrm{S} 38$ & $7.458 .351,43$ & $664.344,08$ & 34,648 & 11 & 1,4 & -1 & 1,138 \\
\hline
\end{tabular}

Tabela 36: Coordenadas Processadas situação crítica - Sem SBAS/RJ (o autor)

\begin{tabular}{ccccccccc}
\hline Nome & Experimento & $\mathbf{E}(\mathbf{m})$ & $\mathbf{N}(\mathbf{m})$ & Altitude $(\mathbf{m})$ & $\mathbf{S V s}$ & PDOP & RDOP & Solução \\
\hline 1016 & $11 \mathrm{GPS}$ & $7.458 .350,66$ & $664.343,25$ & 34,551 & 10 & 1,4 & -1 & 1,138 \\
8002 & $11 \mathrm{GPS}$ & $7.458 .351,43$ & $664.344,08$ & 34,648 & 10 & 1,4 & -1 & 1,138 \\
\hline
\end{tabular}


Tabela 37: Coordenadas Processadas situação crítica - Com SBAS/RJ (o autor)

\begin{tabular}{ccccccccc}
\hline Nome & Experimento & $\mathbf{E}(\mathbf{m})$ & $\mathbf{N}(\mathbf{m})$ & Altitude $(\mathbf{m})$ & $\mathbf{S V s}$ & PDOP & RDOP & Solução \\
\hline 1016 & 04GPS+S38 & $7.458 .350,66$ & $664.343,25$ & 34,551 & 5 & 2,6 & -1 & 1,138 \\
8002 & 04GPS $+S 38$ & $7.458 .351,43$ & $664.344,08$ & 34,653 & 5 & 2,7 & -1 & 1,138 \\
\hline
\end{tabular}

Tabela 38: Coordenadas Processadas situação crítica - Sem SBAS/RJ (o autor)

\begin{tabular}{ccccccccc}
\hline Nome & Experimento & $\mathbf{E}(\mathbf{m})$ & $\mathbf{N}(\mathbf{m})$ & Altitude $(\mathbf{m})$ & $\mathbf{S V s}$ & PDOP & RDOP & Solução \\
\hline 1016 & 04GPS & $7.458 .350,66$ & $664.343,25$ & 34,551 & 4 & 3,1 & -1 & 1,138 \\
8002 & 04GPS & $7.458 .351,43$ & $664.344,08$ & 34,653 & 4 & 3,2 & -1 & 1,138 \\
\hline
\end{tabular}

Neste processamento, o satélite SBAS que foi rastreado continuamente é o S38 (PRN 138), como no rastreio realizado na cidade de São Paulo.

Através das discrepâncias obtidas, verifica-se que quando há grande disponibilidade de satélites, as observáveis $L 1$ do satélite S38 não têm influência na acurácia das coordenadas, no PDOP e no RDOP, mas ao se analisar a situação crítica (apenas 04 GPS), as coordenadas possuem maior discrepância, ao adicionar as observáveis do satélite $\mathrm{S} 38$ ao processamento, esta coordenada não tem melhora na acurácia, mas o PDOP tem uma pequena melhora, passando de 3,2 para 2,7 não houve alteração no RDOP. O Gráfico 10 mostra as discrepâncias obtidas nos vários processamentos realizados e Tabela 39 mostra os valores destas discrepâncias.

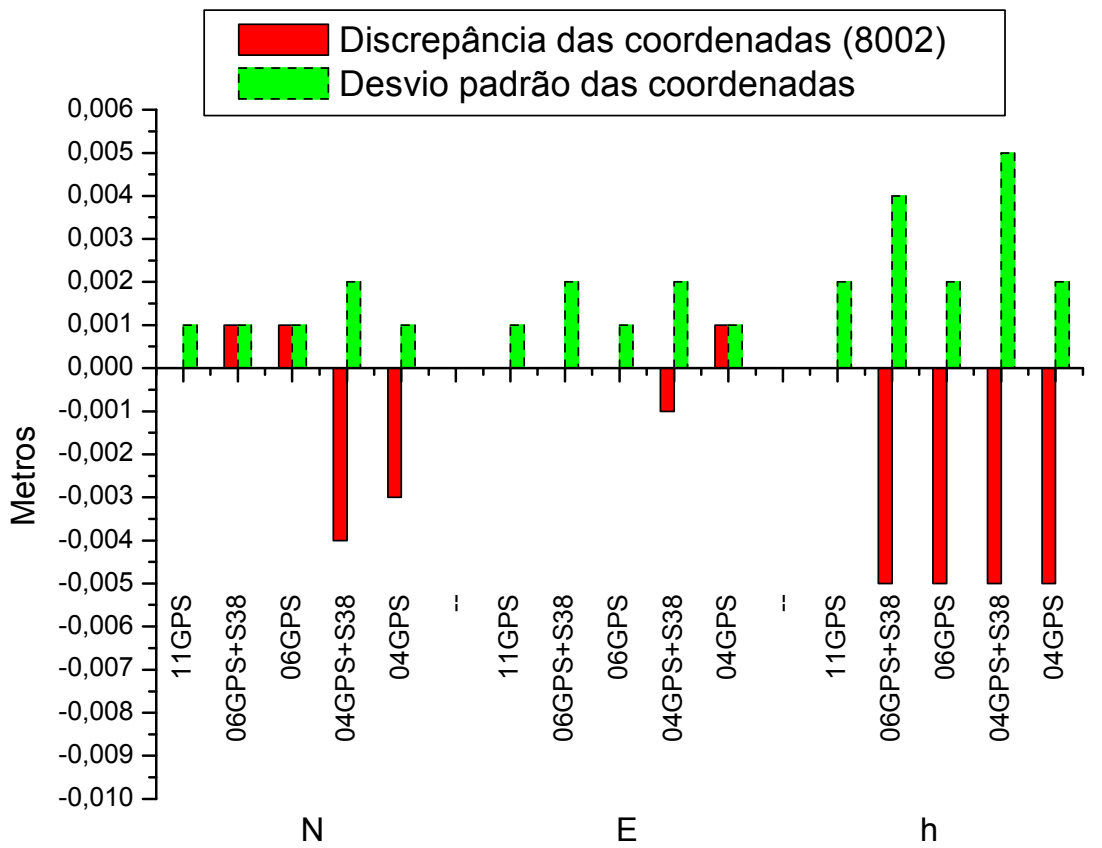

Gráfico 10: Discrepância e desvio-padrão - P8002 (N, E, h) (o autor) 
Tabela 39: Discrepância - P8002 (o autor)

\begin{tabular}{cccc}
\hline Experimento & $\mathbf{N}(\mathbf{m})$ & $\mathbf{E}(\mathbf{m})$ & $\mathbf{h}(\mathbf{m})$ \\
\hline $11 \mathrm{GPS}$ & 0,000 & 0,000 & 0,000 \\
06GPS+S38 & 0,001 & 0,000 & $-0,005$ \\
06GPS & 0,001 & 0,000 & $-0,005$ \\
04GPS+S38 & $-0,004$ & $-0,001$ & $-0,005$ \\
04GPS & $-0,003$ & 0,001 & $-0,005$ \\
\hline
\end{tabular}

\subsection{Experimento 4}

Para os dois rastreios realizados na cidade de Mossoró - RN, será apresentado o gráfico de apenas um ponto dos rastreios realizados, para não ficar repetitivo, pois dos vários pontos rastreados, os resultados obtidos nos processamentos são muito semelhantes. Em cada um dos rastreios realizados, os satélites SBAS visualizados pelos receptores GPS são diferentes. As coordenadas verdadeiras são apresentadas na Tabela 40.

Tabela 40: Coordenadas Verdadeiras - Mossoró (o autor)

\begin{tabular}{cccccc}
\hline Nome & $\mathbf{N}(\mathbf{m})$ & $\mathbf{E}(\mathbf{m})$ & Altitude $(\mathbf{m})$ & Vetor $(\mathbf{m})$ & Solução \\
\hline 35 & $9.446 .971,827$ & $712.880,650$ & 74,509 & --------- & Base \\
319 & $9.448 .176,182$ & $712.006,478$ & 46,965 & $1.488,202$ & Fixa \\
320 & $9.448 .087,782$ & $711.959,854$ & 48,167 & $1.446,821$ & Fixa \\
409 & $9.447 .999,442$ & $711.913,674$ & 50,805 & $1.411,030$ & Fixa \\
410 & $9.447 .910,043$ & $711.867,345$ & 50,223 & $1.380,963$ & Fixa \\
411 & $9.447 .850,396$ & $711.835,259$ & 50,471 & $1.365,558$ & Fixa \\
413 & $9.447 .821,843$ & $711.820,380$ & 50,357 & $1.358,946$ & Fixa \\
419 & $9.447 .375,921$ & $711.592,652$ & 43,377 & $1.350,059$ & Fixa \\
\hline
\end{tabular}

Este rastreio foi o único caso onde dois satélites SBAS (PRN 120 e 124) diferentes foram rastreados simultaneamente no receptor base e também no móvel.

Após o processamento dos dados são apresentadas às coordenadas na situação ideal e também na situação crítica nas Tabelas 41, 42, 43 e 44. 
Tabela 41: Coordenadas Processadas situação ideal - Com SBAS/Mossoró (o autor)

\begin{tabular}{cccccccccc}
\hline Nome & Descrição & $\mathbf{N}(\mathbf{m})$ & $\mathbf{E}(\mathbf{m})$ & Altitude $(\mathbf{m})$ & SVS & PDOP & RDOP & Vetor $(\mathbf{m})$ & Solução \\
\hline 35 & 09GPS+S20 & $9.446 .971,83$ & $712.880,65$ & 74,509 & 9 & 1,9 & 0,35 & $1.411,03$ & Base \\
409 & 09GPS+S20 & $9.447 .999,44$ & $711.913,67$ & 50,805 & 9 & 1,9 & 0,35 & $1.411,03$ & Fixa \\
\hline
\end{tabular}

Tabela 42: Coordenadas Processadas situação ideal - Sem SBAS/Mossoró (o autor)

\begin{tabular}{cccccccccc}
\hline Nome & Descrição & $\mathbf{N}(\mathbf{m})$ & $\mathbf{E}(\mathbf{m})$ & Altitude $(\mathbf{m})$ & SVS & PDOP & RDOP & Vetor $(\mathbf{m})$ & Solução \\
\hline 35 & 09GPS & $9.446 .971,83$ & $712.880,65$ & 74,509 & 9 & 1,9 & 0,35 & $1.411,03$ & Base \\
409 & 09GPS & $9.447 .999,44$ & $711.913,67$ & 50,805 & 9 & 1,9 & 0,35 & $1.411,03$ & Fixa \\
\hline
\end{tabular}

Tabela 43: Coordenadas Processadas situação crítica - Com SBAS/Mossoró (o autor)

\begin{tabular}{cccccccccc}
\hline Nome & Descrição & $\mathbf{N}(\mathbf{m})$ & $\mathbf{E}(\mathbf{m})$ & Altitude $(\mathbf{m})$ & SVS & PDOP & RDOP & Vetor $(\mathbf{m})$ & Solução \\
\hline 35 & 09GPS+S20 & $9.446 .971,83$ & $712.880,65$ & 74,509 & 9 & 1,9 & 0,35 & $1.411,03$ & Base \\
409 & 05GPS+S20 & $9.447 .998,94$ & $711.914,38$ & 50,927 & 4 & 5,3 & 0,60 & $1.411,03$ & Fixa \\
\hline
\end{tabular}

Tabela 44: Coordenadas Processadas situação crítica - Sem SBAS /Mossoró (o autor)

\begin{tabular}{cccccccccc}
\hline Nome & Descrição & $\mathbf{N}(\mathbf{m})$ & $\mathbf{E}(\mathbf{m})$ & Altitude $(\mathbf{m})$ & SVS & PDOP & RDOP & Vetor $(\mathbf{m})$ & Solução \\
\hline 35 & 09GPS & $9.446 .971,83$ & $712.880,65$ & 74,509 & 9 & 1,9 & 0,35 & $1.411,03$ & Base \\
409 & 05GPS & $9.447 .998,94$ & $711.914,38$ & 50,927 & 4 & 5,3 & 0,60 & $1.411,03$ & Fixa \\
\hline
\end{tabular}

As observáveis $L 1$, dos satélites $S 20$ e $S 24$, ao serem adicionadas ao processamento, não contribuíram para a melhoria da acurácia das coordenadas dos pontos rastreados. Verifica-se nos gráficos 11 e 12, que eles são idênticos em todas as componentes e que, apenas na situação ideal, as coordenadas calculadas se aproximam das coordenadas verdadeiras.

Quando se tem pouca disponibilidade de satélites (situação critica), as coordenadas diferem das verdadeiras chegando em 50 centímetros na componente $\mathrm{N}$ e 70 centímetros na componente $\mathrm{E}$, conforme mostram os valores nas Tabelas 45 e 46.

Uma informação importante sobre o rastreio em Mossoró é que o tempo de rastreio foi de apenas cinco minutos em cada ponto, não havendo muita flexibilidade para a realização de diferentes experimentos.

Os gráficos apresentados nos dois procedimentos reforçam a idéia de que as observáveis dos satélites SBAS (PRN 120 e 124) não têm influência alguma na acurácia das coordenadas. Uma vez que as coordenadas são idênticas quando são utilizados apenas as observáveis dos satélites GPS e quando se adiciona as 
observáveis dos satélites SBAS ao processamento e verifica-se ainda que o PDOP e RDOP não se alteram.

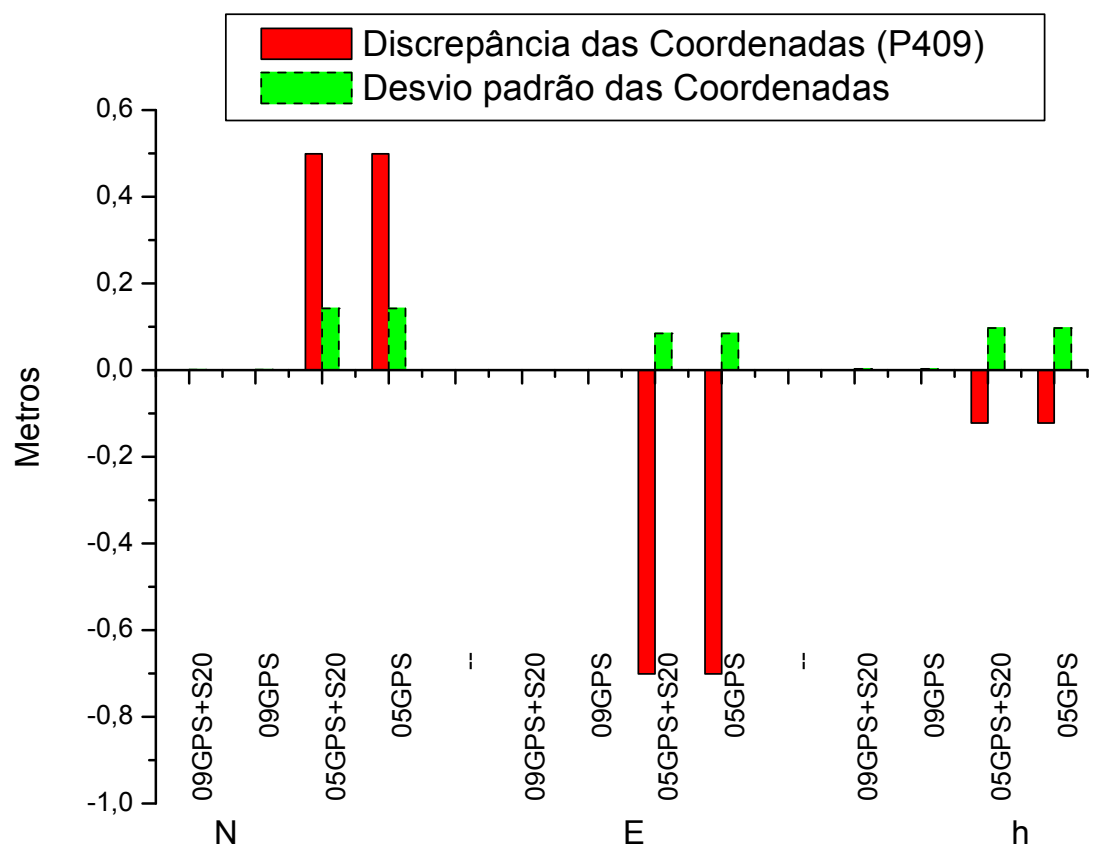

Gráfico 11: Discrepância e desvio-padrão - P409 (N, E, h) (o autor)

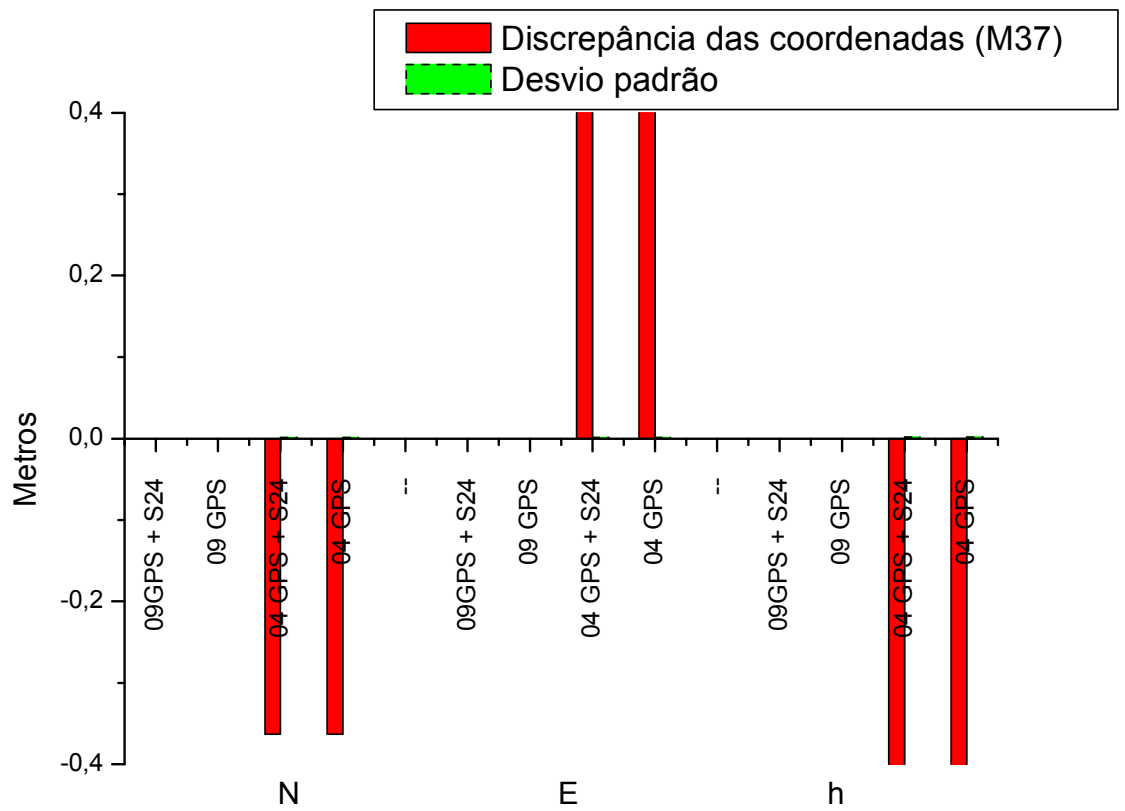

Gráfico 12: Discrepância e desvio-padrão - M37 (N, E, h) (o autor) 


\begin{tabular}{cccc}
\multicolumn{4}{c}{ Tabela 45: Discrepância - P409 (o autor) } \\
\hline Experimento & $\mathbf{N}(\mathbf{m})$ & $\mathbf{E}(\mathbf{m})$ & $\mathbf{h}(\mathbf{m})$ \\
\hline 09GPS+S20 & 0 & 0 & 0 \\
09GPS & 0 & 0 & 0 \\
05GPS+S20 & 0,499 & $-0,701$ & $-0,122$ \\
05GPS & 0,499 & $-0,701$ & $-0,122$ \\
\hline
\end{tabular}

Tabela 46: Discrepância - PM37 (o autor)

\begin{tabular}{cccc}
\hline Experimento & $\mathbf{N}(\mathbf{m})$ & $\mathbf{E}(\mathbf{m})$ & $\mathbf{h}(\mathbf{m})$ \\
\hline 09GPS + S24 & 0,000 & 0,000 & 0,000 \\
09 GPS & 0,000 & 0,000 & 0,000 \\
04 GPS + S24 & $-0,363$ & 0,437 & $-0,429$ \\
04 GPS & $-0,363$ & 0,437 & $-0,429$ \\
\hline
\end{tabular}

\subsection{Experimento 5}

No rastreio realizado na cidade de Manaus - AM, foram ocupados dois pontos com o tempo de coleta de 15 minutos cada, apenas um ponto será apresentado, onde os resultados das coordenadas obtidas nos processamentos são idênticos.

As Tabelas 47 a 50 contêm as coordenadas verdadeiras e dos pontos processados na situação ideal e crítica, com a adição das observáveis L1 satélites SBAS, respectivamente.

Tabela 47: Coordenadas verdadeiras - Manaus (o autor)

\begin{tabular}{cccccc}
\hline Nome & $\mathbf{N}(\mathbf{m})$ & $\mathbf{E}(\mathbf{m})$ & Altitude $(\mathbf{m})$ & Vetor $(\mathbf{m})$ & Solução \\
\hline Base & $9.653 .449,292$ & $830.834,176$ & 132,000 & ------- & Base \\
AM00 & $9.653 .732,018$ & $830.900,827$ & 66,366 & 297,533 & Fixo \\
AM01 & $9.653 .733,686$ & $830.857,482$ & 66,561 & 292,494 & Fixo \\
\hline
\end{tabular}

Tabela 48: Coordenadas Processadas situação ideal - Com SBAS/ Manaus (o autor)

\begin{tabular}{cccccccccc}
\hline Nome & Descrição & $\mathbf{N}(\mathbf{m})$ & $\mathbf{E}(\mathbf{m})$ & Altitude $(\mathbf{m})$ & SVS & PDOP & RDOP & Vetor $(\mathbf{m})$ & Solução \\
\hline Base & 08GPS+S20 & $9.653 .449,29$ & $830.834,18$ & 132 & 8 & 2,0 & $-\cdots---$ & $-\cdots-c-$ & ----- \\
AM00 & 08GPS+S20 & $9.653 .732,02$ & $830.900,83$ & 66,366 & 8 & 2,1 & 0,68 & 297,533 & Fixo \\
AM01 & 08GPS+S20 & $9.653 .733,69$ & $830.857,48$ & 66,561 & 8 & 2,2 & 1,05 & 292,494 & Fixo \\
\hline
\end{tabular}


Tabela 49: Coordenadas Processadas situação crítica Com SBAS Manaus (o autor)

\begin{tabular}{cccccccccc}
\hline Nome & Descrição & $\mathrm{N}(\mathrm{m})$ & $\mathrm{E}(\mathrm{m})$ & Altitude $(\mathrm{m})$ & SVS & PDOP & RDOP & Vetor $(\mathrm{m})$ & Solução \\
\hline Base & 04GPS+S20 & $9.653 .449,29$ & $830.834,18$ & 132,00 & 4 & 3,0 & ----- & ------ & ------ \\
AM00 & 04GPS+S20 & $9.653 .732,00$ & $830.900,81$ & 66,353 & 4 & 3,4 & 0,68 & 297,533 & Fixo \\
AM01 & 04GPS+S20 & $9.653 .733,69$ & $830.857,48$ & 66,56 & 4 & 3,5 & 1,05 & 292,494 & Fixo \\
\hline
\end{tabular}

Tabela 50: Coordenadas Processadas situação crítica Sem SBAS/Manaus (o autor)

\begin{tabular}{cccccccccc}
\hline Nome & Descrição & $\mathbf{N}(\mathbf{m})$ & $\mathbf{E}(\mathbf{m})$ & Altitude $(\mathbf{m})$ & SVS & PDOP & RDOP & Vetor $(\mathbf{m})$ & Solução \\
\hline Base & 04GPS & $9.653 .449,29$ & $830.834,18$ & 132,00 & 4 & 3,0 & $--1---$ & ------- & ----- \\
AM00 & 04GPS & $9.653 .732,01$ & $830.900,83$ & 66,36 & 4 & 3,0 & 0,68 & 297,533 & Fixo \\
AM01 & 04GPS & $9.653 .733,79$ & $830.857,24$ & 66,841 & 4 & 3,6 & 1,05 & 292,494 & Fixo \\
\hline
\end{tabular}

Para melhor elucidar as discrepâncias e os desvios-padrão das componentes das coordenadas são apresentados o Gráfico 13 e a Tabela 51.

Novamente, nota-se que as coordenadas estão próximas das verdadeiras, quando se dispõem de abundância de satélites sendo rastreados, mas quando esta disponibilidade fica insuficiente ou crítica, há uma grande variação nas coordenadas. A adição das observáveis do satélite PRN 120 também não permitiram uma melhora na solução do problema, ou seja, os dados dos satélites SBAS depreciaram a qualidade das coordenadas.

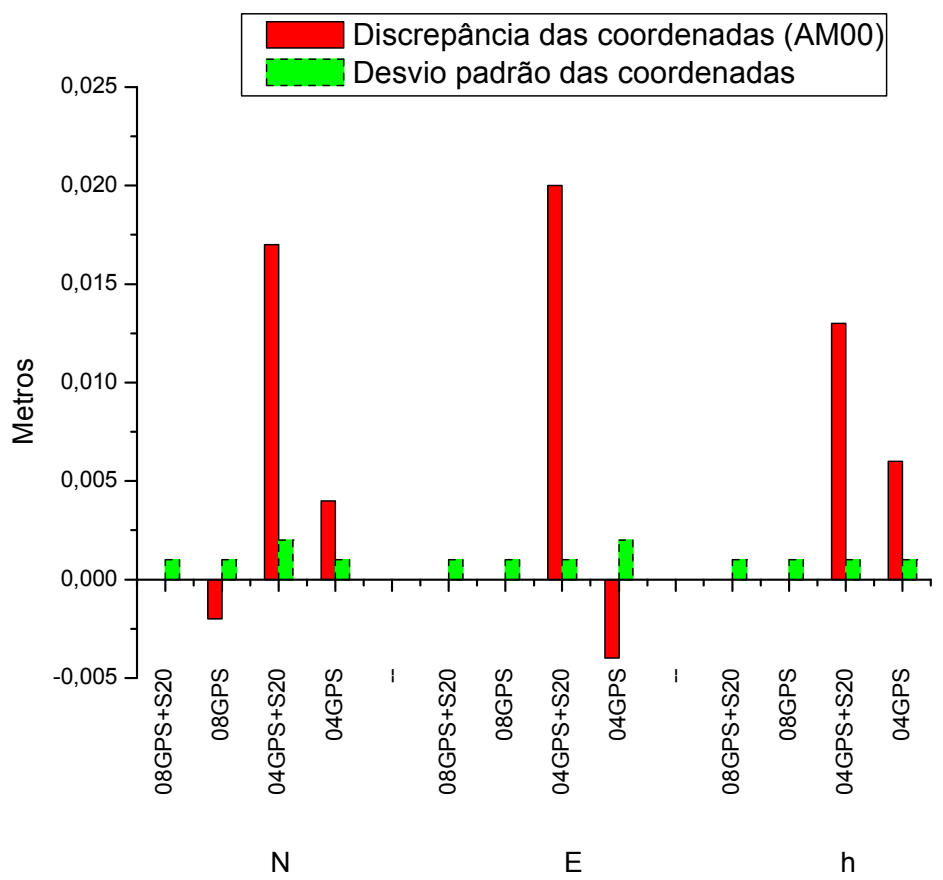

Gráfico 13: Discrepância e desvio-padrão - PAM00 (N, E, h) (o autor) 
Tabela 51: Discrepância - PAM00 (o autor)

\begin{tabular}{cccc}
\hline Experimento & $\mathrm{N}(\mathrm{m})$ & $\mathrm{E}(\mathrm{m})$ & $\mathrm{h}(\mathrm{m})$ \\
\hline 08GPS+S20 & 0,000 & 0,000 & 0,000 \\
08GPS & 0,001 & 0,000 & 0,000 \\
04GPS+S20 & $-0,004$ & $-0,001$ & 0,001 \\
04GPS & $-0,002$ & 0,002 & $-0,003$ \\
\hline
\end{tabular}

Com todos os resultados apresentados, ao se realizar uma análise por cidades e por satélites geoestacionários, pode-se inferir que a observável L1 do satélite SBAS PRN 138 (WAAS), que foi rastreado em São Paulo e no Rio de Janeiro, Experimentos 1 e 3, respectivamente, ao ser adicionada no processamento, teve suas observáveis computadas pelo programa, mas não obteve influência determinante na acurácia das coordenadas quando não se dispunha de uma quantidade suficiente de satélites GPS sendo rastreados. Mas, ao haver abundância de satélites, suas observáveis não têm interferência direta na melhoria dos resultados.

Os satélites PRN 120 e PRN 124 (EGNOS) foram rastreados na cidade de Nova Venécia, Mossoró e Manaus, Experimentos 2, 4 e 5, respectivamente, sendo que suas observáveis L1 não tiveram influência na melhoria dos resultados, não auxiliando na determinação da acurácia das coordenadas nem na melhoria do PDOP e RDOP.

Assim, até o momento, pode-se dizer que ao se adicionar as observáveis L1 dos satélites WAAS ou EGNOS ao processamento, em conjunto com as observáveis L1 dos GPS, não se obteve melhores resultados do que quando se utiliza apenas aos dados GPS.

\subsection{Análise estatística dos resultados}

Será descrito o processo de avaliação da tendência dos dados GPS e GPS+ SBAS. Para esta avaliação utilizou-se o teste $t$-Student.

Este teste tem por objetivo a detecção de erro sistemático numa dada coordenada. Para a análise estatística é necessária a comparação entre coordenadas da fonte mais acurada (coordenadas verdadeiras) com as coordenadas a serem avaliadas. Para realização dos testes de tendência fez-se necessário, 
realizar previamente, os cálculos da média dos erros, da variância e do desvio padrão para cada uma das coordenadas, além do $t_{X}$ tabelado e calculado. A Tabela 52 e 53 mostram os valores obtidos para o GPS e para o GPS + SBAS para a cidade de Nova Venécia - ES, onde rastreou-se as observáveis L1 do satélite SBAS PRN 120, tendo várias sessões de dados em épocas diferentes.

Tabela 52: Análise Estatística dos resultados do processamento GPS - ES

\begin{tabular}{cccc}
\hline Análise de Tendência GPS & $\mathbf{\Delta} \mathbf{N}(\mathbf{m})$ & $\mathbf{\Delta E}(\mathbf{m})$ & $\mathbf{\Delta h}(\mathbf{m})$ \\
\hline$\mu$ & $-0,048$ & $-0,045$ & $-0,017$ \\
${ }^{*} S_{\Delta x}^{2}\left(\mathrm{~m}^{2}\right)$ & 0,014 & 0,011 & 0,001 \\
$\mathrm{~S}_{\Delta x}$ & 0,118 & 0,106 & 0,035 \\
$t x$ & $-1,402$ & $-1,485$ & $-1,667$ \\
$\mathrm{t}$ 95\% tabelado & 1,796 & & \\
\hline
\end{tabular}

Tabela 53: Análise Estatística dos resultados do processamento GPS+SBAS - ES

\begin{tabular}{cccc}
\hline Análise de Tendência GPS+SBAS & $\boldsymbol{\Delta} \mathbf{N}(\mathbf{m})$ & $\boldsymbol{\Delta E}(\mathbf{m})$ & $\mathbf{\Delta h}(\mathbf{m})$ \\
\hline$\mu$ & $-0,048$ & $-0,045$ & $-0,017$ \\
${ }^{*} S_{\Delta x}^{2}\left(\mathrm{~m}^{2}\right)$ & 0,014 & 0,011 & 0,001 \\
$\mathrm{~S}_{\Delta x}$ & 0,118 & 0,106 & 0,035 \\
$t x$ & $-1,402$ & $-1,485$ & $-1,667$ \\
$\mathrm{t}$ 95\% tabelado & 1,796 & & \\
\hline
\end{tabular}

As tabelas 54 e 55, mostram os valores obtidos para a cidade de São Paulo, onde rastreou-se as observáveis L1 do satélite SBAS PRN 138.

Tabela 54: Análise Estatística dos resultados do processamento GPS - SP

\begin{tabular}{cccc}
\hline Análise de Tendência GPS & $\boldsymbol{\Delta N}(\mathbf{m})$ & $\boldsymbol{\Delta} \boldsymbol{E}(\mathbf{m})$ & $\boldsymbol{\Delta} \boldsymbol{h}(\mathbf{m})$ \\
\hline$\mu$ & 0,006 & 0,027 & $-0,003$ \\
$* S_{\Delta x}^{2}\left(\mathrm{~m}^{2}\right)$ & 0,000 & 0,004 & 0,001 \\
$\mathrm{~S}_{\Delta x}$ & 0,015 & 0,064 & 0,028 \\
$t x$ & 0,720 & 0,840 & $-0,230$ \\
$\mathrm{t}_{95 \%}$ tabelado & 1,796 & & \\
\hline
\end{tabular}

Tabela 55: Análise Estatística dos resultados do processamento GPS+SBAS - SP

\begin{tabular}{cccc}
\hline Análise de Tendência GPS & $\boldsymbol{\Delta N}(\mathbf{m})$ & $\boldsymbol{\Delta} \boldsymbol{E}(\mathbf{m})$ & $\boldsymbol{\Delta} \boldsymbol{h}(\mathbf{m})$ \\
\hline$\mu$ & 0,038 & 0,024 & 0,016 \\
$* S_{\Delta x}^{2}\left(\mathrm{~m}^{2}\right)$ & 0,001 & 0,004 & 0,000 \\
$\mathrm{~S}_{\Delta x}$ & 0,059 & 0,064 & 0,026 \\
$t x$ & 1,290 & 0,770 & 1,250 \\
$\mathrm{t}_{95 \%}$ tabelado & 1,796 & & \\
\hline
\end{tabular}


Observando os valores de $t_{N}, t_{E}$ e $t_{h}$ mostrados nas tabelas 52 e 53, pode-se verificar que a partir da desigualdade $\left|t_{X}\right|<t_{(n-1, \alpha / 2)}$, as coordenadas obtidas com o processamento dos dados, de Nova Venécia - ES, não apresentam tendência, o mesmo pode-se dizer sobre os valores de $t_{N}, t_{E}$ e $t_{h}$ obtidos no teste de tendência realizado para o processamento de São Paulo -SP, a partir das desigualdades $\left|t_{X}\right|<t_{(n-1, \alpha / 2)}$ :

$$
\begin{aligned}
& \left|t_{N}\right|<t_{(n-1, \alpha / 2)} \\
& \left|t_{E}\right|<t_{(n-1, \alpha / 2)} \\
& \left|t_{h}\right|<t_{(n-1, \alpha / 2)}
\end{aligned}
$$

Calculou-se também o erro médio quadrático (equação 20) para cada componente das coordenadas $(\mathrm{N}, \mathrm{E}, \mathrm{h})$ sem a adição das observáveis SBAS e com a adição das observáveis SBAS para os estados do Espírito Santo e São Paulo. Os valores estão representados nas Tabelas 56, 57 e 58 , 59, respectivamente.

\begin{tabular}{cc}
\multicolumn{3}{c}{ Tabela 56: RMS GPS $(\mathrm{m})$ - ES } \\
\hline Coordenadas & RMS - GPS \\
\hline $\mathrm{N}$ & 0,122 \\
$\mathrm{E}$ & 0,111 \\
$\mathrm{~h}$ (geométrico) & 0,037 \\
\hline \\
Tabela 57: RMS GPS+SBAS (m) - ES \\
\hline Coordenadas & RMS - GPS+SBAS \\
\hline $\mathrm{N}$ & 0,122 \\
$\mathrm{E}$ & 0,111 \\
$\mathrm{~h}$ (geométrico) & 0,037 \\
\hline
\end{tabular}

Ao analisar e comparar os valores do estimador de acurácia (RMS), com e sem as observáveis L1 dos satélites SBAS, nota-se que os valores são idênticos (gráfico 14) para a cidade de Nova Venécia - ES, não tendo alterações nas componentes das coordenadas. Este é um indício que as observáveis dos satélites SBAS (especificamente da constelação EGNOS), não são determinantes para melhoria da acurácia das coordenadas, quando se faz a combinação com as 
observáveis L1 da constelação GPS.

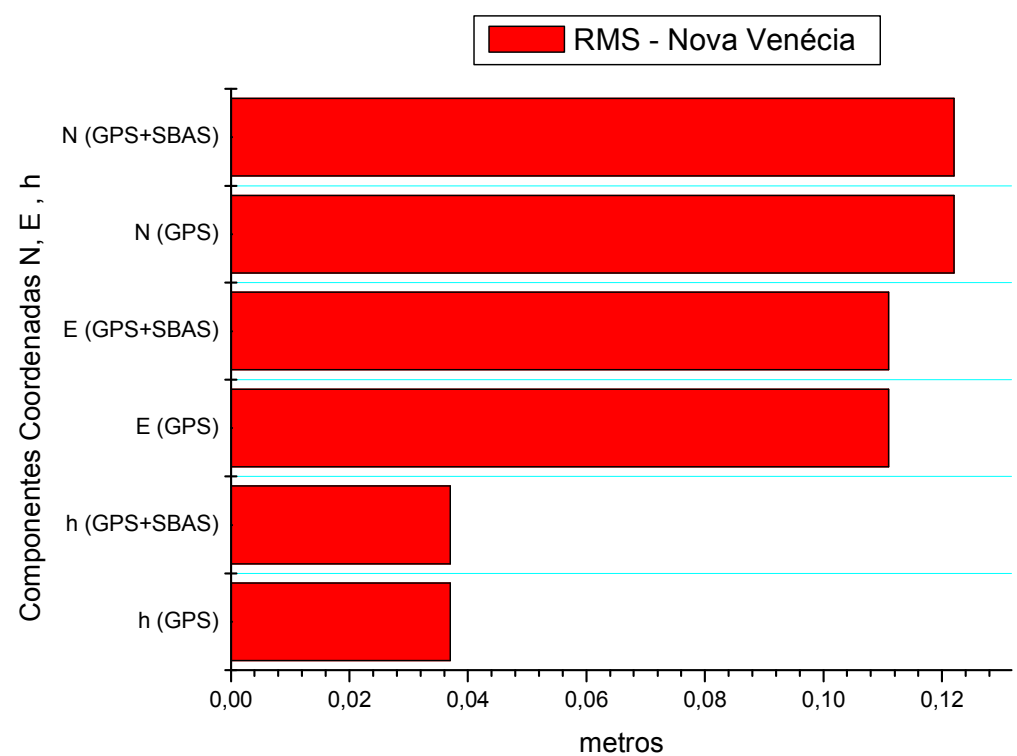

Gráfico 14: RMS - Nova Venécia - ES

Tabela 58: RMS GPS (m) - SP

\begin{tabular}{cc} 
Coordenadas & RMS - GPS \\
\hline N & 0,015 \\
E & 0,060 \\
h (geométrico) & 0,031 \\
\hline
\end{tabular}

Tabela 59: RMS GPS+SBAS (m) - SP

\begin{tabular}{cc}
\hline Coordenadas & RMS - GPS+SBAS \\
\hline N & 0,048 \\
E & 0,060 \\
h (geométrico) & 0,021 \\
\hline
\end{tabular}

Os valores de RMS obtidos nas tabelas 58 e 59 para a cidade de São Paulo SP são diferentes, com uma leve depreciação quando se utiliza as observáveis L1 dos satélites SBAS. O gráfico 15 mostra os valores do estimador de acurácia entre as componentes das coordenadas. 


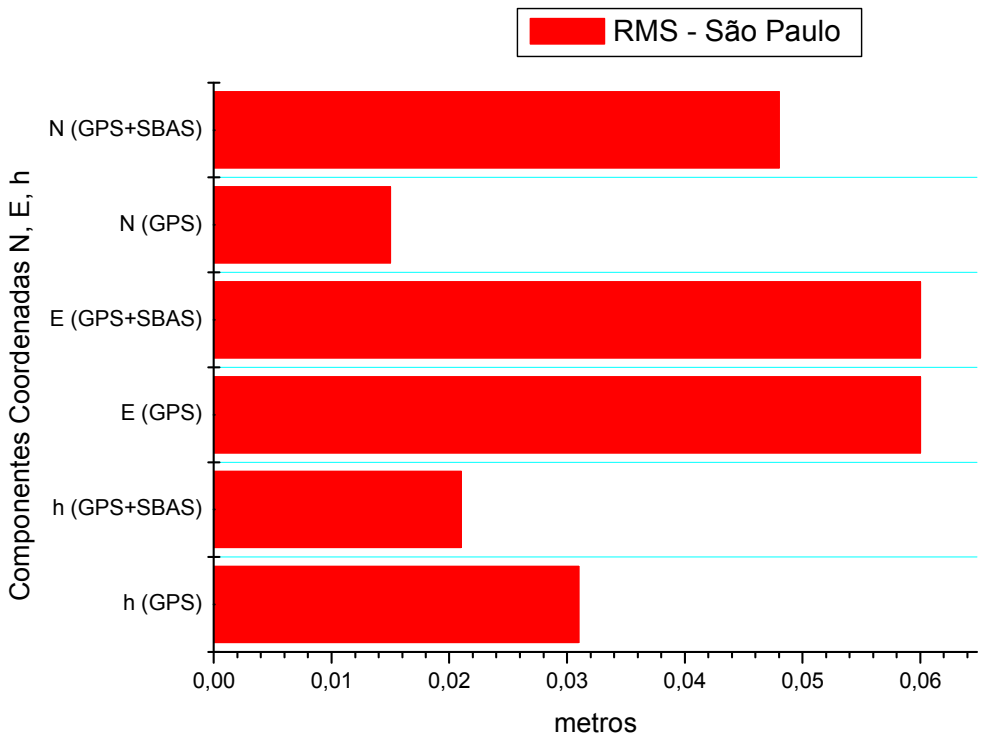

Gráfico 15: RMS - São Paulo - SP

Ao realizar-se posicionamento através do sistema de posicionamento global (GPS), é necessário que se conheça as coordenadas dos satélites, pois as mesmas servirão de referência para a determinação das coordenadas dos pontos de interesse. Com a finalidade de verificar como se comporta a posição dos satélites SBAS no espaço, gerou-se os gráficos das posições, com as componentes $X, Y$ e $Z$, a partir das informações constantes no arquivo Rinex de navegação do SBAS (um exemplo deste arquivo encontra-se no Apêndice A), para os satélites PRN 120 e 138. Os gráfico 16 e 17 ilustram o comportamento das posições para a cidade de São Paulo.

Ao se verificar as posições das componentes $\mathrm{X}, \mathrm{Y}$ e $\mathrm{Z}$ em relação ao tempo, nos gráficos, nota-se no gráfico 16 que, para o satélite PRN 138, as componentes X, Y e Z possuem órbita com comportamento uniforme e semelhante e sua variação é pequena. Em relação ao satélite PRN 120 (gráfico 17), a variação das componentes $\mathrm{X}, \mathrm{Y}$ e $\mathrm{Z}$ é maior e possui órbita mais perturbada.

No Anexo A apresenta-se os gráficos das posições $X, Y$ e $Z$ dos satélites PRN 120 e 138 para cada região onde realizou-se os rastreios. 


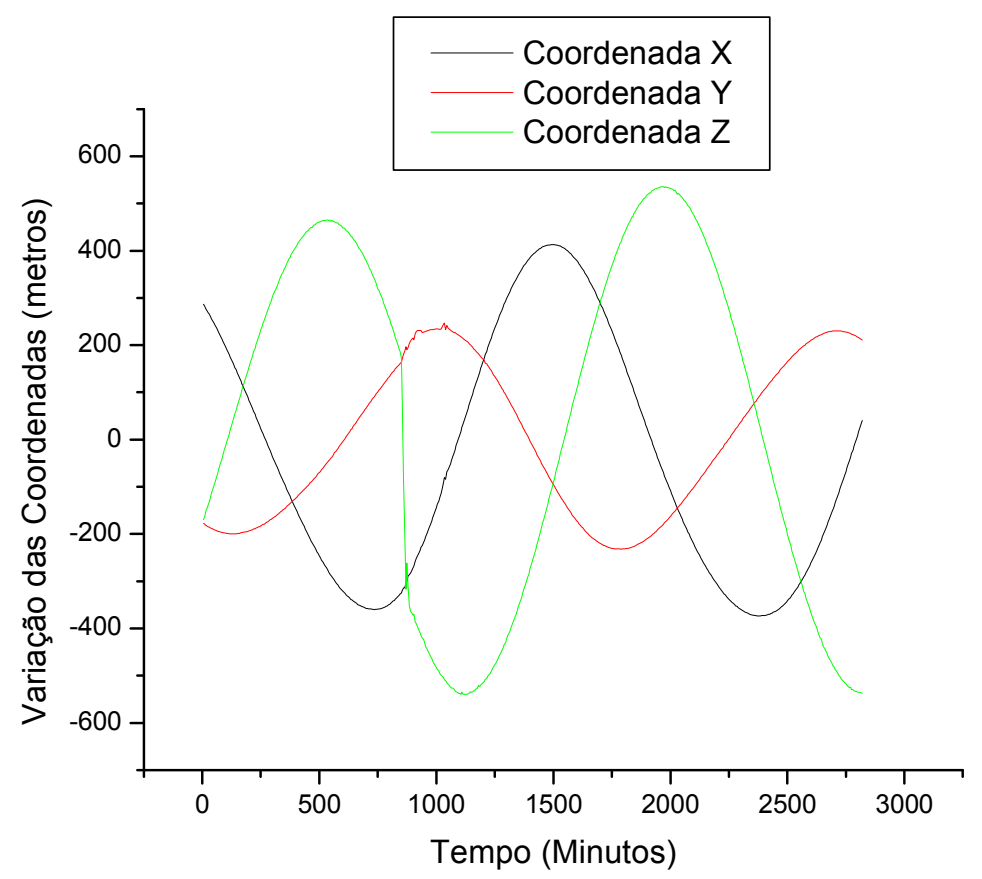

Gráfico 16: Coordenadas satélite PRN 138 - SP (o autor)

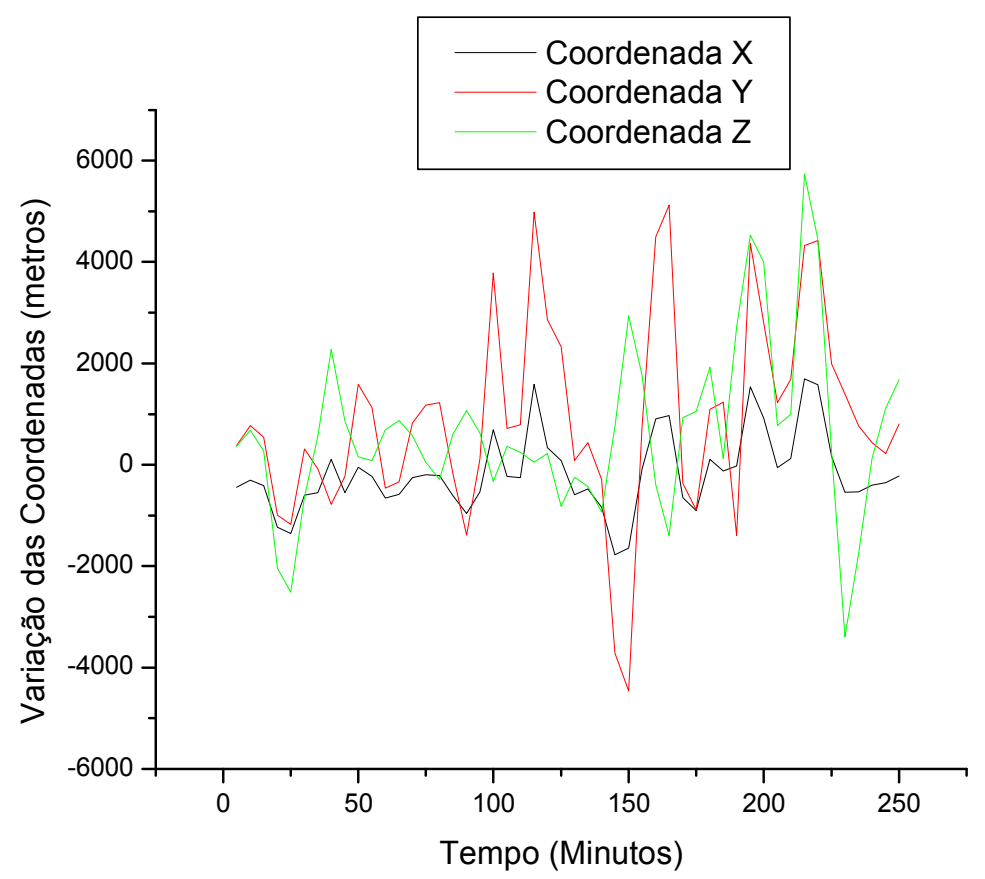

Gráfico 17: Coordenadas satélite PRN 120 - SP (o autor) 


\section{CONCLUSÕES E RECOMENDAÇÕES}

Durante o desenvolvimento desta pesquisa investigou-se a influência da observável L1 dos satélites SBAS na melhoria da qualidade das coordenadas, com relação à acurácia.

Os processamentos das observáveis L1 dos satélites SBAS em conjunto com as observáveis L1 dos satélites GPS, possibilitou verificar quais dos satélites SBAS são rastreados e o desempenho destes dados em algumas regiões do Brasil. Mesmo sem o funcionamento das correções em tempo real para a America do Sul, a observável L1 SBAS está disponível aos usuários.

Como forma de contribuição desta pesquisa, são apresentadas as conclusões e recomendações a partir dos resultados e análises obtidas.

\subsection{Conclusão}

A utilização das observáveis L1 dos satélites SBAS em levantamentos precisos e que necessitam de rapidez e acurácia, ou seja, a diminuição do tempo de rastreio em cada ponto, não é viável, pois tais satélites não influenciaram positivamente a acurácia das coordenadas nas áreas onde os rastreios foram realizados.

As análises realizadas ao longo deste trabalho mostraram que para os satélites do sistema WAAS os resultados são melhores do que para os satélites do EGNOS, mas também não influenciaram de forma determinante na melhoria do resultado final.

Ao realizar-se os processamentos simulando uma situação crítica (poucos satélites disponíveis) e adicionando-se a este processamento as observáveis SBAS, é necessário realizar-se vários experimentos, para obter-se bons resultados, o que acaba prolongando o trabalho de processamento dos dados.

Caso os satélites escolhidos em um dos experimentos estejam bem distribuídos no espaço, ao adicionar as observáveis WAAS ao processamento, o 
PDOP e a acurácia das coordenadas melhoram, mas não de forma acentuada, ficando ainda distante das coordenadas verdadeiras.

Para os casos onde se tem grande disponibilidade de satélites, ao se adicionar a observável L1 dos satélites SBAS (WAAS ou EGNOS) ao processamento estes dados também não tem influência no resultado final do processamento.

Para uma melhor avaliação e conclusão dos resultados apresentados no Capítulo 5, analisa-se em duas parte: apenas com o satélite WAAS (PRN 138), e com os satélites EGNOS (PRN 120 e 124).

Satélite PRN 138 : foi rastreado na cidade de São Paulo (Experimento 1) e Rio de Janeiro (Experimento 3) durante todo o rastreio e sem interrupções, enquanto que os satélites PRN 120 e 124 foram rastreados apenas na base ou apenas no móvel, em alguns poucos momentos durante o rastreio os satélites foram rastreados simultaneamente na base e móvel, não havendo dados simultâneos suficientes para a realização do processamento.

Neste caso onde o satélite PRN 138 foi rastreado, os resultados indicam que até certo ponto as observáveis SBAS influenciaram positivamente no processamento, melhorando o PDOP e a acurácia quando não se dispunha de uma quantidade abundante de satélites sendo rastreados, mas de forma muito discreta, isto é, não influenciaram na acurácia das coordenadas de forma determinante, além de não haver alteração nos valores do RDOP e de seus desvios padrão.

Para o caso de São Paulo, especificamente, onde há linhas de base de até 500 metros de comprimento, estas distâncias não influenciaram nos resultados do processamento, as observáveis $L 1$ do satélite $S 38$ se comportaram da mesma forma em todos os pontos.

No caso do Rio de Janeiro a linha de base é de apenas 1,2 metros e verificouse que os dados se comportaram da mesma forma que em São Paulo. Quando a disponibilidade de satélites é abundante, os dados do satélite PRN 138 não têm influência determinante no processamento, mas quando há pouca disponibilidade e seus dados são adicionados ao processamento existe uma influencia positiva. Apesar do PDOP continuar baixo $(3,2)$, tem uma pequena melhora $(2,7)$, o mesmo não acontece com o RDOP que se mantém com o mesmo valor (Tabela 38), os dados do PRN 138 não melhoram a acurácia das coordenadas.

Uma ressalva deve ser feita, para que a observável L1 do satélites PRN 138 
ao ser adicionando no processamento em conjunto as observáveis L1 dos satélites GPS, melhore o PDOP, os desvios padrão e acurácia, mas não determinante, vários experimentos devem ser realizados no software para se obter a melhor distribuição espacial (geometria dos satélites) possível, o que acaba inviabilizando a agilidade do processamento, e mesmo após obter a melhor geometria, o PDOP e a acurácia ficam altas para os padrões de posicionamento de precisão. No rastreio realizado (Tabela 5) na cidade de São Paulo, com o tempo total de quarenta horas, ao se processar, e comparar estes dados com suas coordenadas verdadeiras, verifica-se que o comportamento do satélite PRN 138 é o mesmo dos rastreios realizados anteriormente, mas com menor tempo de ocupação. Portanto o tempo de rastreio também não é um fator determinante para que as observáveis dos satélites SBAS influencie na melhora da qualidade das coordenadas.

Ao analisar os dados obtidos na cidade de São Paulo e Rio de Janeiro conjuntamente, pode-se dizer que a observável L1 do satélite PRN138 (da constelação WAAS) não é indispensável para melhora da acurácia das coordenadas e das condições do rastreio (RDOP).

Satélite PRN 120 e 124: O satélite PRN 120, foi rastreado em todas as regiões onde se realizaram os rasteiros, mas em São Paulo e Rio de Janeiro como descrito, não tiveram seus dados rastreados no receptor base e móvel simultaneamente. Para o satélite PRN 124, ele apenas foi rastreado em ambos receptores GPS na cidade de Mossoró - RN.

Para estes dois satélites especificamente em todos os processamentos realizados, em todas as regiões onde eles tiveram dados simultâneos, suas observáveis L1 em hipótese alguma contribuíram para a melhoria do PDOP, RDOP, acurácia e desvios padrão das coordenadas. Ou seja, ao se adicionar as observáveis destes satélites ao processamento em conjunto com as observáveis dos satélites GPS, verifica-se que eles não influenciam nem positivamente e nem negativamente nos resultados do processamento. Em e-mail enviado para a ESA, questionando-se sobre a forma de disponibilização e funcionamento das observáveis L1 do satélites EGNOS (PRN 120) para o Brasil, respondeu-se que os dados são disponibilizados através de uma mensagem chamada MT27, segue trecho do e-mail (mensagem pessoal): [...] Therefore, EGNOS corrections are not applicable in Brasil. In order to protect civil aviation users from using EGNOS signal outside this area, EGNOS is broadcasting MT27[...]. Os receptores utilizados nos rastreios recebem a 
mensagem MT27.

Chega-se a conclusão que ao se analisar os resultados obtidos nesta pesquisa verificou-se que as observáveis L1 dos satélites SBAS (WAAS e EGNOS) ao serem adicionados no processamento em conjunto com as observáveis L1 dos satélites GPS, não influenciam, de forma determinante, na melhoria da acurácia das coordenadas, no posicionamento preciso, bem como não tem melhora significativa nos desvios padrão de cada linha de base processada.

\subsection{Recomendações}

Embasado nos resultados obtidos e nas análises realizadas, recomenda-se.

- Realizar rastreios com tempo mínimo de 24 horas para cada ponto, a fim de se obter dados abundantes para realizar uma boa análise estatística e analisar o comportamento da órbita dos satélites SBAS;

- Utilizar um programa científico, onde se tenha o influência sobre o processamento e a escolha dos parâmetros disponibilizados, afim de se comparar os resultados obtidos com programas comerciais disponíveis.

- Verificar sobre a disponibilidade do sinal dos satélites SBAS em outras regiões, para que se entenda a forma de disponibilização destes dados para a América do Sul.

- Realizar novos testes com outros tipos de receptores GPS, para verificar as potencialidade das observáveis L1 SBAS.

- Acompanhar os estudos atuais e futuros sobre a possibilidade de instalação de bases SBAS na América do Sul, assim disponibilizando, além da observável L1, também a L2. 


\section{REFERÊNCIAS}

CAMARGO, P., O., MATSUOKA., M., T., Cálculo do TEC usando dados de receptores GPS de dupla frequência para a produção de mapas da ionosfera para a região brasileira - Revista Brasileira de Cartografia, v.1, n 56, p. 14-27.01/2004.

CAMARGO, P., O., , Ajustamento de Observações. Presidente Prudente: FCT/UNESP, 2000. 270p. Notas de aula do curso de graduação em Engenharia Cartográfica.

CHAVES, E., E., D. Análise da qualidade de dados georreferenciados utilizando a tecnologia GPS. 1998. 100p. Dissertação (Mestrado) - Universidade de São Paulo. São Carlos, 1998.

ESA - European Space Agency. Satellite PRN 120 [mensagem pessoal]. Mensagem recebida < fbalbarici@bol.com.br> 10/03/2010 e 29/03/2010

FAA., Technical Operation, Navigation Services, Global positioning system wide area augmentation system (waas) - performance standard - Washington DC, 2008. 60p.

FEDERAL SPACE AGENCY, Information-analitical centre. Disponível em <http://www.glonass-ianc.rsa.ru> Acesso em: 15 ago. 2010.

FALCONE, M. et al., The European Galileo Programme. The European EGNOS Project, 2006, The Netherlands Proceedings The Netherlands: Bruce Battrick \& Dorothea Banesy, 2006. p. 435-455.

FLAMENT, D. et al., The EGNOS system Architecture Explained. The European EGNOS Project, 2006,The Netherlands Proceedings The Netherlands :Bruce Battrick \& Dorothea Banesy, 2006. p. 133-152.

GALO, M.; CAMARGO, P. O. O uso do GPS no controle de qualidade de cartas. COBRAC - Congresso Brasileiro de Cadastro Técnico Multifinalitário Tomo II. Proceedings Florianópolis - SC, p. 41-48. 1994.

GOOGLE EARTH. 2010. Disponível em: < kh.google.com> Acesso em 20 set. 2010.

GPS World Magazine, October. 2010. Disponível : http://www.gpsworld.com/gnsssystem/augmentation-assistance/news/first-broadcast-sbas-test-signal-caribbeancentral-america- > Acesso em: 27 abr. 2011.

GROVES., P., D., Principles of GNSS, Inertial, and multisensory integrated navigation Systems, London: Artech House, 2008. 518p. 
GLICA. Sistemas Globais de Navegação por Satélites - A constelação GALILEO 1 ed. Itália, 2007. 48p.

HEIN, G. W., From GPS and GLONASS via EGNOS to Galileo - Positioning and navigation in the third millennium. Institute of Geodesy and Navigation, Proceedings Germany: University FAF Munich,. p 39-47. 2000.

HOFMANN - WELLENHOF, B.; LICHTENEGGER, H.; WASLE, E.; GNSS: GIobal Navigation Satellite Systems - GPS, GLONASS, Galileo \& more. Austria: Springer-Verlag Wien, New York, 2008. 516 p.

HOFMANN - WELLENHOF, B.; LICHTENEGGER, H.; COLLINS, J.; GPS, Theory and Practice -4 ed. Austria: Springer-Verlag-Wien New York, 1997 389p.

KLIMOV, V.N., REVNIVYKH, S.G., The GLONASS System: Current status and future development. The European EGNOS Project, 2006, The Netherlands Proceedings The Netherlands :Bruce Battrick \& Dorothea Banesy, 2006. p. 35-42.

LEICK, A. GPS Satellite Surveying 3 ed. New York: John Wiley \& Sons, 2004, 434p.

MACHADO, T. M., Avaliação de desempenho de receptores GPS em modo estático e cinemático - 115p. Dissertação (Mestrado) - ESALQ , Piracicaba, Piracicaba -SP, 2008.

MAGELLAN, Reciver GPS Promark3, Disponível em: <ftp://ftp.magellangps.com/> Acesso em: 24 mar. 2010.

MONICO, J.F.G., Posicionamneto pelo GNSS: descrição,fundamentos e aplicações. São Paulo: Editora UNESP, 2008. 476p.

MONTGOMERY, D. C., RUNNGER, G. C., Estatística aplicada e probabilidade para engenheiros. 2 ed. LTC - livros técnicos e científicos editora S.A. 1999. 463p.

SÁNCHEZ, D. P., BERGES, C. P. The EGNOS SBAS Message Format Explained. The European EGNOS Project, 2006, The Netherlands Proceedings The Netherlands :Bruce Battrick \& Dorothea Banesy, 2006. p.115-129.

SEEBER,G., Satellite Geodesy: Foundations, methods and aplications. 3 ed. Berlin: Walter de Gruyter. 1993. 529p.

Satellite Geodesy: Foundations, methods and aplications. 2 ed. Berlin: Walter de Gruyter. 2003. 588p.

SOUZA, D. V. de Avaliação de distorções da RAFB no Sul/Sudeste do Brasil usando o geóide e GPS, 124 p. Dissertação (Mestrado) - Instituto de Astronomia, Geofísica, Universidade de São Paulo, São Paulo, 2006.

SOUZA, C. R. M., DIAS, M. H. C., SANTOS , J. C. A., Análise da Vulnerabilidade de Receptores GPS Comerciais sob Ação de Interferência Intencional. VIII SIGE Simpósio de Guerra Eletônica. Proceedings. Rio de Janeiro. IME- Instituto Militar 
de Engenharia - Rio de Janeiro, p.4. 2005.

TORAN-MARTI, F., VENTURA-TRAVESET, J., The ESA EGNOS Project: The First Step of the European Contribution to the Global Navigation Satellite System (GNSS) GNSS-1 (Project Office.). European Space Agency (ESA), 2004, France, Proceedings France: ESA, 2004. p.1-17.

TORAN-MARTI, $F$., VENTURA-TRAVESET , J., BASKER, S., The Global Positioning System (GPS). The European EGNOS Project, 2006, The Netherlands Proceedings The Netherlands :Bruce Battrick \& Dorothea Banesy, 2006. p.21-33.

VENTURA-TRAVESET, J. et al., The European EGNOS Project: Mission, Programme and System. The European EGNOS Project, 2006, The Netherlands Proceedings The Netherlands :Bruce Battrick \& Dorothea Banesy, 2006. p.03-20.

VENTURA-TRAVESET, J., GAUTHIER,L., MICHEL, P., Architecture, mission and signal processing aspects of the EGNOS System: the first European implementation of GNSS. European Space Agency (ESA), 2006, France. Proceedings. France, 2006. p. 01-11.

WALTER, T., ENGE, P. The Wide Area Augmentation System - The European EGNOS Project, 2006,The Netherlands Proceedings The Netherlands :Bruce Battrick \& Dorothea Banesy, 2006. p 395 - 411.

WALTER, T., BLANCH, J., ENGE, P., Coverage Improvement for Dual-Frequency SBAS, GPS World Magazine, March 2010, Disponível em: http://www.gpsworld.com/GNSS-system/augmentation-assistance/future-augmented9606?page_id=6. Acesso em 26/04/2010.

WALTER, T., PULLEN, S., ENGE, P., System Overview, Recent Developments, and Future Outlook for WAAS and LAAS, In: GPS Symposium, 2002, Tokyo. Proceedings. Tokyo: Tokyo University of Mercantile Marine, 2002. p. 1-12

WANNINGER, L. Combined processing of GPS, GLONASS, and SBAS code phase and carrier phase measurements. In: ION GNSS 2007. Fort Worth, USA Proceedings. Fort Worth, USA, 2007. pp. 866-875. 


\section{BIBLIOGRAFIA CONSULTADA}

ASSOCIAÇÃO BRASILEIRA DE NORMAS TÉCNICAS. NBR n. projeto: controle de qualidade posicional em cartografia - procedimento. São Paulo, 2007. 15p.

ARNOLD L, L., Positional accuracy of the wide area augmentation system. The University of New Mexico, 134p Dissertação (Mestrado), The University of New Mexico,New Mexico, 2009.

ALCANTARILLA, I., ZARRAOA, N., CARO, J, EGNOS and WAAS Performance The European EGNOS Project, 2006, The Netherlands Proceedings The Netherlands :Bruce Battrick \& Dorothea Banesy, 2006. p. 245-258.

BAVUSO, S. J. A novel solution-technique applied to a novel WAAS architecture Technical Report,1998, USA Proceedings. USA: NASA. p. 1 -6. 1998.

BENEDICTO, J. et al., GALILEO : Satellite System Design and technology developments. Disponível em: <http://esamultimedia.esa.int/docs/galileo_world_paper_Dec_2000.pdf> Acesso em: 14 nov. 2009.

BELLEI, L. N., O Sistema WAAS e a Estimação do Atraso lonosférico no Sinal GPS.210p, Dissertação (Mestrado), ITA - Instituto Tecnológico da Aeronáutica, São José dos Campos - SP, 2006.

BISQUERRA, R., Introdução a estatística: enfoque informático com pacote estatístico SPSS/ tradução Fátima Murad - Porto Alegre : Arted, 2004. 255p.

DREDGING NEWS ONLINE. Magellan unveils BLADE technology. Disponível em: <http://www.sandandgravel.com/news/article.asp?v1=10093> Acesso em: 25. mar. 2010.

DIXON, K,. - StarFire ${ }^{\mathrm{TM}}$ : A Global SBAS for sub-decimeter precise point positioning, 2006, Proceedings 2006 Fort Worth, USA Proceedings. Fort Worth, USA, 2006. pp. 2286-2296.

EUROPEAN SATELLITE SERVICES PROVIDERS, About EGNOS. Disponível em: $<w w w . e s s p . b e / a b o u t \_e g n o s . h t m l>$ Acesso em: 20 jun. 2010.

EUROPEAN SATELLITE SERVICES PROVIDERS. Receiver technology. Disponível em: <http://www.essp.be/recievers.html> Acesso em: 20 ago. 2009. 
EUROPEAN SPACE AGENCY. SBAS Simulator. Disponível em: <http://www.egnospro.esa.int/sbassimulator/index.html> Acesso em: 08 fev. 2010.

EUROPEAN SPACE AGENCY . Galileo : a constellation of 30 navigation satellites. Disponível em: <http://www.esa.int/esaNA/galileo.html> Acesso em: 25 out. 2009.

EUROPEAN SPACE AGENCY. EGNOS system description. Disponível em: <http://www.essp-sas.eu/egnos_system_description > Acesso em: 20 abr. 2010.

FEDERAL AVIATION ADMINISTRATION, Navigation Services - Global Positioning System - Policy - Modernization. Disponível em : <http://www.faa.gov/about/office_org/headquarters_offices/ato/service_units/techops/ navser ices/GNSS/gps/policy/modernization/index.cfm> Acesso em: $0 \overline{9}$ jan. 2010.

FEDERAL AVIATION ADMINISTRATION, The third WAAS geosynchronous satellite (NMEA \#46 / PRN \#133) is now operational. It is located at $98^{\circ}$ west longitude. Disponível em: < http://www.nstb.tc.faa.gov> Acesso em: 18 dez. 2010.

FEDERAL AVIATION ADMINISTRATION. Navigation Services - Global Navigation Satellite System. Disponível em: <http://www.faa.gov/about/office_org/headquarters_offices/ato/service_units/techops/ navservices/GNSS/> Acesso em: 15 ago. 2009.

FEDERAL AVIATION ADMINISTRATION. Navigation Services - WAAS - How It Works.

<http://www.faa.gov/about/office_org/headquarters_offices/ato/service_units/techops/ navservices/GNSS/waas/howitworks/ > Acesso em: 15 ago. 2009.

FREE FLIGTH SYSTEM. About WAAS - WAAS structure. Disponível em: < http://www.freeflightsystems.com/waas_structure.htm> Acesso em: 18 ago. 2009.

GALILEO INFORMATION CENTER. GNSS and Galileo frequently asked questions. Disponível em: < http://www.galileoic.org/la/?q=node/190> Acesso em: 20 abr. 2010.

GAKSTATTER. E., Satellite (GPS, GLONASS, SBAS) mission planning. GPS World Magazine, August. 2009. Disponível em: <http://www.gpsworld.com/survey/satellitegps-glonass-sbas-mission-planning-8635> Acesso em: 29 jan. 2010.

GEMAEL, C.; ANDRADE, J. B.; Geodésia Celeste. 1 ed. Curitiba: Editora UFPR, 2004. 390p.

GIM INTERNATIONAL. BLADE GNSS Signal. Disponível em: <http://www.giminternational.com/news/id2346Magellans_BLADE_GNSS_Signal_Pr ocessing.html> Acesso em: 08 fev. 2009. 
INSTITUTO BRASILEIRO DE GEOGRAFIA E ESTATÍSTICA, Rede Brasileira de Monitoramento Contínuo dos Sistemas GNSS - RBMC. Disponível em:

<http://www.ibge.gov.br/home/geociencias/geodesia/default_sgb_int.shtm?c=1> Acesso em: 12 maio. 2010.

LANGLEY. R. B., RHO. H., Innovation: The WAAS L5 Signal. GPS World Magazine, May. 2009. Disponível em: <http://sidt.gpsworld.com/gpssidt/Innovation/InnovationThe-WAAS L5Signal/ArticleStandard/Article/detail/597762?contextCategoryld=285> Acesso em: 29 abr. 2010.

MCDONALD, K., D. The modernization of GPS The European EGNOS Project, 2006, The Netherlands Proceedings The Netherlands: Bruce Battrick \& Dorothea Banesy, 2006. p.457-483.

MEINDL, M. et al., Precise Orbit Determination for ESTB Satellites Using Microwave and Optical Observations. Disponível em: <ftp://ftp.estec.esa.nl/pub3/tosett/navitec2004/papers/8.4-Meindl.pdf> Acesso em: 29 jan. 2010.

MONICO, J.F.G., Posicionamento pelo NAVSTAR-GPS: descrição,fundamentos e aplicações. São Paulo: Editora UNESP, 2000. 287p.

MONTEFUSCO, C. et al., Enhancing SBAS performance: the EGNOS pseudolite concept, European Navigation. Conference GNSS, 2005, Munich. Proceedings. Munich, 2005. p. 01-13.

NATURAL RESOURCES CANADA, CSRS-PPP (Precise Point Positioning) Service. Disponível em: <http://ess.nrcan.gc.ca/2002_2006/gnd/csrs_e.php> Acesso em: 20 jun. 2010.

NOUVEL, O. et al., SBAS C/A Code Interferences: Observations and Induced Tracking Errors. ION GNSS, 2007, Fort Worth,USA. Proceedings. Fort Worth, USA, 2007. pp. 950-959.

OBER, P. B. et al., SBAS Integrity Verification, 2001 - Proceedings ION GPS, Salt Lake City, UT. p 1805-1812. 2001.

PAIVA, J.A.G., Efeitos da lonosfera de Baixas Latitudes no GPS - SBAS, 96p. Dissertação (Mestrado) - PUC - Pontifícia Universidade Católica do Rio -Rio de Janeiro - RJ, 2004.

PACIFIC CREST, GPS-GNSS Receiver Modules Brochure. Disponível em: <http://www.paccrst.com> Acesso em: 20 jul. 2010.

PRASAD, R., RUGGIERI, M., Apllied satellite navigation using GPS, Galileo, and augmentation systems. Artech house mobile communications series, 2005. 290p.

RIFE, J., WALTER, T., BLANCH, J. Overbounding SBAS and GBAS Error Distributions with Excess-Mass Functions. International Symposium on GNSS/GPS, 2004, Sydney. Proceedings. Sydney, 2004. p. 01-15. 
ROTURIER, B., CHATRE, E., VENTURA-TRAVESET, J. The SBAS Concept Standardised by ICAO: Application to EGNOS. The European EGNOS Project, 2006,The Netherlands Proceedings The Netherlands :Bruce Battrick \& Dorothea Banesy, 2006. p. 43-54.

SPIEGEL, M, R., Probabilidade e Estatística. $3^{\circ}$ Ed.- São Paulo: Makon Books, 1993. 643p. (Coleção Schaum).

TEUNISSEN, P.J.G. Least-squares estimation of the integer GPS ambiguities. Invited lecture, Section IV Theory and Methodology, In: IAG General Meeting, Beijing, China, 1993.

THE OFFICIAL WEBSITE OF LOS ANGELES AIR FORCE BASE. L1 C/A PRN code assignments.

<http://www.losangeles.af.mil/shared/media/document/AFD-090206-044.pdf> Acesso em: 21 mar. 2009.

TOLEDO, G. L., OVALLE, I, I., Estatística básica, 2 ed, São Paulo: Atlas 1985, $457 p$.

UNAVCO. Data - GNSS \& archive glossary. Disponível em: <http://facility.unavco.org/data/glossary.html\#SBAS > Acesso em: 29 ago. 2009.

VENTURA-TRAVESET, J.et al., EGNOS start of operations and modernization programme 2006-2012). The European EGNOS Project, 2006, The Netherlands Proceedings The Netherlands :Bruce Battrick \& Dorothea Banesy, 2006. p. 485-496.

WALTER, T., BLANCH, J., ENGE, P., Future Augmented, GPS World Magazine, March 2010, Disponível em: http://www.gpsworld.com/GNSS-system/augmentationassistance/future-augmented-9606?page_id=2 > Acesso em: 15 maio. 2010.

WANNINGER. L., Innovation: The future is now. GPS World Magazine, July. 2008. Disponível em: <http://sidt.gpsworld.com/gpssidt/Innovation/Innovation-The-Futureis- Now/ArticleStandard/Article/detail/528733?contextCategoryld=285> Acesso em: 29 abr. 2010. 


\section{APENDICE A}

\begin{tabular}{|c|c|c|}
\hline GEOSTATIONARY N & $\begin{array}{l}\text { TABLE A16 } \\
\text { AVIGATION MESSAGE FILE - DATA RECORD DESCP }\end{array}$ & ION \\
\hline OBS. RECORD & DESCRIPTION & FORMAT \\
\hline $\mathrm{PRN} / \mathrm{EPOCH} / \mathrm{SV}$ CLK & $\begin{array}{l}\text { - Satellite number (PRN - 100) } \\
\text { - Epoch of ephemerides (GPS) } \\
\text { - year (2 digits, padded with } 0 \\
\text { if necessary) } \\
\text { - month, day, hour, minute, } \\
\text { - second } \\
\text { - sv clock bias (sec) } \\
\text { - SV relative frequency bias } \\
\text { - message frame time (sec of day GPS) }\end{array}$ & 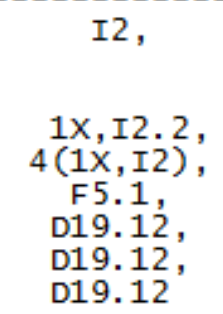 \\
\hline BROADCAST ORBIT - 1 & $\begin{array}{lll}\text { - satellite } & \text { position } x & (\mathrm{~km}) \\
\text { - } & \text { velocity } x \text { dot } & (\mathrm{km} / \mathrm{sec}) \\
\text { - } & \text { X acceleration } & (\mathrm{km} / \mathrm{sec} 2) \\
- & \text { health }(0=0 \mathrm{~K}) & \end{array}$ & $\begin{array}{l}3 \mathrm{X}, 4 \mathrm{D} 19.12 \\
*)\end{array}$ \\
\hline BROADCAST ORBIT - 2 & $\begin{array}{lll}\text { - satellite position } \mathrm{Y} & (\mathrm{km}) \\
\text { - } & \text { velocity } \mathrm{dot} & (\mathrm{km} / \mathrm{sec}) \\
\text { - } & \text { Y acceleration } & (\mathrm{km} / \mathrm{sec}) \\
\text { - } & \text { Accuracy code } & \text { (URA, meters) }\end{array}$ & $3 \mathrm{x}, 4 \mathrm{D} 19.12$ \\
\hline BROADCAST ORBIT - 3 & $\begin{array}{lll}\text { - satellite position } z & (\mathrm{~km}) \\
- & \text { velocity } \mathrm{z} \text { dot } & (\mathrm{km} / \mathrm{sec}) \\
- & \mathrm{z} \text { acceleration } & (\mathrm{km} / \mathrm{sec} 2) \\
\text { - spare } & & \end{array}$ & $3 \mathrm{x}, 4 \mathrm{D} 19.12$ \\
\hline
\end{tabular}

Informações do Arquivo Rinex de Navegação 2.10 Satélites SBAS

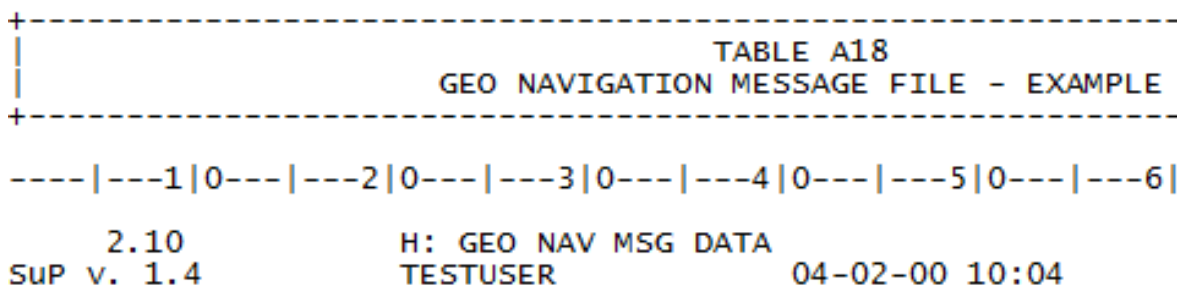

The file contains navigation message data of the geostationary AOR-E satellite (PRN $120=520)$

$\begin{array}{llllllll}20 & 00 & 01 & 13 & 14 & 46 & 24.0\end{array}$ $.406131052800 \mathrm{D}+08$

$-.112454290400 D+08$ $781616000000 D+05$

$\begin{array}{lllllll}20 & 00 & 01 & 13 & 14 & 48 & 00.0\end{array}$ $.406132503200 \mathrm{D}+08$

$-.112451338400 \mathrm{D}+08$ $790812000000 \mathrm{D}+05$

$\begin{array}{lllllll}20 & 00 & 01 & 13 & 14 & 49 & 36.0\end{array}$ $.406133961600 \mathrm{D}+08$

$-.112448396800 D+08$ $.799968000000 D+05$

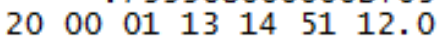
$.406135428800 \mathrm{D}+08$

$-.112445465600 \mathrm{D}+08$ $.809084000000 \mathrm{D}+05$
$.209547579288 \mathrm{D}-07-.545696821064 \mathrm{D}-11$ $.150625000000 \mathrm{D}+01 \quad .875000000000 \mathrm{D}-04$ $.308125000000 \mathrm{D}+01-.112500000000 \mathrm{D}-03$ $.204890966415 \mathrm{D}-07$-.545696821064D-11 $.151500000000 \mathrm{D}+01 \quad .875000000000 \mathrm{D}-04$ $.307000000000 \mathrm{D}+01-.125000000000 \mathrm{D}-03$ $.955600000000 \mathrm{D}+01-.437500000000 \mathrm{D}-03$ $.195577740669 \mathrm{D}-07-.545696821064 \mathrm{D}-11$ $.152375000000 \mathrm{D}+01 \quad .875000000000 \mathrm{D}-04$ $.305875000000 \mathrm{D}+01-.125000000000 \mathrm{D}-03$ $.951600000000 \mathrm{D}+01-.437500000000 \mathrm{D}-03$ $.190921127796 \mathrm{D}-07-.545696821064 \mathrm{D}-11$ $.153250000000 \mathrm{D}+01 \quad .875000000000 \mathrm{D}-04$ $.304687500000 \mathrm{D}+01-.125000000000 \mathrm{D}-03$ $.947600000000 \mathrm{D}+01-.437500000000 \mathrm{D}-03$ $959600000000 \mathrm{D}+01-.437500000000 \mathrm{D}-03$
$|0---|---7|0---|---8 \mid$

RINEX VERSION / TYPE PGM / RUN BY / DATE COMMENT

COMMENT

COMMENT

COMMENT

END OF HEADER

$.532351280000 D+05$ $.000000000000 \mathrm{D}+00$ $.400000000000 \mathrm{D}+01$ $.000000000000 \mathrm{D}+00$ $.533161280000 \mathrm{D}+05$ $.000000000000 \mathrm{D}+00$ $.400000000000 \mathrm{D}+01$ $.000000000000 \mathrm{D}+00$ $.533981280000 \mathrm{D}+05$ $.000000000000 \mathrm{D}+00$ $.400000000000 \mathrm{D}+01$ $.000000000000 \mathrm{D}+00$ $.534791280000 \mathrm{D}+05$ $.000000000000 \mathrm{D}+00$ $.400000000000 \mathrm{D}+01$ $.000000000000 \mathrm{D}+00$

Exemplo de Arquivo Rinex de Navegação 2.10 Satélites SBAS 


\section{ANEXO A}

Gráficos comparativo das componentes N, E e h , utilizando os dados GPS e GPS + SBAS.
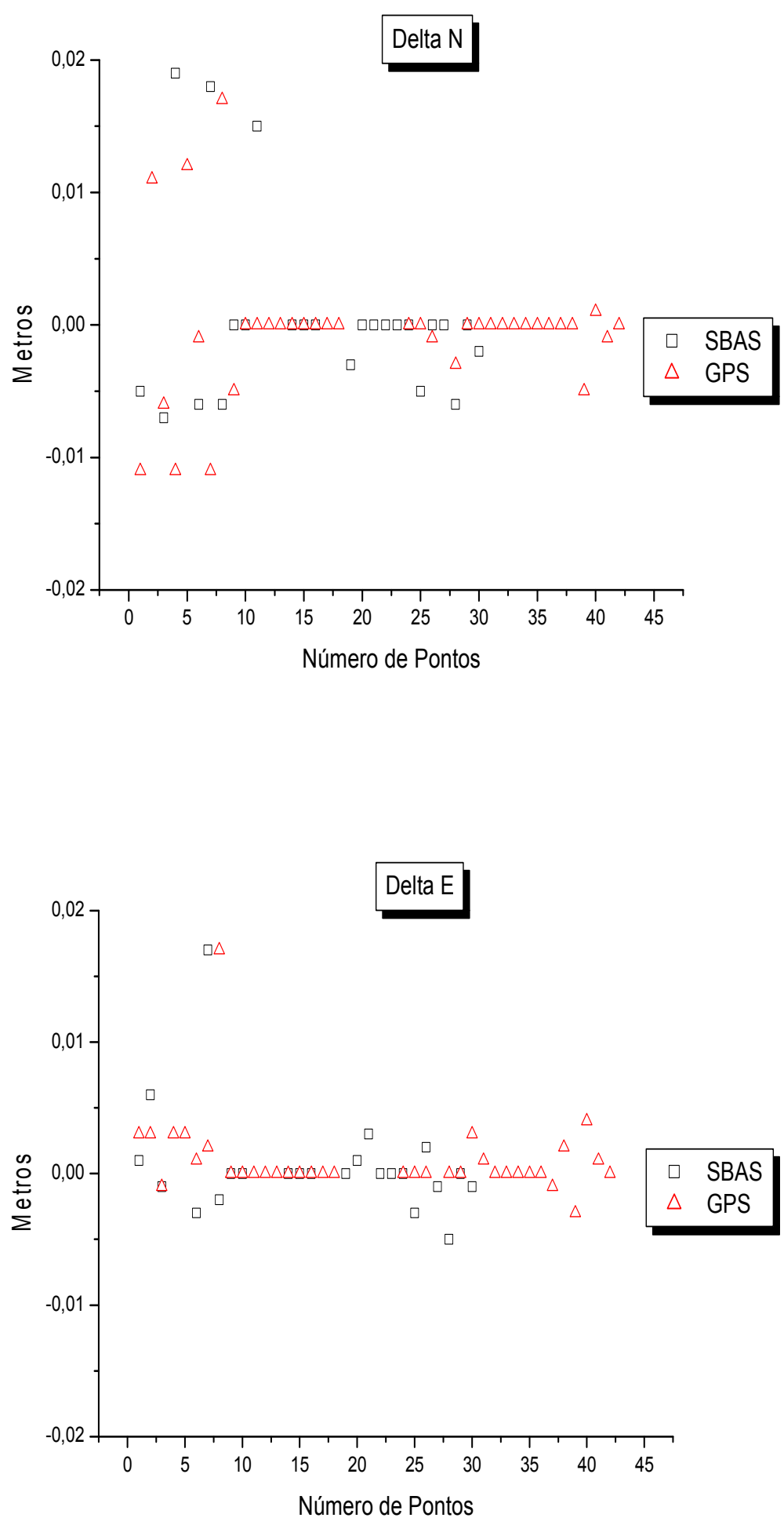


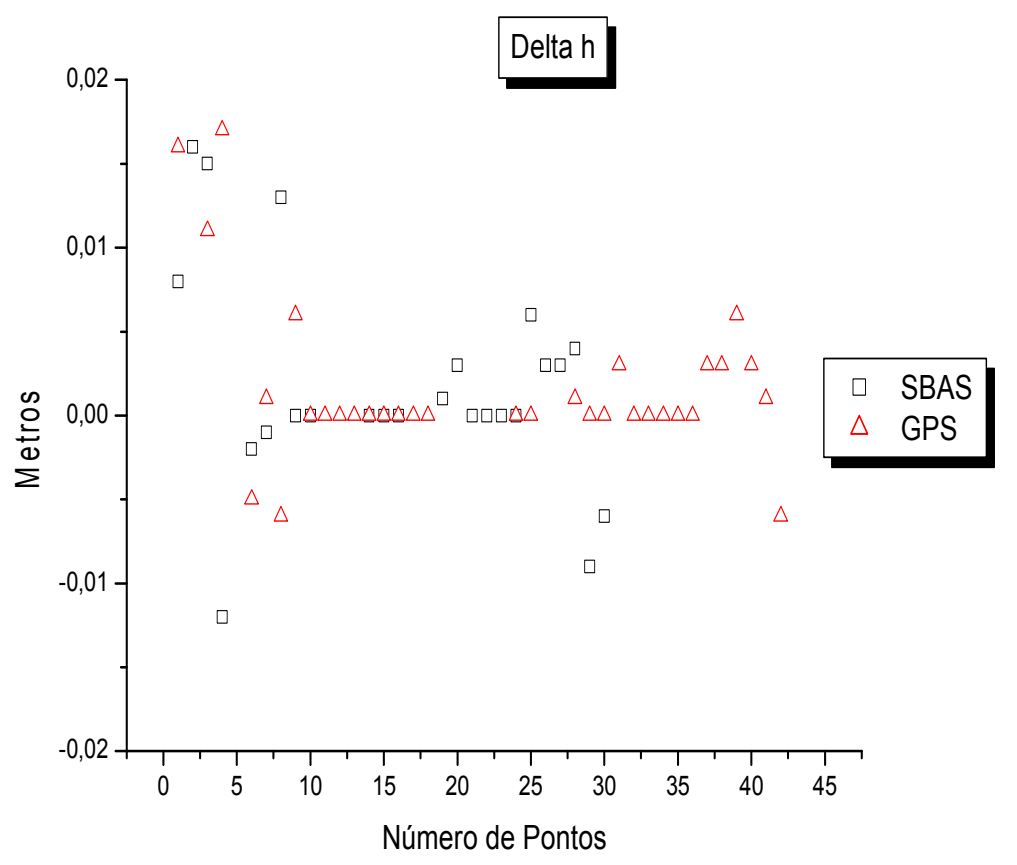

Gráfico utilizando apenas as discrepâncias dos dados GPS + SBAS

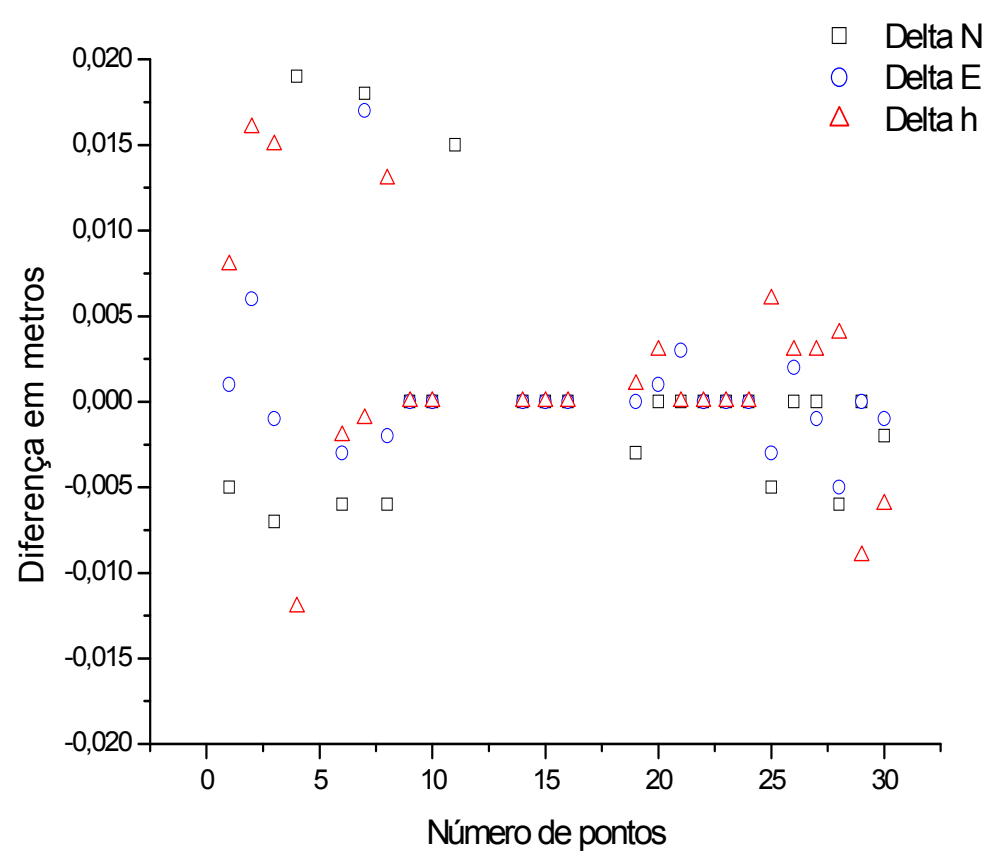


Gráficos utilizando apenas as discrepâncias dos dados GPS.

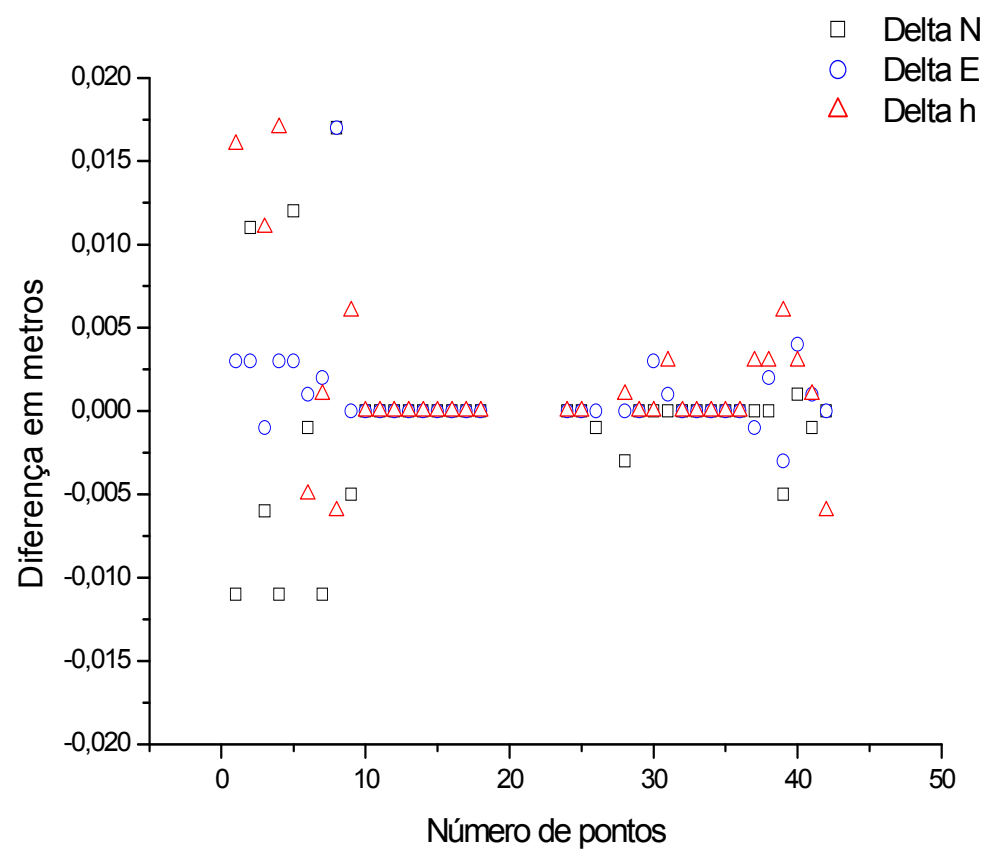

Gráficos das posições $\mathrm{X}, \mathrm{Y}$ e $\mathrm{Z}$ fornecidas pelo arquivo de navegação transmitido pelos satélites SBAS por região.

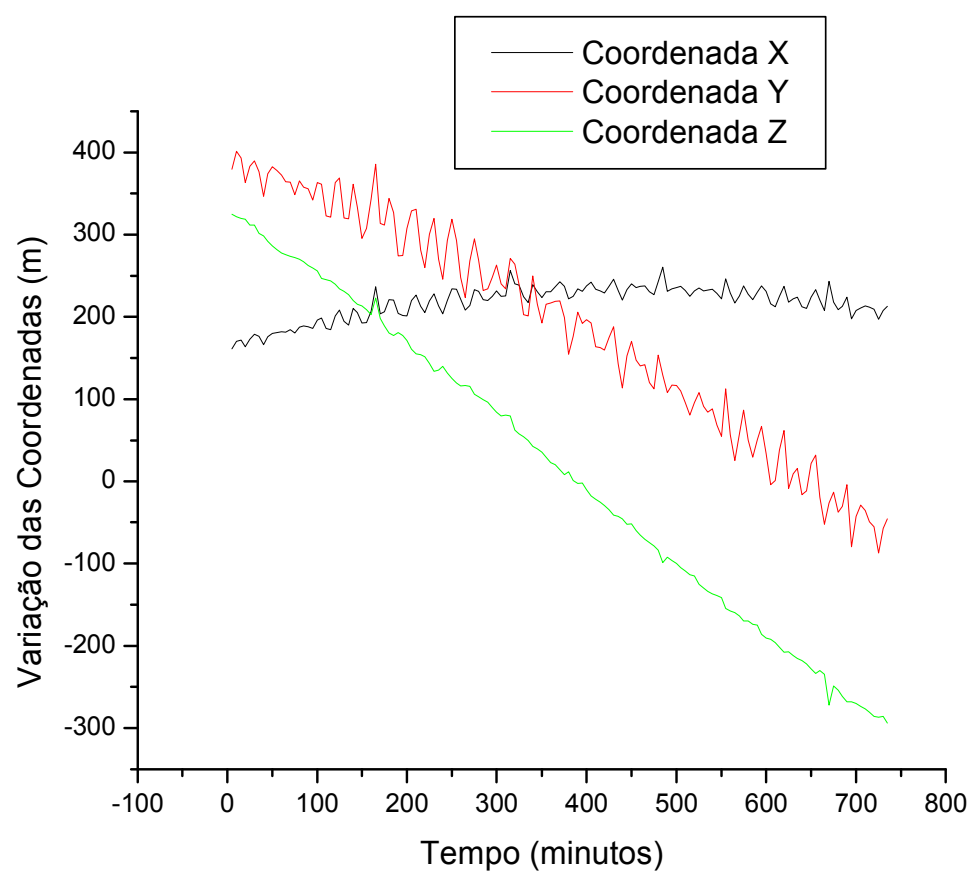

Posição PRN 120 - Manaus 


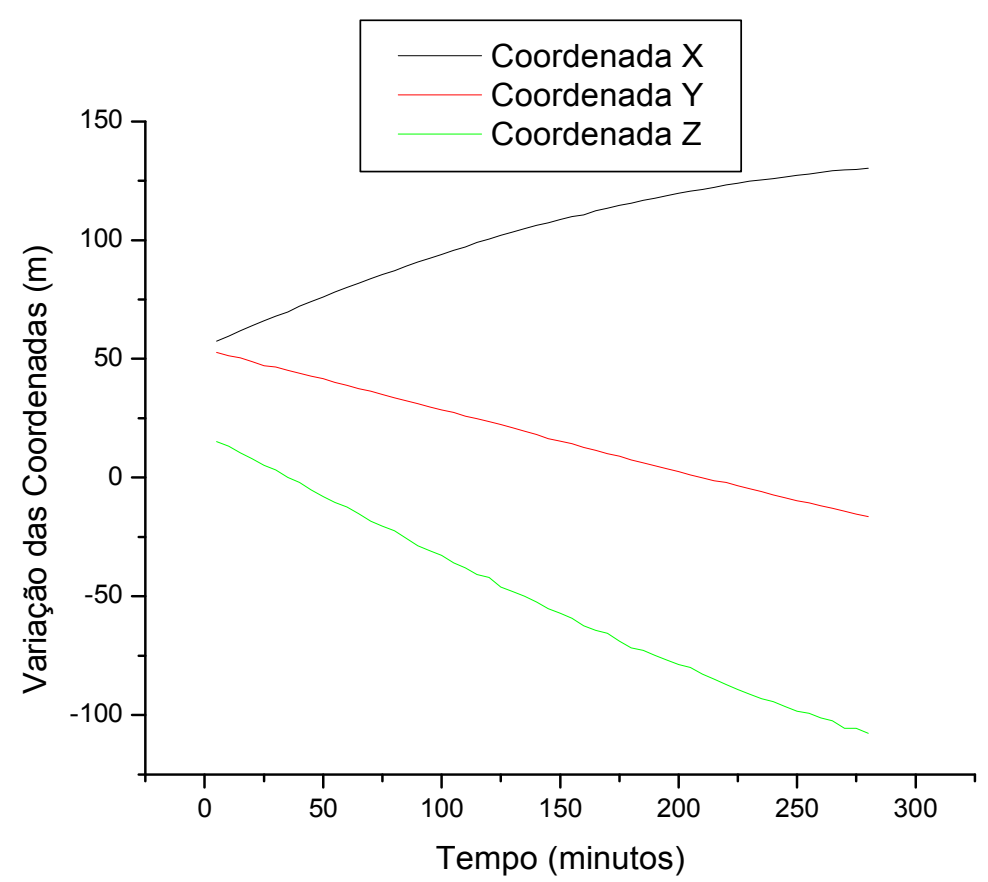

Posição PRN 138 - Manaus

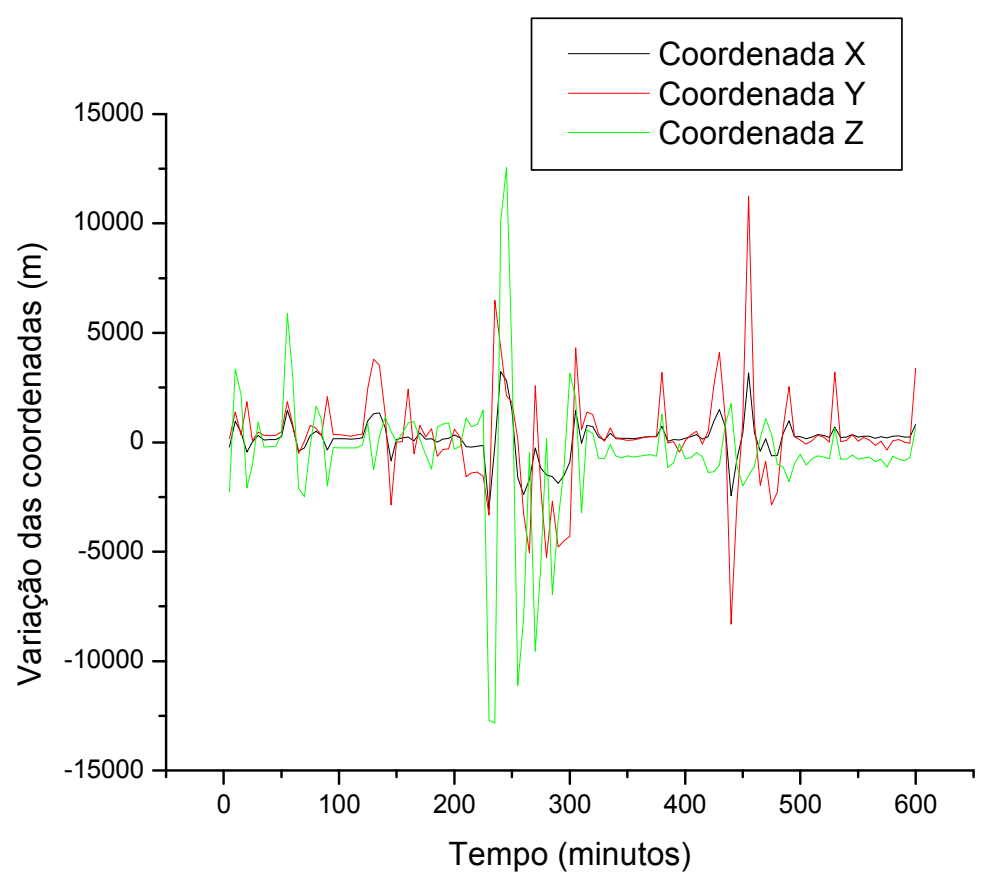

Posição PRN 120 - Rio de Janeiro 


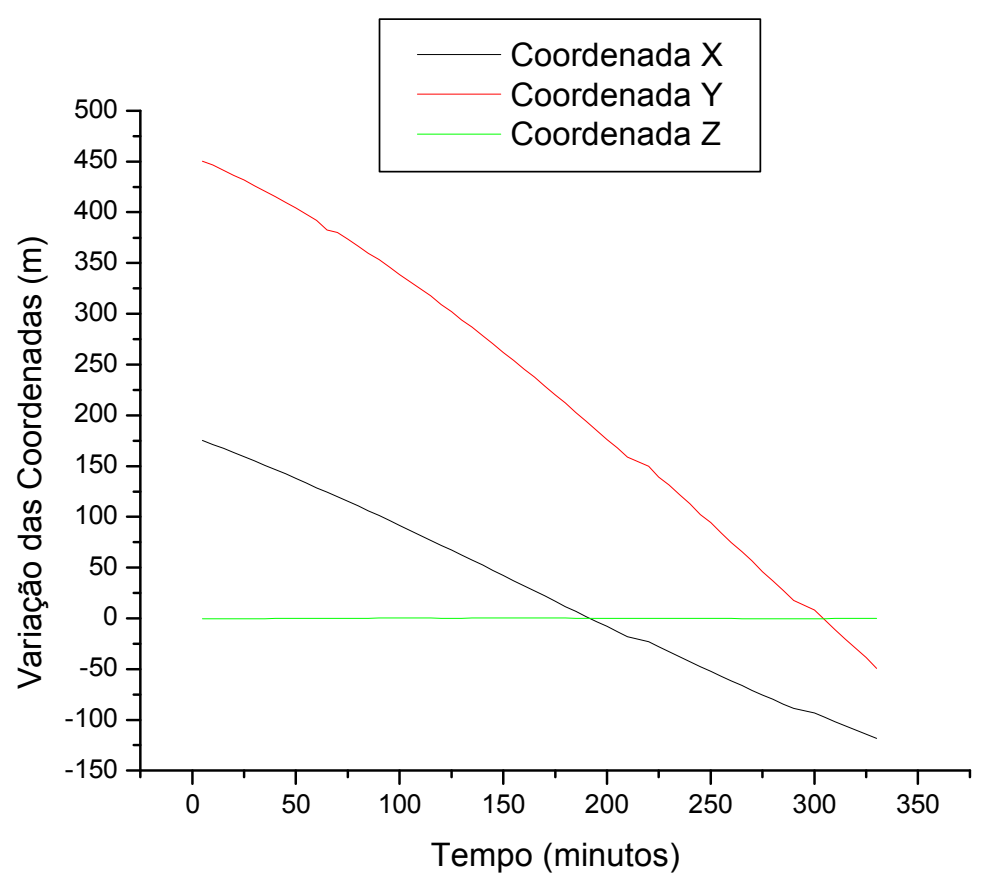

Posição PRN 138 - Rio de Janeiro 